\title{
The Psychology of Becoming a Successful Worker
}

What is success at work and why is it important? How do top workers describe their success? How can work, community, leadership, family, or home and school promote success?

Success at work is often associated with career-oriented individuals who sacrifice other areas of life to achieve highly in the workplace, but success can also be defined in other ways. It can consist of feelings of knowledge, competence and accomplishment, stemming from an inner drive to work well and create an expression of mastery. This book focuses on employees who have been rewarded for their skills and expertise.

Based on the authors' in-depth research into the phenomenon of success at work, this book provides a positive human-strength based approach to success and offers a fresh viewpoint to the modern, demanding and hectic work life. Drawing from the theory of positive psychology and outlining new theoretical ideas including work motivation, career orientation, work characteristics, and positive states of work, success is described as a combination of multiple elements which include other areas of life. The book is illustrated throughout with case studies from employees, and it will ignite thoughts about what success at work is and can be, and how to recognise factors which enhance or hinder success in varying contexts.

Considering a variety of data, this book will appeal to researchers and academics from the fields of work and organisational psychology, positive psychology, career counselling and coaching.

Satu Uusiautti is Adjunct Professor of Educational Psychology at the University of Helsinki, Finland, and a Researcher in the Department of Education at the University of Lapland, Finland.

Kaarina Määttä is Professor of Educational Psychology at the University of Lapland, Finland. 



\section{The Psychology of Becoming a Successful Worker}

Research on the changing nature of achievement at work

\section{Satu Uusiautti and \\ Kaarina Määttä}


First published 2015

by Routledge

27 Church Road, Hove, East Sussex, BN3 2FA

and by Routledge

7II Third Avenue, New York, NY 10017

Routledge is an imprint of the Taylor \& Francis Group, an informa business

(C) 2015 S. Uusiautti and K. Määttä

The right of S. Uusiautti and K. Määttä to be identified as author of this work has been asserted by them in accordance with sections 77 and 78 of the Copyright, Designs and Patents Act 1988.

The Open Access version of this book, available at www.taylorfrancis. com, has been made available under a Creative Commons AttributionNon Commercial-No Derivatives 4.0 license.

Trademark notice: Product or corporate names may be trademarks or registered trademarks, and are used only for identification and explanation without intent to infringe.

British Library Cataloguing in Publication Data

A catalogue record for this book is available from the British Library

Library of Congress Cataloging-in-Publication Data

Uusiautti, Satu.

The psychology of becoming a successful worker : research on the changing nature of achievement at work / Satu Uusiautti and Kaarina Määttä.

pages $\mathrm{cm}$

Includes bibliographical references and index.

I. Employee motivation. 2. Success, 3. Job satisfaction. 4. EmployeesPsychology. 5. Psychology, Industrial. I. Määttä, Kaarina. II. Title HF5549.5.M63U97 2015

I58.7-dc23

$20140077 \mid 4$

ISBN: 978-I-I38-78742-I (hbk)

ISBN: 978-I-3I5-7665I-5 (ebk)

Typeset in Times New Roman

by Cenveo Publisher Services 


\section{Contents}

List of figures

vi

Foreword

vii

Acknowledgements

viii

1 Introduction

2 The theoretical starting point: everyone can succeed at work

3 A successful worker

4 Success begins in childhood

5 Success and the influence of exogenous factors in adulthood

6 The road to success - why pursue success at work?

Index 


\section{Figures}

3.1 The interconnectedness of the factors that explain success at work among Employee of the Year awardees (Uusiautti, 2008)

3.2 The connection of individual and communal factors with the perceived success at work (Uusiautti and Määttä, 2013)

4.1 Core factors affecting students' success (adapted from Määttä and Uusiautti, 2011: 52)

6.1 The elements of success and their interconnectedness (Uusiautti, 2013) 


\section{Foreword}

The word 'success' brings many things to mind. If we stop and think, we will probably be able to name people who we consider successful. However, upon closer examination the criteria for our nominations might vary, fade and become vague. While someone might have thought about his colleague who has just moved into a new office with a huge mahogany desk and a view overlooking the city, another might have thought about a friend who has a beautiful home, a friendly wife and well-behaved children, plus a nice job. What about an artist who leads an austere life but sells his paintings around the world for big money? Is success then something one has achieved - but what? Is it possible to study success? Is it possible to define it?

In this book, we introduce our research on success at work in a very broad sense. This research can be said to have begun during the first years of this millennium. Adjunct Professor Uusiautti first focused on work drive in nurses and midwives, expanding her analysis to Finnish Employees of the Year, while Professor Määttä conducted her studies on love and human relationships. When our specific research streams converged, we began studying positive development in childhood and adolescence as well as in adulthood and later life. We even managed to incorporate our ideas on leadership. Now, we think it is time to compile our findings into a psychology of success. In many parts of this book, we will refer to the route to success - we hope that this book will function as a signpost showing the way to happiness-promoting success at work.

The standpoint in this book rests on psychology, particularly positive psychology. This means that we deliberately aimed to combine the themes of work success with flourishing and favourable development. Our purpose is to inspire and challenge researchers and all those interested to examine the possibilities of this positive approach and to consider this as one example of how to seize phenomena that are difficult to define comprehensively but, first and foremost, we want them to see the connection between success and happiness.

In Cape Coral and Rovaniemi, 14 February 2014

Satu Uusiautti and Kaarina Määttä 


\section{Acknowledgements}

This book draws upon the publications and studies listed below, which have been revised and rewritten for the purposes of this book:

Uusiautti, S. (2008) “Tänään teen elämäni parhaan työn” Työmenestys Vuoden Työntekijöiden kertomana ['Today, I'll work better than ever': employees of the year describe their experiences of success at work]. (PhD Diss., University of Lapland, Rovaniemi, Finland)

Uusiautti, S. (2013) 'An action-oriented perspective on caring leadership: a qualitative study of higher education administrators' positive leadership experiences'. International Journal of Leadership in Education: Theory and Practice, 16(4), pp. 482-496

Uusiautti, S. (2013) 'On the positive connection between success and happiness'. International Journal of Research Studies in Psychology, 3(1), pp. 1-11

Uusiautti, S. and Määttä, K. (2010) 'What kind of employees become awarded as Employees of the Year in Finland?' Enterprise and Work Innovation Studies, 6, pp. $53-73$

Uusiautti, S. and Määttä, K. (2011) 'Process of becoming a top worker'. International Education Studies, 4(4), pp. 69-79

Uusiautti, S. and Määttä, K. (2011) 'Top workers' virtues and strengths'. GJES: Education Sciences and Psychology, 2(19), pp. 46-56

Uusiautti, S. and Määttä, K. (2012) 'The successful combination of work and family in Finland: The ability to compromise as the key factor'. Journal of Comparative Family Studies, 43(2), pp. 151-163

Uusiautti, S. and Määttä, K. (2013) 'Brisk attitude and optimism - top workers' childhood experiences forming the basis of success at work'. European Journal of Educational Research, 2(2), pp. 69-82

Uusiautti, S. and Määttä, K. (2013) 'Does success at work produce well-being and happiness or vice versa?' The International Journal of Interdisciplinary 
Organizational Studies, 7(3), pp. 11-25 (journal published by Common Ground Publishing, Champaign, IL, USA)

Uusiautti, S. and Määttä, K. (2013) 'Enhancing university students' study success through caring leadership'. The European Scientific Journal, Special Edition, 2/2013

Uusiautti, S. and Määttä, K. (2014) 'Leaders' flow'. Paper presented at the International Conference on Social Science and Management, 14-16 March 2014, Chicago, Illinois, USA

Määttä, K. and Uusiautti, S. (2012) 'The four-leaf clover of human resources'. Journal in Organizational Psychology and Educational Studies, 1(1), pp. 37-42

Note: we have made every effort to gain permission for material in the book regarding the article Määttä, K. and Uusiautti, S. (2012) 'The four-leaf clover of human resources'. Journal in Organizational Psychology and Educational Studies, 1(1), pp. 37-42. 



\section{Chapter I}

\section{Introduction}

\section{The positive sides of work}

The latest studies on work life tend to focus on overburdened working conditions; negative concepts like stress, burnout and lassitude are some of the most common descriptors in work-related research, which is less than surprising in the present economic situation. It is true that accelerated changes in work life, as well as efficiency-based demands, tend to exert greater levels of stress on employees. On the other hand, the image of work life becomes unilateral if we focus only on the problems and drawbacks of work.

The nature of work life is changing. Motivation to work is no longer dependent on salary alone. Instead, employees' personalities and moral valuations have increasingly had a considerable effect, even to the extent that it has already been stated that the admiration of social skills has gone almost too far in today's working life. Therefore, it appears that there is a need for studies that bring other aspects of work life to the discussion and that shed light on the positive sides of work. This is one purpose of this book: to not only explore how to cope with work but also how to succeed. We also want to respond to the need for qualitative research to survey human experiences, although this kind of research introduces a methodological challenge, namely, how to examine experiences without placing them into predetermined categories. The importance of positive feeling as a source of human strength is a strong foundation for our research. Therefore, following in the footsteps of some of the great names in positive psychology, Diener, Csikszentmihalyi, Seligman, Peterson, Fredrickson, Isen, among others, we place the theoretical framework for success at work in positive psychology.

This book has a positive starting point, which is, instead of focusing on all the problems and stress factors of today's working life this research concentrates on the positive sides of work and success (Almost and Spence Laschinger 2002; Spence Laschinger et al. 2004). But what is success at work? How can it be defined, and whose definition counts?

In this book, we analyse the concept of success from a particular point of view. The purpose is to explain our viewpoint and open up the fundamental idea of 
considering success as something positive. But in what way is it positive? Is success manifested in some other, perhaps material, dimension? Does it mean that successful people are also happy? Could it mean that? In this book, we discuss success as a form of positive human development.

\section{'Success is as ice cold and lonely as the north pole'}

Nicki Baum's thought, as presented in heading, gets straight to the point: this is what success is traditionally associated with. Similarly, success at work is often correlated with career-oriented individuals who make sacrifices in other areas of life in order to achieve success. Materialistic values and career orientation are emphasised. Consequently, control, production, results and money have become central (see, for example, Riikonen et al. 2002).

According to an online dictionary, 'success' as a noun means (1) the favorable outcome of something attempted; (2) the attainment of wealth, fame, etc.; (3) an action, performance, etc., that is characterised by success; (4) a person or thing that is successful. The definitions give and maintain the impression that success is something that only a few of us can achieve. Success is associated with fancy cars, suits, huge offices, fine dining and cocktail parties - in other words, with money. It also has connotations of opportunism, heartlessness, toughness, goalorientation, and less of friendliness, altruism, love and care. Indeed, financial success has formed the core component of people's dreams and, for example, in the 1990s three-fourths of Americans declared that a very important life goal was being financially rich (Myers and Diener 1995).

Interestingly, David Myers and Ed Diener conducted a multidimensional analysis of people's happiness - including money and work dimensions. Although the goal of being well-off ranked higher than, say, helping others, the researchers observed that once people were able to afford life's necessities, increasing levels of affluence mattered surprisingly little. Rather it appeared that the idea of having a high income as a means to happiness was important, but the actual correlation between income and happiness appeared modest.

Indeed, there has been a change in attitudes toward life goals and career expectations in general over the past few decades. Up until the 1970s, Finnish workers valued work more highly in their lives than home and leisure time outside work, and we assume that this tendency has been similar in many other countries too. Likewise, success at work was mainly seen as climbing hierarchical ladders. In the 1980s values began changing as the home and family began witnessing greater levels of appreciation (Maljojoki 1989). Today, these factors are of greater importance to employees' lives than ever before, and workplaces have become less and less hierarchical. So, let's have a look at success in today's world. Is it still something ice cold? Could a positive climate change have occurred? 


\section{Description of the book}

The book consists of six chapters. The purpose of this first chapter is to have readers think about the multidimensional nature of success, to ignite thoughts, opinions, viewpoints and interest in questions such as 'What is success at work?' and 'Who defines success?'

The second chapter provides a theoretical basis for the research on success at work. Numerous theories that purport to explain success are introduced and their role in this positive phenomenon is discussed. Relevant theories of work motivation, career orientation, work characteristics and positive work states, such as engagement, joy of work and flow, are introduced along with the offerings of positive psychology. We also introduce the research on which this book is based. The fundamental idea is to discover whether everyone can succeed at work.

The third chapter covers research results describing the core characteristics of top workers, their attitude toward work and life in general, and their way of working: what are they like, how do they perceive their work and how do they cope with the challenges at work? In addition, a specific strength-based viewpoint to success is introduced.

Success is not a self-supporting endpoint and it is influenced by many factors in various areas of employees' lives. In Chapter 4, we discuss how success can be promoted and, starting with home and school, how to help children and pupils discover their strengths and resources. We will also introduce university leaders' viewpoints on how to support students' success and provide an all-encompassing illustration of the factors influencing study success.

Chapter 5 looks at the exogenous factors enhancing success at work in adulthood. Top workers also have to solve the eternal dilemma of how to combine work, hobbies and leisure, and family life. We introduce possible solutions and key factors in finding the successful combination of work and family. The role of hobbies and leisure time is also discussed in the light of top workers' experiences. Moreover, the importance of supportive work communities will be brought out in the context of leadership studies.

The sixth chapter concludes the book and focuses on the holistic nature of success. The purpose is first to show that success is not a static state but a process, and no one becomes a top worker just like that, in the twinkling of an eye. Success is a process that involves many phases. Chapter 6 describes the process of becoming successful by looking at the autobiographical narratives of top workers, their roads to success, ups and downs, crossroads and pit stops. Knowledge about the various phases and even hardships that are also faced by top workers can help other people discover the good causes in their lives, maintain belief and encourage them to make even difficult decisions in the pursuit of fulfilling lives. Also, the process of developing expertise is described. We then look at the phenomenon from yet another perspective and find the common denominator for the process, i.e., love as a human strength. The role of love for work as a source of human happiness and wellbeing is discussed. 
This chapter answers the question 'Why pursue success at work?' We present an analysis of the concept of success and its connection with happiness and wellbeing. The question of whether success at work - when defined as a positive manifestation of human development - results in wellbeing and happiness or vice versa is discussed.

\section{References}

Almost, J. and Spence Laschinger, H. K. (2002) 'Workplace empowerment, collaborative work relationships, and job strain in nurse practitioners'. Journal of the American Academy of Nurse Practitioners, 14(9), pp. 408-420

Maljojoki, P. (1989) Ammatinvalinnanohjauksen taustoja ja kehityspiirteitä Suomessa [Background and Development of Occupational Guidance in Finland]. Reports of Faculty of Education 32, Joensuu, Finland: University of Joensuu

Myers, D. G. and Diener, E. (1995) 'Who is happy?' Psychological Science, 6(1), pp. 10-19

Riikonen, E., Makkonen, M. and Vilkkumaa, I. (2002) Hullun työn tauti. Lukemisto tulevan työhyvinvointikeskustelun pohjaksi [Mad Work Disease. Digest for future discussion about well-being at work]. Jyväskylä: Gummerus

Spence Laschinger, H. K., Finegan, J. E., Shamian, J. and Wilk, P. (2004) 'A longitudinal analysis of workplace empowerment on work satisfaction'. Journal of Organizational Behavior, 25, pp. 527-545 


\title{
The theoretical starting point
}

\author{
Everyone can succeed at work
}

\section{Introduction}

An interest in themes such as wellbeing, happiness, quality of life and positive feelings has become germane to positive psychology, a field offering studies on the positive characteristics, feelings and strengths of individuals, and one that also seeks to identify the nature of institutions that promote and enhance such positive attributes (Aspinwall and Staudinger 2006; Seligman et al. 2005). In this chapter, we introduce the background of our studies and the main concepts used. We realise that there are numerous concepts that could describe the phenomenon of success and that therefore there was a need for careful selection. What follows is a brief discussion of some basic theories and concepts, as well as an introduction to our empirical studies.

\section{Positive psychology and success at work}

\section{Focus on the positive}

Gable and Haidt (2005: 104) briefly define positive psychology in the following terms: 'Positive psychology is the study of the conditions and processes that contribute to the flourishing or optimal functioning of people, groups, and institutions'. The aim of positive psychology is to study the reasons why people feel joy, show altruism, and create healthy families and institutions. This focus has been criticised because it concentrates on exploring normal and healthy activities instead of helping dysfunctional people with a variety of problems. On the other hand, perhaps focusing on problems has taken attention away from studying why the majority of people are actually psychologically, physically and socially healthy - or happy, so to speak (Gable and Haidt 2005). Simply stated, a study on successful workers will provide hands-on and positively-toned information about success at work.

We will connect the concept of success with an important research target of positive psychology, namely, happiness. Research on happiness has also increasingly taken root. In order to understand why some people are happier, regardless 
of the setbacks encountered, than others, we have to understand the cognitive and motivational processes that maintain and even increase happiness and positive attitudes (Lyubomirsky 2001). Here, success at work is dissected from a positive perspective.

Positive psychology is also interested in whether the lifespans of positively behaving people differ from those of others. If they do, what factors play a key role during the lifespans of strong and optimistic people, and how can these factors be recognised? These questions are essential to research on the experiences of successful workers and in seeking to identify the factors that have contributed to their successful careers. An individual's differences are traditionally characterised by achievements as opposed to the processes in which he or she takes part (see, for example, Feldt et al. 2005); the process of achieving success at work seems extremely interesting when considered from this point of view.

We will also place the phenomenon in context and acknowledge the individual, communal and social dimensions of success. At the subjective level, positive psychology concentrates on subjective experiences, wellbeing, satisfaction, flow, joy, pleasure and happiness, as well as on optimistic and hopeful attitudes and confidence in the future. At the group level, the interest is in the civic skills and institutions that turn individuals into better citizens - responsible, flexible and ethical workers (Seligman 2002).

Turner et al. (2002) have introduced the Healthy Work Model (HWM). This heuristic model explains how to create healthy work systems. The model presents healthy work characteristics as good work practices, positive psychological processes and mechanisms, as well as various health-related outcomes. Healthy work systems require good external environments and develop strategies for good work practices (for example, autonomy, teamwork and leadership) that enhance positive psychological processes and other mechanisms (for example, trust, perceived control and organisational commitment) in order to increase healthy outcomes (for example, wellbeing and proactivity). Happiness not only produces a quantitative improvement by increasing efficiency but also a qualitative one by making a better product or outcome on the basis of pride, belief and commitment to one's job.

\section{Positive emotions and experiences}

The importance of experiencing positive emotions can be reasoned in a variety of ways. Diener et al. (2009: 187) broadly define subjective wellbeing as experiencing high levels of pleasant emotions and moods, low levels of negative emotions and moods, and high life satisfaction. If the experience of success is considered positive, it may be one factor that also increases wellbeing. Experiences also relate to people's perception of them. 'Moods and emotions, which together are labeled affect, represent people's on-line evaluations of the events that occur in their lives' (Diener et al. 1999: 277). For example, Fredrickson's (1998) broadenand-build model of positive emotions explains why the propensity to experience positive emotions has evolved into a ubiquitous feature of human nature and how 
positive emotions might be tapped to promote individual and collective wellbeing and health. Positive emotions serve as markers of flourishing or optimal wellbeing (Fredrickson 2001), and research on experiences can be useful for measuring wellbeing (Kahneman et al. 2004; Kahneman and Krueger 2006).

Fredrickson (2001) considers pride as a distinct positive emotion that follows personal achievements. In order to feel pride one has to succeed; in other words, one must experience success. Likewise, Lyubomirsky et al. (2005) claim that positive affect or regard engenders success; positive emotions signify that one's life is going well and goals are being met.

Therefore, goals are also important for the emergence of the experience of success; the types of goals one has, the structure of one's goals, the success with which one is able to attain one's goals, and the rate of progress toward one's goals can all potentially affect one's emotions and life satisfaction. The general conceptual model is that people react in positive ways when they make progress toward goals and react negatively when they fail to achieve goals. Thus, a central idea is that goals serve as an important reference standard for the affect system (Diener et al. 1999).

Positive feelings and experiences support problem-solving skills and the ability to operate in an innovative way. The importance and potential of this may seem surprising, as feelings of happiness are simple and common in nature (Isen 2006). Considering the issue in the context of work, there are such interesting and useful concepts as work engagement (referring to work drive) (see Hakanen 2002; Hakanen et al. 2008; Schaufeli et al. 2002), flow (Csikszentmihalyi 2008; Csikszentmihalyi et al. 2005), and joy of work (Varila and Lehtosaari 2001). All these concepts describe a positive feeling toward work that one may experience after active, motivated and engaged working, and which we will discuss in detail later in this book. According to Isen (2001; see also Isen and Reeve 2006), positive feelings sustain intrinsic motivation and help with successfully performing pleasing work tasks and new challenges as well as enjoying them. However, this does not mean that one would not accomplish less interesting tasks any less responsibly. These concepts help with understanding the kinds of actions that may lead to the experience of success. But first we look at a favorable way of achieving success, namely, optimism.

\section{Optimism}

Optimism is one of the core concepts of positive psychology (Peterson 2000) and affects how people pursue goals; if they believe their goals are achievable, they are optimistic (Carver and Scheier 2002). This is why the concept of optimism is often confused with hope. Gillham and Reivich (2004) explain that the difference between these two concepts is that hope is often defined as a wish for something with some expectation that it will happen, while optimism is typically defined as a tendency or disposition to expect the best. Thus, hope typically refers to expectations in a specific situation, while optimism refers to general expectations. 
Peterson and Luthans (2003) consider optimism a vital part of hope, but emphasise that they still are distinctively separate concepts.

Optimism therefore determines how we experience events. The author of The Happiness Advantage, Shawn Achor (2010: 109), develops a remarkable notion: 'By scanning our mental map for positive opportunities, and by rejecting the belief that every down in life leads us only further downward, we give ourselves the greatest power possible'. This means that people have a habitual way of explaining events (Peterson 2000; Peterson et al. 1988).

Peterson (2000) suggests that instead of clinging to a pessimistic explanatory style, an optimistic one deserves more attention. Furthermore, he separates 'little optimism' from 'big optimism' as optimism may function differently depending on the level. Little optimism seems to be connected to concrete events, and this is also interesting from the point of view of the experiences of success. Big optimism provides a general state, 'vigor' (see also Pajares 2001), whereas little optimism leads to desirable outcomes in concrete situations (Peterson 2000).

Optimism is shown to be connected to higher life satisfaction, health, perseverance, and resilience, whereas pessimism has connection to depression (Reivich and Gillham 2003; Reivich et al. 2013). Still, like too much pessimism, too much optimism is also likely to be harmful. Optimism and pessimism are also closely related to the phenomenon of 'learned helplessness'. Seligman (1990) observed that individuals who were exposed to uncontrollable negative events often overgeneralised from this experience and became passive in other situations that were, in fact, controllable. He also discovered that the behaviour can be turned the other way round too, into 'learned hopefulness' or, in other words, 'learned optimism'. Dispositional optimism refers to a general tendency to expect positive outcomes, and these positive expectations can partly result from the individual's belief that he or she can control good outcomes (Gillham and Reivich 2004).

It has also been argued that the best results in life can be achieved with 'realistic optimism' (see Schneider 2001). Realistic optimism involves enhancing and focusing on the favorable aspects of our experiences. Consequently, Schneider (2001: 253) includes the awareness of reality in optimism by stating that 'realistic optimism involves hoping, aspiring, and searching for positive experiences while acknowledging what we do not know and accepting what we cannot know'. It is worth noticing that realistic, positive expectations closely relate to self-awareness and self-knowledge as well as to the concept of self-efficacy, which refers to an expectation that one's behaviour will be effective (Bandura 1997). We will discuss these factors in greater detail later in this chapter. When considering the phenomenon of success at work, realistic optimism may be particularly important as it can considerably predict the likelihood of achieving future goals and plans.

\section{People strive for success}

According to Krueger (1990), success can be considered the fullest expression of mastery in any area of life. However, the concept is not that easily approachable; for 
instance, what factors form the elements of success? To begin constructing the definition of success at work, the first step is to think about and choose between certain psychological concepts that foster positive emotions, and that are acquired through feelings of mastery and inner drive, which perhaps form the core of success. Indeed, there are numerous theories that explain the connection between mastery and performance that can be viewed from the point of view of success. Psychological research is replete with concepts that define human action, motives, as well as the outcomes of these, which can all be seen as manifestations of mastery and performance; but the suggestion here is that their common nominator, the umbrella term, could be success.

Naturally, there are also external factors that influence all the aforementioned states and behaviours. For example, encouraging learning environments, loving parents or supportive workplaces are likely to enhance one's success, while underestimating, oppressive or unstable environments are likely to hinder such positive development. Therefore, this review will include a perspective on the individual person's success as always context-bound. What follows is a detailed introduction of these concepts. They are partly overlapping and interconnected; in other words, they complement each other and coalesce in such a way as to form the heart of success.

\section{Success is about competence}

Originally, White (1959) utilised the concept of competence to describe a person's ability to perform efficiently in his or her environment. In order to do that, one's development must be seen as the acquisition of greater competence, and the subjective side of competence is the sense of competence. Deci and Moller (2005) view the concept from the perspective of motivation psychology and have complemented White's thoughts by adding the need for competence as one dimension of competence. The term 'intrinsic motivation' refers to this need. Deci and Ryan (2008) have later shown that autonomous motivation predicts persistence and adherence and is advantageous for effective performance. Furthermore, this is shown to be related to psychological health.

Adler (1982) is credited with an early definition of the elements of competence, which provides a good way of analysing the multidimensional nature of the concept. Perhaps the most important element of an individual's competence is the ability to perform the social roles that the community and society have set for each and every one of us. The second element is self-conception. A competent person has a stable and well-developed identity that includes awareness of his or her strengths and weaknesses, an optimistic conception of the relationship with the surrounding world, and a realistic understanding of his or her abilities to control his or her destiny. The third element consists of interaction skills, which include communication, credibility and reliability, sensitivity and empathy, and negotiation skills. The fourth element is the ability to regulate emotions, especially the negative ones such as fear, frustration, anger and guilt, and to learn to 
recognise and control inappropriate reactions to these emotions. The fifth dimension of competence is the ability to develop and move from one developmental stage to another. The sixth element refers to the ability to cope with stressful experiences, life crises and other events that one cannot prevent or influence. The seventh element is the ability to acquire the resources that one needs in order to get through a certain phase.

The last element of competence is cognitive skills, that is, the ability to work with words, concepts, symbols and to process information. Causal thinking and planning, as well as understanding of social reality and social problem-solving skills, are important areas of competence (Adler 1982).

Competence is also related to how people perceive their control over the activities and tasks they undertake (for example, Paulsson et al. 2005). Karasek's (see Karasek and Theorell 1990) model of work-control shows that in situations in which people have a high-strain job with high demands and low control, they cannot meet challenges efficiently. On the other hand, while a low-strain job with low demands and high control enables optimal responses to challenges, it is not likely to bring about satisfaction or wellbeing. A passive job has low control and low mental strain and people can feel that their skills and abilities are misspent and not optimally utilised. A state of indifference and lack of challenges can expand to other areas of life as people lose the courage to develop and test their skills. In active jobs, people have a significant amount of mental strain but also high control. They can utilise their abilities, which may, for example, lead to the experience of total concentration and absorption, i.e., 'flow' (Csikszentmihalyi 2008; Csikszentmihalyi et al. 2005).

When considered from the point of view of success, competence combined with opportunities to actively use skills and strengths - whether at work, in leisure, at school, in parenting, etc. - could be one of the core elements of success. Naturally, it is also about the person himself or herself and whether he or she is ready to seize challenges.

\section{Success is about motivation}

The role of motivation has already been mentioned in the previous section as one of the core elements of competence. Indeed, motivation is also a crucial element of success. Fundamentally, motivation can be considered a critical factor in any theory attempting to predict and explain behaviour and performance (Mitchell 1997). The ability to predict, understand and influence employees' motivation has increased markedly, and modern psychological studies try to pay attention to work motivation in a comprehensive manner (Latham and Pinder 2005).

Actually, it is quite easy to list various obvious reasons why people work in the first place: work provides your daily bread, it activates and stimulates, it is a source of social contacts, it is a way of structuring one's time management, and it can also be rewarding (Furnham 1992). These factors do not, however, say much about the motivation that lies behind the foundation of true success at work. 
According to Eccles and Wigfield (2002; see also Campbell and Pritchard 1976), success can be discussed from four theoretical dimensions related to motivation. First, many theories (such as Bandura 1997) focus on individual employees' belief in their talents and efficiency, the likelihood of success or failure, and the sense of being able to control their work results. All this starts from the question 'Can I handle this task?' When people are aware of their talents, they actually do perform better and are more willing to seize new challenges.

The second theoretical viewpoint is based on engagement, which has not been considered in the theories of personal beliefs. Even if people knew that they could successfully perform a task, they would not necessarily have a compelling need to do it (Eccles and Wigfield 2002) - in other words, they may not be interested in it. Many recent studies have shown, for example, how the sense of meaningful work, brought on by power and responsibility, can enable employees to become engaged in their work. The worker becomes like an entrepreneur; through engagement, he or she takes success as his or her goal. Engagement theories, in other words theories answering the question 'why', include intrinsic motivation theories and goal theories (see, for example, Deci et al. 1991; Latham and Pinder 2005). The benefits of this kind of positive approach are clear; it leads to greater persistence, greater flexibility in strategies to reach a goal, greater creativity in solutions, better outcomes, and higher subjective wellbeing (Schneider 2001).

Intrinsic motivation describes the need to learn new things and skills and to develop toward greater autonomy, competence and self-determination. It also includes the structure of personality and the development of motivation. Action that is intrinsically motivated is experience valued as such. Action has an intrinsic attribution and, thus, it does not threaten the feeling of autonomy, thereby leading to satisfaction and positive experiences. Moreover, intrinsic motivation is not regulated by extrinsic rewards or punishments, but doing becomes self-purposeful (Ryan and Deci 2000a, 2000b).

The positive experience connected to motivation and doing is worthy of further investigation. For example, in the 1990s, Locke and Latham (1990) introduced a theory in which they combined work motivation and work satisfaction and called the model the 'high performance cycle'. The cycle starts by giving an employee a challenging task. If the challenge includes an expectation of success, high performance is guaranteed, assuming that the employee is engaged in the goal, receives adequate feedback, and situational factors do not considerably affect performance. Similar findings have resulted from various educational experiments (for example, Gilpin 2008; Green et al. 2012; Oades et al. 2011) and hobbies (for example, Carruthers and Hood 2005).

Thirdly, there are theories that combine expectations and value constructs (for example, Weiner 1992). Expectation value refers to an evaluation of the outcome of action and the likelihood of achieving the outcome (Mitchell 1997). These theories are based on the idea that employees are more interested in the outcomes of work than working itself (Eccles and Wigfield 2002). In addition to achievements and related outcomes, the goal or the benefit value can be appreciation and 
better self-esteem. For example, Covington's (1992: 74) self-worth theory supposes that 'individuals are thought to be only as worthy as their achievements'. Expectation value also includes an assessment of the instrumentality between the fundamental goal (for example the performance) and the secondary outcome (for example salary or promotion), and of the valence of these secondary outcomes (Mitchell 1997).

Theories that combine motivation and cognition (for example, Rosenthal and Zimmerman 1978) provide a different perspective on success because they are interested in an individual's ways of regulating his or her behaviour and using cognitive strategies in order to achieve his or her goals (Eccles and Wigfield 2002).

Mitchell (1997) has presented a useful theory of work motivation that deserves a closer look. According to his interpretation, work motivation includes various components such as, for example, needs, goals, expectations, fairness, rewards, social influences and work description. He lists seven features that can explain a high motivation level in a work situation: the situation has to (1) correspond to the employee's needs, (2) involve goals, (3) reward for a good performance, (4) be fair and equal, (5) include stimulating tasks, (6) involve colleagues who also work diligently, and (7) have an accepting atmosphere with an emphasis on hard work and engagement. The employee responds to the work situation with his or her skills, knowledge, goals, values and mood, whereas the work context includes the work task, colleagues, work environment and culture. When added together, these categories can influence motivation. Motivation, together with abilities, work knowledge and context-bound factors, leads to behaviour, which again leads to performance - one of the cornerstones in considerations of success.

Mitchell (1997) emphasises that all theories that attempt to describe performance, whether they are belief, goal, efficiency or expectation value theories, share certain features. Goals describe what we want to do, self-efficacy describes what we think we can do and expectations describe our best evaluation of the consequences our action can have. All these influence motivation, either directly or indirectly, and are also connected to effort, attention, persistence and strategies.

\section{Success is about good performance}

Performance is often confused with its neighbouring concepts such as competence, behaviour or action. It is crucial to realise the differences between them. Performance is the result of behaviour; it is something measurable and comparable, and a clearly definable result. This idea is based on the finding that positive experiences concerning one's own doing make for one of the most central dimensions of good performance (Uusiautti 2008; Uusiautti and Määttä 2011; see also Liden et al. 2000). It is important to analyse some of the core concepts that might help with an understanding of the positive experience of doing. Competence, indeed, is often confused with performance, but they are not synonymous (Kanfer 
and Ackerman 2005). Competence refers to a more stable state or to a person's characteristic. Performance is a momentary happening and can vary according to many factors, even if competence is high in relation to the task at hand.

Kanfer and Ackerman (2005) distinguish two dimensions of performance: maximal and typical performance. The former refers to a person's skills and abilities and describes all that the person can do when inner states (for example, sleep, concentration, etc.) are optimal and when it is possible to concentrate on the task. The latter dimension is typical behaviour, which refers to how the person usually does things or how he or she is likely to perform. The researchers point out that although maximal performance is an interesting research target, it would perhaps be more beneficial to pay attention to the difference between what the person can do and what he or she actually does. In Kanfer and Ackerman's (2005) model, performance consists of various factors, namely, abilities, skills and knowledge, personality, motivation and self-image. Motivation is affected by personal interest and general motivational tendencies. Performance lays the foundation for a learning mechanism that is connected to features that increase competence (see also Stoltenberg 2005).

The concept of self-efficacy is also closely related to competence and performance. Self-efficacy means a person's assessment of his or her own abilities to use his or her resources and to regulate his or her behaviour in order to perform a task (Caprara and Cervone 2006; Judge et al. 1997; Mitchell 1997). It is therefore similar to the aforementioned sense of competence. It has been shown that positive self-efficacy improves a person's performance and wellbeing in numerous ways (Schunk and Pajares 2005). People who have high self-efficacy devote more to their activities and persevere more than those who estimate that their competence is weaker. In addition, people with high self-efficacy are likely to select more high-level goals and engage in them (Bandura 1997; Mitchell 1997). High self-efficacy, as the manifestation of accurate recognition of one's skills and abilities, is also related to how optimistically and realistically one can estimate one's performances (Shepperd et al. 1996).

Work engagement - referring to work drive - can be used to describe wellbeing and positive experiences at work. Schaufeli et al. (2002) have defined work engagement as a positive, fulfilling, work-related state of mind that includes three sub-scales: vigor, dedication and absorption. Vigor refers to high levels of energy and willingness to work well in typical and in challenging, conflict-filled situations. It could be described as the feeling of 'bursting with energy' when working. Dedication refers to having experiences such as appreciation for your work and being filled with enthusiasm and inspiration. Absorption refers to having a deep focus on work and the pleasure that follows the completion of work (see also Hakanen 2002; Hakanen et al. 2008).

Work engagement, when understood from this definition, is similar to the concept of flow (see Csikszentmihalyi 2008). Flow is a subjective state of feeling control - or, better yet, feeling that you can act without any control, without hindrance (Csikszentmihalyi et al. 2005). According to Gardner et al. (2001), 
contrary to common belief, flow is more often experienced at work than in leisure. Furthermore, features such as gender and cultural norms affect the experience of flow. However, here, the focus is on the experience of flow at work. Flow at work is usually experienced when goals are high and feedback is immediate and fair. In addition, the work itself has to include continuous challenges that match employees' skills. Nevertheless, flow is a temporary feeling, whereas work engagement is a more stable and comprehensive state that does not focus on any particular task, behaviour, or individual. Flow is equivalent to absorption from the sub-scales of work engagement (Csikszentmihalyi 2008; Hakanen 2002).

\section{Success is about positive strategies}

Although top performances or steady, quality performance can lead to success, it can also be seen as a more comprehensive process. Namely, people who want to develop and seize opportunities in life can be seen as following a positive strategy. This is an interesting perspective on the phenomenon of success. Carver and Scheier (2005) have pointed out that it is also important that people realise when goals can be met and when it is time to give up. Ultimately, it is about the ability to estimate the situation and act accordingly. Likewise, future expectations greatly affect how people react to changes and challenges. An optimistic attitude plays a salient role (Carver and Scheier 2002), however, the strategy of success can also be described in other ways.

For example, Locke (2002) claims that success requires persistent trials. One has to think about what a desirable goal is and why, what kinds of intermediate goals should be set, how to reach the goal, how to prioritise demands that are contradictory in relation to the goal, how to overcome future obstacles and setbacks - how to achieve a dream?

Baltes and Freund (2006; see also Freund and Baltes 1998) refer to the SOC model, which provides a general framework for understanding developmental change and resilience across one's lifespan. The fundamental idea is that people's lives are awash opportunities and limitations that can be 'mastered adaptively as an orchestration of three components: selection, optimization, and compensation' (Freund and Baltes 1998: 531) - SOC.

On the other hand, Covey (2006) considers success as a strategy in which knowledge, skills and will are combined. Knowledge answers the question of what to do and why. Skills can make it happen whereas will is synonymous with motivation or the need to achieve something. As these three dimensions meet, a strategy leading to success can emerge.

Naturally, the constant pursuit of success can lead to an endless treadmill. The theory of the hedonic treadmill (see Brickman et al. 1978; Diener et al. 2006) claims that people constantly strive for a happier life because they believe that greater happiness awaits right around the corner from achieving the next goal or solving the next problem. Success is there but not yet achieved. 


\section{Success happens in context}

Even though one possessed the most exquisite level of competence and high motivation, one is still tied to a certain time and place. Behaviour depends on context and outcome. In addition, contexts are dynamic and change during an individual's lifespan (Baltes and Freund 2006). However, according to selfdetermination theory (SDT), people are by nature active and self-motivated, curious and interested, vital and eager to succeed because success itself is personally satisfying and rewarding (Deci and Ryan 2008).

Context-bound factors can be viewed from two perspectives: first, there is the actual work context; second, an employee's personal development always happens in context. The actual work context always influences work motivation and the ways that employees perceive and experience their work. Considered from the point of view of success, certain features, such as interesting or challenging work, could be keys.

Notwithstanding, there are several characterisations of work. In the 1970s, Kaufman (1974) noticed that work-related challenges were also positively correlated with work performance, professional expertise and competence later in one's career. Ever since, researchers have agreed that work involving the right amount of challenges can increase productivity and motivation. In addition to challenges, work outcomes should somehow be measurable or recognisable (by others too). Moreover, responsibility and opportunities for self-development boost motivation, satisfaction and engagement (see, for example, Almost and Spence Laschinger 2002; Spence Laschinger et al. 2004) and, according to Laubach (2005), these features are best realisable in informal organisations in which employers can offer autonomy, flexible schedules and an opportunity to participate in decision-making.

Indeed, good performances and motivated working not only depend on the employee but also on the contents of work and the conditions in the workplace (Latham and Pinder 2005). On the other hand, there are also different kinds of jobs and, for example, in monotonous or predictable jobs, autonomy is not likely to be a very important feature.

Hackman and Oldham (1976) have defined three core dimensions of work, namely, autonomy, the nature of tasks, feedback, the significance of tasks and the selection of required skills. These dimensions influence three psychological states: the experience of the importance of the work, responsibility over the results and awareness of the real consequences of the work. The fundamental idea is that an employee, for example John, will perceive his work positively if he knows that he has performed well in a task he considered important. John's personal need for growth speaks to how powerfully he reacts to the psychological states. Thus, the dimensions of work and psychological states have impact on both individual and work outcomes; these are high work motivation, high performances at work and high work satisfaction, and little absenteeism and turnover of workers.

As a matter of fact, jobs that require high performance, without the attendance of negative psychological strain, offer good opportunities for controlling one's 
work, allow employees to utilise their skills and provide the scope to develop and learn new skills. Karasek and Theorell (1990) call them 'active jobs'. We think that active jobs can present an opportunity for success but, naturally, it is also a matter for an employee himself or herself and whether he or she is ready to seize the opportunities provided by an active job.

This leads us back to the individual. Moving from a particular work context to a wider perspective on success requires an acknowledgement of interactions with the surrounding environment in one's positive development. Every one of us has a personal history; we have not become like this in the wink of an eye, and we take our entire background with us to the workplace. Some of us have learned to perceive challenges positively, while others tend to stick to the familiar. Development, including positive development, always happens in context.

Magnusson and Mahoney (2006) present four theses on the nature of phenomena when dissecting positive development, all of which can also be relevant for the conceptualisation of success. First, the individual acts and develops as an active, intentional part of the integrated, multidimensional, dynamic and adaptive person-environment system. The nature of this system changes along one's lifespan through developmental processes, societal changes and as a result of constant individual-environment interaction processes. Second, the individual develops along the course of time as an integrated, undivided organism within a multidimensional, dynamic, adaptive, maturing and learning process. This interaction process involves mental, biological and behavioural factors of the individual and social, cultural and physical features of the environment. Third, the preconditions provided by the environment, including the possibilities, limitations, demands and expectations, are especially important for research on positive development. Fourth is the theoretical model that aims to explain that a human being's positive development has to include and integrate his or her mental, biological and behavioural aspects as well as the physical, social and cultural features of this individual's environment (Magnusson and Mahoney 2006).

These viewpoints felicitously highlight the basic idea of positive development from the point of view of success. Positive development cannot be defined without referring to the individual but merely that attention must be paid to natural features, resources and limitations within his or her cultural, physical and historical context (Magnusson and Mahoney 2006).

What this means is that success, when considered from this positive point of view, also needs to be seen in context. First, the processes have a holistic nature that means that success is merely a result of the functional interaction of its elements rather than how each element influences entity. Second, the inner processes, such as mental, biological and behavioural functions, and outer processes, such as opportunities, obligations and rules, and how well these processes are synchronised, contribute to the possibility of success.

It is therefore relevant to ask whether the lifespans of positively acting people differ from those of others and, if they do, how. Basically, the discussion of the phenomenon of success seeks to analyse how it can be enhanced, the ways of 
conceptualising it as positive development and, most importantly, it opens up discussion on how the elements can be recognised. The next chapters will sink some teeth into this interesting matter.

\section{Top workers: who are they?}

We have now introduced the fundamental ideas directing our research on success. But how do they appear in practice, if at all? Understood as the result of an inner drive to work well and as an expression of mastery, success is an indication of positive attitudes and wellbeing at work. Given such a definition, everyone has an equal chance to succeed at work; in other words, more people would be considered successful.

Experience has already shown that healthier and more satisfied employees work better (Rissa 2007). However, not everyone's goal of success at work is the same, and a variety of motivating factors can be recognised. One may aim to earn a living, the another's goal may be to achieve top expertise in his or her professional field, to enhance the quality of life, or to strive for a personally significant long-term goal (Locke 2002) - not to mention that success is experienced subjectively and that personal achievements are evaluated in different ways (Maddux 2002).

The purpose of this book is to introduce the positive sides of work: how you can not only manage your work life, but also succeed. We will introduce our empirical research on the phenomenon. Although we take a specific viewpoint of success, it is not very straightforward to find suitable people to represent top workers. How do you define whether someone has achieved success at work or not? Who can define this?

\section{How to study success at work?}

As referenced in the introduction to this book, we considered any employee in any occupation as having the chance to succeed. However, in order to find the top workers, we could not just go into workplaces to interview employees. Instead, we decided to contact workers who had received a top-worker award in their field. Every now and then in Finland - and we know that the same is true for numerous other countries - people are selected as excellent workers in their specific fields.

The main research on which this book is based included participants who represented top workers from different occupations (see Uusiautti 2008). Each participant was nominated 'Employee of the Year' by Finnish labour unions as most Finnish workers are members of a labour union in their respective fields. These top workers were considered representatives of successful workers and suitable informants for describing their experiences of success at work. The selection of successful employees was not done by the researchers, thereby ensuring that there was public justification for selecting the participants. The criteria for 
the award of 'Employee of the Year' were gathered for the 20 occupations from which the participants were chosen (examples of these professions include fields such as psychology, policing, teaching, etc.). The criteria were mostly found on the internet, but some of them were obtained through email inquiries to the labour unions.

We will now briefly introduce how the participants were described with reference to the criteria for Employee of the Year. In different occupations, the award emphasised different qualities that could be categorised into three groups. Firstly, having a high professional standard was named as one of the most important qualities among the participants. Regarding this quality, expertise was recognised as referring not only to excellent work quality but also to the ability to actively develop one's work and skills. The following occupations best represented this theme: priest, police officer, nurse and psychologist. The second group consisted of employees' actions that led to making their work and occupation recognised. Examples of these actions included paying attention to the contents of the occupation (for example work tasks), publicly discussing current topics regarding their occupational field, and facilitating the recognition of Finnish proficiency abroad. For example, the criteria for the 'Artisan of the Year', 'Journalist of the Year', and 'Athlete of the Year' awards typified this theme. The difference between these two themes was that the first emphasised winners who had developed their field through their own professional development, while the second emphasised winners who used their proficiency to gain publicity.

Some of the rewarded employees were selected not by their colleagues but through competitions. These competitions differ remarkably, depending on the occupation (for example 'Chef of the Year' and 'Cleaner of the Year'). However, one feature was common among them, namely, professional skills in several sectors were evaluated (for example, customer service skills and working methods) as these depicted core occupational expertise. In other words, only a true professional can win this kind of competition. Therefore, employees who had won a competition were also asked to participate in this research. On the other hand, employees who had been selected for these competitions from their workplace had also already been nominated by their colleagues as excellent workers.

In addition to the three themes mentioned above, the criteria for 'Employee of the Year' awards can be studied by analysing the specific words describing the awards. Three different categories were found: attributes that described top workers, action-related attributes and profession-specific qualifiers. The most common attributes were adjectives such as competent, innovative, punctual, celebrated, effective, open-minded and social. Action-related descriptions covered factors such as developing work and occupation, improving one's occupation, making one's occupation noted in Finland and abroad, dedication to one's occupation and active cooperation. Profession-specific qualifiers were language proficiency, tidiness, expertise, care for one's own and others' wellbeing at work, punctuality, a well-functioning business idea, courage to create new ideas, cooperation skills and service skills. Top workers' attributes were essentially words that described 
employees, regardless of occupation. Action-related attributes paid attention to how an employee had been working or what an employee had done in order to earn the nomination. Profession-specific qualifiers referred directly to occupation and specific profession-bound skills. Thus, one qualifier could describe several occupations but with different meanings (for example, tidiness can be considered differently among taxi drivers, chefs and cleaners).

It was interesting to note that the criteria for Employee of the Year did not differ substantially between fields. The aim of this introduction was to give an idea of the kinds of characteristics emphasised in the criteria. Nevertheless, it is worth deliberating on how much this actually framed the picture of successful employees used in this research, as winners of Employee of the Year awards were, and still are, mainly selected by their own labour unions. For example, making one's occupation renowned can be advantageous for a particular union, thereby influencing one's chances of being selected. Additionally, persons who are more sociable could be seen as more appealing, further influencing the likelihood of their selection for Employee of the Year.

Nonetheless, and most importantly, Employee of the Year winners are top workers rewarded in their own fields. Thus, they constitute a group of successful and excellent workers.

\section{The data and analyses}

The research consisted of two phases. In the first phase, success at work was analysed by focusing on motivation as well as on work engagement. In addition, those work characteristics considered most rewarding by participants were studied. The participants were nominated employees of the year in a variety of occupational field $^{1}$. Altogether, 44 employees were contacted. Of this figure, 16 participated by answering the questionnaires. Five of them were men and 11 were women. Seven of those who responded to the questionnaires were interviewed during the first phase of the study. Participants were between 29 and 71 years old (mean $=49$ ). Their occupations represented different fields and could be divided into the following professional groups: academic occupations, artistic occupations and labourers.

The research used a mixed-methods approach (see, for example, Creswell 2002; Teddlie and Tashakkori 2003). Data were collected via questionnaires and interviews. Questionnaires consisted of both quantitative and qualitative sections. The quantitative section was designed to assist answering the open-ended questions. The participants were asked to describe:

- their experiences about their work (How do you usually feel about your work [for example, rewarding/frustrating, interesting/boring] and why?);

- the significance of their work (How important do you consider your work, and why?);

- their job satisfaction (Are you usually satisfied with your work, and why? Please, also write about what inspires you about your work); 
- $\quad$ work-related challenges (Is your work challenging? Do you think that you are capable of handling these challenges? How so?);

- $\quad$ whether their work was rewarding (Is your work rewarding?);

- the most important characteristics of their work (Mention three things that you consider to be most important about your work. Why have you chosen this particular work/occupation?);

- themselves as workers (In your opinion, what kind of employee are you? Please describe yourself as a worker).

The interviews were based on the questionnaires and were qualitative theme interviews, i.e., all themes included in the interviews were decided beforehand, but the order and form of the questions were not (Hirsjärvi et al. 2000). In other words, the interviewer ensured that all the predetermined topics were discussed, but the order and extent could vary (Eskola and Vastamäki 2001). In this research, the researcher analysed the questionnaires before each interview and, based on that analysis, determined the focus of each interview. For example, if a participant had found it difficult to answer a certain question on the questionnaire, that theme was discussed more thoroughly in an interview. Therefore, the themes in the interviews were the same for everyone (work motivation, experiences about work and participants' characteristics as workers) but were given varying degrees of emphasis according to the participants' answers on the questionnaires.

In this research, the data were analysed through qualitative content analysis with predetermined categories derived from a theoretical background (such as , for example, the key concepts mentioned). Qualitative content analysis emphasises a relevant selection and rational organisation of categories (Kracauer 1952; Mayring 2000). This formed the basis for analysis. Furthermore, these categories were divided into reasonable subcategories that emerged in the data (based on the number of references).

The second phase of the research concentrated on the process of becoming a top worker. In this phase, the employees of the year $(n=8)$ were Nurse of the Year, Farmer of the Year, Police Officer of the Year $(n=2)$, Psychologist of the Year, Priest of the Year $(n=2)$ and Artisan of the Year. Six of them were men and two were women. Participants were between 36 and 64 years old (mean = 49). In the interviews, the participants were asked to discuss the following themes: factors that enhance success, difficulties and obstacles they had confronted, and choices and decisions they had made during the course of their lives. As this was a piece of narrative research, the data were collected using interviews.

Narrative research can be defined as research that utilises or analyses data collected via narratives (for example, biographies) or other similar ways (for example, anthropologists' observational narratives). Thus, a narrative can be either a research object or a means to study a phenomenon (Lieblich, TuvalMashiach, and Zilber 1998). Narrative research does not focus on objective and generalized facts but on local, personal, and subjective information - this is 
considered a strength of narrative research because informants' voices can be heard authentically (Guba and Lincoln 1994). Narratives can also be used when analyzing the reasons for actions (Moilanen 2002). To best serve this research the narrative interview was complemented with characteristics of the themed interview, thereby aiming at a thick description of the phenomenon of success at work (see Rubin and Rubin 1995).

Polkinghorne (1995) distinguishes the analysis of narratives and narrative analysis. The former means categorising by types, for example, and metaphors. The latter refers to the composition of a new narrative based on various original narratives. Both of these analytical methods were used in this research. On the one hand, the participants' narratives were categorised by predetermined categories and, on the other hand, a narrative of becoming a top worker was composed (see also Kuusela 2003).

In this research, an analysis of narratives and narrative analyses was conducted. The analysis consisted of narrative structuring, which tries to put together a cohesive narrative of experiences and events during interviews (Kvale 1997). Furthermore, the analysis typified a category-content-focused approach, with parts of narratives being placed in different categories (Lieblich, Tuval-Mashiac, and Zilber, 1998).

As the participant group was quite a selective one, some reliability issues need to be addressed. To what extent are the stories of top workers biased? Certainly, they already had a particular attitude and idea of the purpose of the study when they answered the questionnaire and were interviewed. Indeed, the aim was to study their positive experiences, although the themes and questions did also cover negative happenings. However, they were regarded as top workers, examples of successful people, and that starting point may have affected their responses. However, especially in the interviews, the participants thoroughly contemplated their experiences. In the second phase, in particular, when they described their entire life stories, their answers could not have been structured entirely on the basis of extrinsic norms or expectations and were thus considered reliable and valuable. Furthermore, when the participants describe their experiences of success, there was no reason to think that they were not be honest. Consequently, the question was merely about what the participants considered so important that it was worth telling.

\section{Studies on the factors contributing to success at work}

Research on employees of the year forms the main study on which this book is grounded. However, we have complemented and viewed the phenomenon of success from various perspectives, especially in Chapter 5 when we discuss external factors that influence the process. We include Professor Kaarina Määttä's research on Finnish married couples $(\mathrm{N}=342)$ who had been married for more than ten years. In her study, couples, inspired by a writing competition arranged by a Finnish magazine, wrote about the secret of their own long-lasting marriage, as well as the variety of solutions they had tried in terms of combining work and 
family. The theoretical basis of the study was grounded in many theories and previous research on marital quality and marital stability, especially Sternberg's Triangular theory of Love (1986), the Love is a Story theory (Sternberg, 1999), Gottman's publications (1994; 1999), and A Vulnerability-Stress-Adaption Model of Marriage by Karney and Bradbury (1995). The participants were a good representation of the gamut of Finnish married couples; they represented different age groups, most of them had been married for 10-15 years, and they had one or two children. For many of the writers, this was their first marriage; for others, this was at least their second marriage. The stories did not only describe the bright sides of marriage; there were also some rough experiences and survival stories. What they had in common was that the relationships endured more than ten years. The data analysis was based on inductive content analysis and the qualitative categorising of the written stories. In addition, the question about the kinds of solutions couples employed in order to combine work and family produced interesting results.

In Chapters 4 and 5 we also lean on a research project called 'Love-based Leadership - An Interdisciplinary Approach,' which focuses on enhancing employees' happiness at work by supporting their individual strengths and creating productive work communities that are ready for change - thus, the starting point and emphasis is on an individual. This study approach can be identified within the area of positive psychology called positive organisational behaviour (POB) (see Youssef and Luthans 2007). Luthans (2002: 59) defines POB as 'the study and application of positively oriented human resource strengths and psychological capacities that can be measured, developed, and effectively managed for performance improvement in today's workplace'. The viewpoint is interested in positivity and psychological resources that illustrate capacity that must be theory- and research-based and validly measurable as well as 'state-like' (i.e., open to change and development) and have a demonstrated performance impact. This viewpoint offers a great addition to the analysis of the process of becoming a successful worker.

In this study, 13 leaders were interviewed. The interviews consisted of four themes, from leaders' strengths to their understanding of caring leadership, and from positive and love-based work communities to interrelationships between positive, appreciative and happy experiences and leadership. The interviewees included deans and associate deans $(\mathrm{n}=5)$ and department chairs or department managers $(n=8)$. Seven participants (three women and four men) came from a general university and a university of applied sciences in Finland, while six (all men) came from one university in the USA. The purpose of including participants from two countries was to gather experiences that were as diverse as possible. And indeed, leaders revealed a rich store of personal perceptions and experiences. In this book, we will especially employ the findings to analyse how leadership can enhance employees' success (see also Peterson and Luthans 2003).

Having introduced the theoretical assumptions and empirical solutions, it is time to move on to practical examples and viewpoints concerning success at work. Let us have the top workers reveal their secrets! 


\section{Note}

1 Employees of the year represented the following awards: in the first phase, Coach of the Year, Artisan of the Year, Cleaner of the Year, Nurse of the Year, Doctor (of Medicine) of the Year, Industrial Designer of the Year, Farmer of the Year, Textile Artist of the Year, Psychologist of the Year, Police Officer of the Year and Graphic of the Year and, in the second phase, Nurse of the Year, Farmer of the Year, Police Officer of the Year, Artisan of the Year, Priest of the Year, and Psychologist of the Year.

\section{References}

Achor, S. (2010) The Happiness Advantage. The Seven Principles of Positive Psychology that Fuel Success and Performance at Work. New York, NY: Crown Business

Adler, P. T. (1982) 'An analysis of the concept of competence in individuals and social systems'. Community Mental Health Journal, 18(2), pp. 34-45

Almost, J. and Spence Laschinger, H. K. (2002) 'Workplace empowerment, collaborative work relationships, and job strain in nurse practitioners'. Journal of the American Academy of Nurse Practitioners, 14(9), pp. 408-420

Aspinwall, L. G. and Staudinger, U. M. (2006) 'Ihmisen vahvuuksien psykologia: kehittyvän tutkimuskentän kysymyksiä [A psychology of human strengths: Questions from a developing field of study]' pp. 21-33 in Aspinwall, L. G. and Staudinger, U. M. (Eds.) Ihmisen vahvuuksien psykologia [A Psychology of Human Strengths]. Helsinki: Edita

Baltes, P. B. and Freund, A. M. (2006) 'Ihmisen vahvuudet ja viisaus [The human strengths and wisdom]' pp. 34-46 in Aspinwall, L. G. and Staudinger, U. M. (Eds.) Ihmisen vahvuuksien psykologia [A Psychology of Human Strengths]. Helsinki: Edita

Bandura, A. (1997) Self-efficacy: The Exercise of Control. New York, NY: Freeman

Brickman, P., Coates, D. and Janoff-Bulman, R. (1978) 'Lottery winners and accident victims: is happiness relative?' Journal of Personality and Social Psychology, 36(8), pp. 917-927

Campbell, J. P. and Pritchard, R. D. (1976) Motivation theory in industrial and organizational psychology' pp. 63-129 in Dunnette, M. D. (Ed.) Handbook of Industrial and Organizational Psychology. Chicago, IL: Rand McNally Publishing Company

Caprara, G. V. and Cervone, D. (2006) 'Persoonallisuus toimivana, itsesäätelevänä järjestelmänä [Personality as a functional, self-regulating system]’ pp. 69-82 in Aspinwall, L. G. and Staudinger, U. M. (Eds.) Ihmisen vahvuuksien psykologia [A Psychology of Human Strengths]. Helsinki: Edita

Carruthers, C. and Hood, C. D. (2005) 'The power of positive psychology'. Parks and Recreation, Oct 2005, pp. 30-37

Carver, C. S. and Scheier, M. F. (2002) Optimism pp. 231-243 in Snyder, C. R. and Lopez, S. J. (Eds.) Handbook of Positive Psychology. Oxford: Oxford University Press

Carver, C. S. and Scheier, M. F. (2005) 'Engagement, disengagement, coping, and catastrophe' pp. 527-547 in Elliot, A. J. and Dweck, C. S. (Eds.) Handbook of Competence and Motivation. New York and London: The Guilford Press

Chang, E. C. (2001) (Ed.) 'Optimism and pessimism: Implications for theory, research, and practice’ (pp. 53-75). Washington, DC, US: American Psychological Association

Covey, S. R. (2006) 'Tie menestykseen. 7 toimintatapaa henkilökohtaiseen kasvuun ja muutokseen [Road to Success. 7 Methods of Personal Growth and Change]' (5th Ed.). Jyväskylä: Gummerus 
Covington, M. V. (1992) Making the Grade: A Self-worth Perspective on Motivation and School Reform. Cambridge: Cambridge University Press

Creswell, J. W. (2002) Research Design. Qualitative, Quantitative, and Mixed Methods Approaches. (2nd Ed.). Thousand Oaks, CA: Sage

Csikszentmihalyi, M. (2008) Flow. The Psychology of Optimal Experience (10th Ed.). New York, NY: HarperPerennial

Csikszentmihalyi, M., Abuhamdeh, S. and Nakamura, J. (2005) 'Flow' pp. 598-608 in A. J. Elliot, A. J. and Dweck, C. S. (Eds.) Handbook of Competence and Motivation. New York and London: The Guilford Press

Deci, E. L. and Moller, A. C. (2005) 'The concept of competence. A starting place for understanding intrinsic motivation and self-determined extrinsic motivation' pp. 579597 in Elliot, A. J. and Dweck, C. S. (Eds.) Handbook of Competence and Motivation. New York and London: The Guilford Press

Deci, E. L. and Ryan, R. M. (2008) 'Facilitating optimal motivation and psychological wellbeing across life's domains'. Canadian Psychology, 49(1), pp. 14-23

Deci, E. L., Vallerand, R. J., Pelletier, L. G. and Ryan, R. M. (1991). 'Motivation and education: the self-determination perspective'. Educational Psychologist, 26(3 and 4), pp. 325-346

Diener, E., Lucas, R. E. and Napa Scollon, C. (2006) 'Beyond the hedonic treadmill. Revising the adaptation theory of wellbeing'. American Psychologist, 61(4), pp. 305-314

Diener, E., Oishi, S. and Lucas, R. E. (2009) 'Subjective wellbeing: the science of happiness and life satisfaction' pp. 187-194 in Lopez, S. J. and Snyder, C. R. (Eds.) Oxford Handbook of Positive Psychology. Oxford: Oxford University Press

Diener, E., Suh, E. M., Lucas, R. E. and Smith, H. L. (1999) 'Subjective wellbeing: three decades of progress'. Psychological Bulletin, 125(2), pp. 276-302

Eccles, J. S. and Wigfield, A. (2002) 'Motivational beliefs, values, and goals'. Annual Review of Psychology, 53(1), pp. 109-132

Eskola, J. and Vastamäki, J. (2001) 'Teemahaastattelu: opit ja opetukset [Theme interview: tenets and instruction]' pp. 24-42 in Aaltola, J. and Valli, R. (Eds) Ikkunoita tutkimusmetodeihin I [Introduction to Research Methods I]. Jyväskylä: Gummerus

Feldt, T., Mäkikangas, A. and Kokko, K. (2005) 'Persoonallisuus ja työhyvinvointi [Personality and wellbeing at work]' pp. 75-94 in Kinnunen, U., Feldt, T. and Mauno, S. (Eds.) Työ leipälajina Työhyvinvoinnin psykologiset perusteet [Work as a Job. The Psychological Foundations of Wellbeing at Work]. Keuruu: Otava

Fredrickson, B. L. (1998) 'What good are positive emotions?' Review of General Psychology, 2(3), pp. 300-319

Fredrickson, B. L. (2001) 'The role of positive emotions in positive psychology: the broaden-and-build theory of positive emotions'. American Psychologist, 56(3), pp. 218-226

Freund, A. M. and Baltes, P. B. (1998) 'Selection, optimization, and compensation as strategies of life management: correlations with subjective indicators of successful aging'. Psychology and Aging, 13(4), pp. 531-543

Furnham, A. (1992). Personality at Work: the Role of Individual Differences in the Workplace. London: Routledge

Gable, S. and Haidt, J. (2005) 'What (and why) is positive psychology?' Review of General Psychology, 9, pp. 103-110

Gardner, H., Csikszentmihalyi, M. and Damon, W. (2001) Good Work. When Excellence and Ethics Meet. New York, NY: Basic Books 
Gillham, J. and Reivich, K. (2004) 'Cultivating optimism in childhood and adolescence'. The ANNALS of the American Academy of Political and Social Science, 591, pp. 146-163

Gilpin, J. M. (2008) 'Teaching happiness. The role of positive psychology in the classroom'. Pell Scholars and Senior Theses, 12, pp. 1-23

Gottman, J. (1994) What Predicts Divorce? The Relationships between Marital Process and Marital Outcomes. Hillsdale: Erlbaum

Gottman, J. (1999) The Seven Principles for Making Marriage Work. New York, NY: Crown Publishers

Green, J., Liem G. A., Martin, A. J., Colmar, S., Marsh, H. W. and McInerney, D. (2012) 'Academic motivation, self-concept, engagement and performance in high school: key processes from a longitudinal perspective'. Journal of Adolescence, 35(5), pp. 1111-1122

Guba, E. G. and Lincoln, Y. S. (1994) 'Competing paradigms in qualitative research' pp. 105-117 in Denzin, N. K. and Lincoln, Y. S. (Eds) Handbook of Qualitative Research. Thousand Oaks, CA: Sage

Hackman, J. R. and Oldham, G. R. (1976) 'Motivation through the design of work: test of a theory'. Organizational Behaviour and Human Performance, 16, pp. 250-279

Hakanen, J. (2002) 'Työuupumuksesta työn imuun - positivvisen työhyvinvointikäsitteen arviointimenetelmän suomalaisen version validointi opetusalan organisaatiossa [From burnout to work engagement - validation of the Finnish version of evaluation method to positive concept of wellbeing at work in educational organizations]'. Työ ja ihminen, $16,42-58$

Hakanen, J., Perhoniemi, R. and Toppinen-Tanner, S. (2008) 'Positive gain spirals at work: from job resources to work engagement, personal initiative and work-unit innovativeness'. Journal of Vocational Behaviour, 73, pp. 78-91

Hirsjärvi, S., Remes, P. and Sajavaara, P. (2000) Tutki ja kirjoita [Reseach and Write]. Vantaa: Tummavuoren Kirjapaino

Isen, A. M. (2001) 'Some perspectives on positive affect and self-regulation'. Psychological Inquiry, 11(3), pp. 184-187

Isen, A. M. (2006) 'Myönteinen tunne ihmisen vahvuuden lähteenä [Positive feeling as a source of human strength]' pp. 186-201 in Aspinwall, L. G. and Staudinger, U. M. (Eds.) Ihmisen vahvuuksien psykologia [A Psychology of Human Strengths]. Helsinki: Edita

Isen, A. M. and Reeve, J. (2006) 'The influence of positive affect on intrinsic and extrinsic motivation: facilitating enjoyment of play, responsible work behaviour, and selfcontrol'. Motivation and Emotion, 29, pp. 297-325

Judge, T. A., Locke, E. A. and Durham, C. C. (1997) 'The dispositional causes of job satisfaction'. Research in Organizational Behaviour, 19, pp. 151-188

Kahneman, D. and Krueger, A. B. (2006) 'Developments in the measurement of subjective wellbeing'. The Journal of Economic Perspectives, 20(1), pp. 3-24

Kahneman, D., Krueger, A. B., Schkade, D. A., Schwarz, N. and Stone, A. A. (2004) 'A survey method for characterizing daily life experience: the day reconstruction method'. Science, 306, pp. 1776-1780

Kanfer, R. and Ackerman, P. L. (2005) 'Work competence: a person-oriented perspective' pp. 336-353 in Elliot, A. J. and Dweck, C. S. (Eds.) Handbook of Competence and Motivation. New York and London: The Guilford Press

Karasek, R. and Theorell, T. (1990) Healthy Work. Stress, Productivity, and Reconstruction of Working Life. New York, NY: Basic Books

Karney, B. and Bradbury, T. N. (1995) 'The longitudinal course of marital quality and stability: A review of theory, method and research'. Psychological Bulletin, 111, pp. 3-34 
Kaufman, H. G. (1974) 'Relationship of early work challenge to job performance, professional contributions, and competence of engineers'. Journal of Applied Psychology, 59(3), pp. 377-379

Kracauer, S. (1952) 'The challenge of qualitative content analysis'. The Public Opinion Quarterly, 16, pp. 631-642

Krueger, D. W. (1990) 'Success and success inhibition' pp. 246-260 in Sternberg, R. J. and Kolligian, J. Jr. (Eds.) Competence Considered. New Haven, CN: Yale University Press

Kuusela, P. (2003) 'Metafora, metateoria ja sosiaalitieteet [Metaphor, metatheory and social sciences]' pp. 77-104 in Eskola, J. and Pihlström, S. (Eds) Ihmistä tutkimassa. Yhteiskuntatieteiden metodologian ajankohtaisia kysymyksiä [Studying Human Beings. Current Questions in the Methology of Social Sciences]. Kuopio: Kuopio University Press

Kvale, S. (1997) Den kvalitativa forskningsintervjun [The Qualitative Interview]. Lund: Studentlitteratur

Latham, G. P. and Pinder, C. C. (2005) 'Work motivation theory and research at the dawn of the twenty-first century'. Annual Review of Psychology, 56, pp. 485-516

Laubach, M. (2005) 'Consent, informal organization and job rewards: a mixed methods analysis'. Social Forces, 83(4), pp. 1535-1566

Liden, R. C., Wayne, S. J. and Sparrowe, R. T. (2000) 'An examination of the mediating role of psychological empowerment on the relations between the job, interpersonal relationships, and work outcomes'. Journal of Applied Psychology, 85(3), pp. 407-416

Lieblich, A., Tuval-Mashiach, R. and Zilber, T. (1998) Narrative Research: Reading, Analysis and Interpretation. Thousand Oaks, CA: Sage

Locke, E. A. (2002) 'Setting goals for life and happiness' pp. 299-312 in Snyder, C. R. and Lopez, S. J. (Eds.) Handbook of positive psychology. Oxford: Oxford University Press

Locke, E. A. and Latham, G. P. (1990) 'Work motivation and satisfaction: light at the end of the tunnel'. Psychological Science, 1(4), pp. 240-246

Luthans, F. (2002) 'Positive organizational behaviour. Developing and managing psychological strengths'. Academy of Management Executive, 16(1), pp. 57-72

Lyubomirsky, S. (2001) 'Why are some people happier than others? The role of cognitive and motivational processes in wellbeing'. American Psychologist, 56(3), pp. 239-249

Lyubomirsky, S., King, L. and Diener, E. (2005) 'The benefits of frequent positive affect: does happiness lead to success?' Psychological Bulletin, 131, pp. 803-855

Maddux, J. E. (2002) 'Self-efficacy. The power of believing you can' pp. 277-287 in Snyder, C. R. and Lopez, S. J. (Eds) Handbook of Positive Psychology. Oxford: Oxford University Press

Magnusson, D. and Mahoney, J. L. (2006) 'Holistinen lähestymistapa myönteisen kehityksen tutkimuksessa [A holistic approach in research on positive development]' pp. 232250 in Aspinwall, L. G. and Staudinger, U. M. (Eds.) Ihmisen vahvuuksien psykologia [A Psychology of Human Strengths]. Helsinki: Edita

Mayring, P. (2000) 'Qualitative content analysis'. Forum: Qualitative Social Research, 1(2). Available online at: http://www. qualitativeresearch.net/fqs/fqs-e/2-00inhalt-e. htm (last accessed 4 April 2014)

Mitchell, T. R. (1997) 'Matching motivational strategies with organizational contexts'. Research in Organizational Behaviour, 19, pp. 57-149

Moilanen, P. (2002) 'Narrative, truth, and correspondence: a defence' pp. 91-104 in Huttunen, R., Heikkinen, H. L. T. and Syrjälä, L. (Eds) Narrative Research. Voices of Teachers and Philosophers. Jyväskylä: Kopijyvä 
Oades, L. G., Robinson, P., Green, S. and Spence, G. B. (2011) 'Towards a positive university'. The Journal of Positive Psychology: Dedicated to furthering research and promoting good practice, 6(6), pp. 432-439

Pajares, F. (2001) 'Toward a positive psychology of academic motivation'. The Journal of Educational Research, 95(1), pp. 27-35

Paulsson, K., Ivergård, T. and Hunt, B. (2005) 'Learning at work: competence development or competence-stress'. Applied Ergonomics, 36, pp. 135-144

Peterson, C. (2000) 'The future of optimism'. American Psychologist, 55(1), pp. 44-55

Peterson, C., Seligman, M. E. P. and Vaillant, G. E. (1988) 'Pessimistic explanatory style is a risk factor for physical illness: a thirty-five year longitudinal study'. Journal of Personality and Social Psychology, 55, pp. 23-27

Peterson, S. J. and Luthans, F. (2003) 'The positive impact and development of hopeful leaders'. Leadership and Organization Development Journal, 24(1), pp. 26-31

Polkinghorne, D. E. (1995) 'Narrative configuration in qualitative analysis'. Qualitative Studies in Education, 8, pp. 5-23

Reivich, K. and Gillham, J. (2003) Learned optimism: The measurement of explanatory style pp. 57-74 in Lopez, S. J. and Snyder, C. R. (Eds.) Positive Psychological Assessment: A Handbook of Models and Measures. Washington, DC: American Psychological Association

Reivich, K., Gillham, J. E., Chaplin, T. M. and Seligman, M. E. P. (2013) 'From helplessness to optimism: The role of resilience in treating and preventing depression in youth' pp. 201-214 in Goldstein, S. and Brooks, R. B. (Eds.) Handbook of Resilience in Children. New York, NY: Springer

Rissa, K. (2007) Well-being Created Productivity: The Druvan Model. Helsinki: The Centre for Occupational Safety and the Finnish Work Environment Fund

Rosenthal, T. L. and Zimmerman, B. J. (1978) Social Learning and Cognition. New York, NY: Academic Press

Rubin, H. J. and Rubin, I. S. (1995) Qualitative Interviewing. The Art of Hearing Data. Thousand Oaks, CA: Sage

Ryan, R. M. and Deci, E. L. (2000a) 'Self-determination theory and the facilitation of intrinsic motivation, social development, and wellbeing'. American Psychologist, 55(1), pp. 68-78

Ryan, R. M. and Deci, E. L. (2000b) 'When rewards compete with nature: the undermining of intrinsic motivation and self-regulation' pp. 14-54 in Sansone, C. and Harackiewicz, J. M. (Eds.) Intrinsic and Extrinsic Motivation. The Search for Optimal Motivation and Performance. Thousand Oaks, CA: Academic Press

Schaufeli, W. B., Salanova, M., Gonzalez-Roma, V. and Bakker, A. B. (2002) 'The measurement of engagement and burnout: A two sample confirmatory factor analytic approach'. Journal of Happiness Studies, 3, pp. 71-92

Schneider, S. L. (2001) 'In search of realistic optimism. Meaning, knowledge, and warm fuzziness. American Psychologist, 56(3), pp. 250-263

Schunk, D. H. and Pajares, F. (2005) 'Competence perceptions and academic functioning' pp. 85-104 in Elliot, A. J. and Dweck, C. S. (Eds.) Handbook of Competence and Motivation. New York and London: The Guilford Press

Seligman, M. E. P. (1990) Learned Optimism. New York, NY: Knopf

Seligman, M. E. P. (2002) Authentic Happiness. New York, NY: Free Press

Seligman, M. E. P., Steen, T. A., Park, N. and Peterson, C. (2005) 'Positive psychology progress. Empirical validation of interventions'. American Psychologist, 60(5), pp. 410-421 
Shepperd, J. A., Ouellette, J. A. and Fernandez, J. K. (1996) 'Abandoning unrealistic optimism: Performance estimates and the temporal proximity of self-relevant feedback'. Journal of Personality and Social Psychology, 70(4), pp. 844-855

Spence Laschinger, H. K., Finegan, J. E., Shamian, J. and Wilk, P. (2004) 'A longitudinal analysis of workplace empowerment on work satisfaction'. Journal of Organizational Behaviour, 25, pp. 527-545

Sternberg, R. (1986) 'A triangular theory of love'. Psychological Review, 93(2), pp. 119-135

Sternberg, R. (1999) Love is a Story: A New Theory of Relationships. Oxford: Oxford University Press

Stoltenberg, C. D. (2005) 'Enhancing professional competence through developmental approaches to supervision'. American Psychologist, 6, pp. 857-864

Teddlie, C. and Tashakkori, A. (2003) 'Major issues and controversies in the use of mixed methods in the social and behavioral sciences' pp. 3-50 in Tashakkori, A. and Teddlie, C. (Eds). Handbook of Mixed Methods in Social \& Behavioral Research. Thousand Oaks, CA: Sage

Turner, N., Barling, J. and Zacharatos, A. (2002) 'Positive psychology at work' pp. 715728 in Snyder, C. R. and Lopez, S. J. (Eds.) Handbook of Positive Psychology. Oxford: Oxford University Press

Uusiautti, S. (2008) "Tänään teen elämäni parhaan työn” Työmenestys Vuoden Työntekijöiden kertomana ['Today, I'll work better than ever'. Success at work described by the Employees of the Year]. PhD Dissertation, University of Lapland, Rovaniemi, Finland

Uusiautti, S. and Määttä, K. (2011) 'Love for work as the way towards wellbeing'. Global Journal of Human Social Science, 11(9), pp. 63-68

Varila, J. and Lehtosaari, K. (2001) Työnilo - Ahkeruudella ansaittua, sattuman synnyttämää vai oppivan organisaation vaatimaa? [Joy of work - earned by diligence, occurs by accident or required by learning organization?]. Joensuu: University of Joensuu

Weiner, B. (1992) Human Motivation: Metaphors, Theories and Research. Thousand Oaks, CA: Sage

White, R. W. (1959) 'Motivation reconsidered: the concept of competence'. Psychological Review, 66(5), pp. 297-333

Youssef, C. M. and Luthans, F. (2007) 'Positive organizational behaviour in the workplace: the impact of hope, optimism, and resilience'. Journal of Management, 33(5), pp. $774-800$ 


\section{Chapter 3}

\section{A successful worker}

\section{Introduction}

What features do top workers share? How do they perceive their work? Do they face setbacks (at all)? Are they always excited about their work, or do they also have boring work tasks? Work cannot be all about sunshine, can it?

These questions came to mind as we glanced at the work attitudes and personalities of Employees of the Year. In this chapter, we reveal their thoughts, allow them to describe their motivation, engagement and themselves as employees. Surprisingly, the Employees of the Year participating in our studies had many things in common - regardless of occupation.

The chapter consists of three viewpoints of top workers' descriptions of themselves and their work. First, their opinions on the most important features of their work and other relevant factors that enhance success are introduced. Second, we look at the top workers as persons following the ideas of positive psychology and human strengths. Finally, a new perspective on success is introduced: the experience of success. Here, we focus on experiences of success at work as described by top workers. All these contribute to a special perspective on the phenomenon of success when the analysis is limited to the employee as well as the workplace and its distinctive features.

\section{Work itself boosts motivation and provides experiences of joy and accomplishment}

\section{Challenging work is most appreciated}

Some commonalities emerged as employees listed the most important factors that resulted in positive experiences at work. The most significant factor concerned the challenges at work and opportunities to improve skills and/or work. They described such situations as those in which you can learn more and develop yourself through new challenges at work. The participants emphasised that recognising your core skills is essential as it becomes possible to concentrate on doing what is most suitable for you. Indeed, knowing your strengths and weaknesses as 
well as your values and interests is crucial for enhancing your career (see also Arnold et al. 1993).

'I'm excited mostly in situations that enable me to develop something, to change something for the better, in a more reasonable direction.'

'Every day is different. It's challenging to see every customer as an individual and not as a group of clients!'

'I can actually say that we have very diverse training at work. And all these courses help with doing this work as this environment is changing constantly and, of course, the whole society. Continuously educating yourself in this way is essential in order to maintain your proficiency.'

Surprisingly, participants were not mavericks at their work, but they highly valued successful and effortless cooperation with their co-workers. Similarly, it has been discovered that social support is an effective means of enhancing selfesteem and feelings of mastery (Rousseau et al. 2009), thus promoting success at work. Argyle (1987) points out that contentment with relationships in the workplace, both horizontally - between employees - and vertically - between employers and employees - is central to happiness at work.

'I like working in teams. It's interesting to work with different kinds of people.'

'I think that my most powerful experiences at work are those in which we are working together as a group.'

'I think that [good relationships in the workplace] are an unquestionable precondition; everybody works better when they feel good.... So, if you spend five or ten minutes chatting, it doesn't harm because it contributes to the system in general.'

Thirdly, participants considered opportunities to work autonomously as a salient dimension of their experience. The Job Demands-Resources (JD-R) Model suggests that job resources (for example, autonomy, immediate feedback and rewards) are especially salient for resource gain, for example, true wellbeing and motivation at work, i.e., work engagement (Bakker and Demerouti 2007). In addition, individuals should be encouraged to rest, to engage in positive work reflection, and to prevent negative work-related thoughts (Binnewies et al. 2009).

'I can autonomously determine what I'm doing and when.'

'I can determine the content of my work.'

'Work drive, engagement, and the joy of work.'

All Employees of the Year thought that their work was rewarding. According to them, new challenges, as well as opportunities to develop themselves at work, were most exciting to them. It seemed certain that they experienced work 
engagement and joy of work. From the sub-scales of work engagement, the significance of work refers to dedication. All participants were proud of their work and considered their work meaningful. Furthermore, the sub-scales of flow, namely, vigor and absorption, were apparent in their descriptions.

'I am able to concentrate so deeply that I escape from reality. I can close my ears, and my husband tells me that I'm a closed book... I am riveted by my work, and I see it as a blessing.'

The interviewees were asked to describe how they focused on work. This was supposed to provide information about their flow experiences. In addition, they were asked to describe setbacks and hardships and their ways of handling such situations. Likewise, top workers described the challenges of their work and some aspects of work that had recently made them excited. One way of expressing top workers' inspiration for their work was their descriptions of how pleasurable it was for them to go to work every day. Many of them spoke of how important it was to be able to develop their work.

The experience of flow was familiar to almost everyone. Their descriptions were convincing; they kept talking about how fantastic it was to be absorbed by their work. However, the conditions leading to flow varied from person to person: some could reach this state in cooperation with colleagues, while others did so independently.

'I become absorbed when the [work] space is as undisturbed as possible.'

Inspiration and enthusiasm were concretely described as they said that they became riveted by work and did not remember to check the time or count the hours.

'Sometimes I can come here during weekends if I am very enthusiastic about developing something, for example an initial idea, so the time can pass quickly and it can be that I come here to my office on Saturday and Sunday.'

Above all, the most extraordinary characteristic among Employees of the Year was their positive attitude, which was specific to informants. For instance, they did not give up in the face of conflicts. Instead, they saw such situations as opportunities to reassess their occupational skills and, if necessary, to study and develop. Thus, conflict situations were seen as challenges that had to be solved. This kind of positive and optimistic attitude was at the very core of the participants' characteristics and may explain why they did not consider demanding situations to be stressful.

'Firstly, you have to try again if it's worth it. And if it's not, it might be that you weren't right after all. But then again, you can think that now is the time 
to look in the mirror and accept the fact that that way isn't leading you anywhere and find another one. This I have done many times along my way. And what else can you do...?'

'Sometimes I think that I'm a little bit stupid.... But I'm not because it might be that I don't see those [conflict situations]. I've always taken more responsibility than I should have and thus got more interesting duties...'

This is also an instance of the rewards of a proactive (as opposed to reactive) attitude (see Covey 2006). Proactive people can change their behaviour, see things from a different angle, make choices, and know what they want. Reactive people, on the other hand, concentrate on things that they cannot control or change, such as other people's weaknesses and poor circumstances. Accordingly, proactive people function in more effective and positive ways.

\section{Positive experiences at the core?}

This research has shown that one's positive work experiences (both the work itself and the employee's way of working) could be placed at the core of success. Employees of the Year found their jobs pleasing. Having a holistic positive experience is crucial to this (Seligman and Csikszentmihalyi 2000; see also Mäkikangas et al. 2005). Moreover, finding a balance between an employee's skills and work-related expectations, as well as between opportunities and challenges, is shown to lead to better performance at work, contentment, higher motivation and self-efficacy (Mäkikangas et al. 2005).

How then can success at work be outlined? The positive attitude that Employees of the Year demonstrated toward work and life in general was a common factor among them. As they outlined the phenomenon of success at work, the manner in which the participants experienced their work appeared to lie at the core of their success. Their positive experiences regarding their work and themselves as employees can be seen as a salient factor whereas the other features of work professional proficiency, life situation, work motivation and personality - merely appeared to be dependent on this positive experience. Notwithstanding, all these factors affect each other to a certain extent. Especially the above-mentioned features of work seemed to affect both the experience of work and work motivation. All features together form the basis and prerequisites for success at work. The interconnectedness of these factors is illustrated in Figure 3.1.

Placing the experience of work at the center is, in fact, a unique way of understanding success at work because it is not usually considered the most salient factor when compared with, for example, work motivation (cf. Ruohotie and Honka 2003).

On the other hand, the positive development that leads to becoming a top worker cannot be considered separate from an individual's environment (Magnusson and Mahoney 2006). Factors outside working life that influence success include one's overall life situation, family, friends, hobbies, physical and psychological health, and so on. 


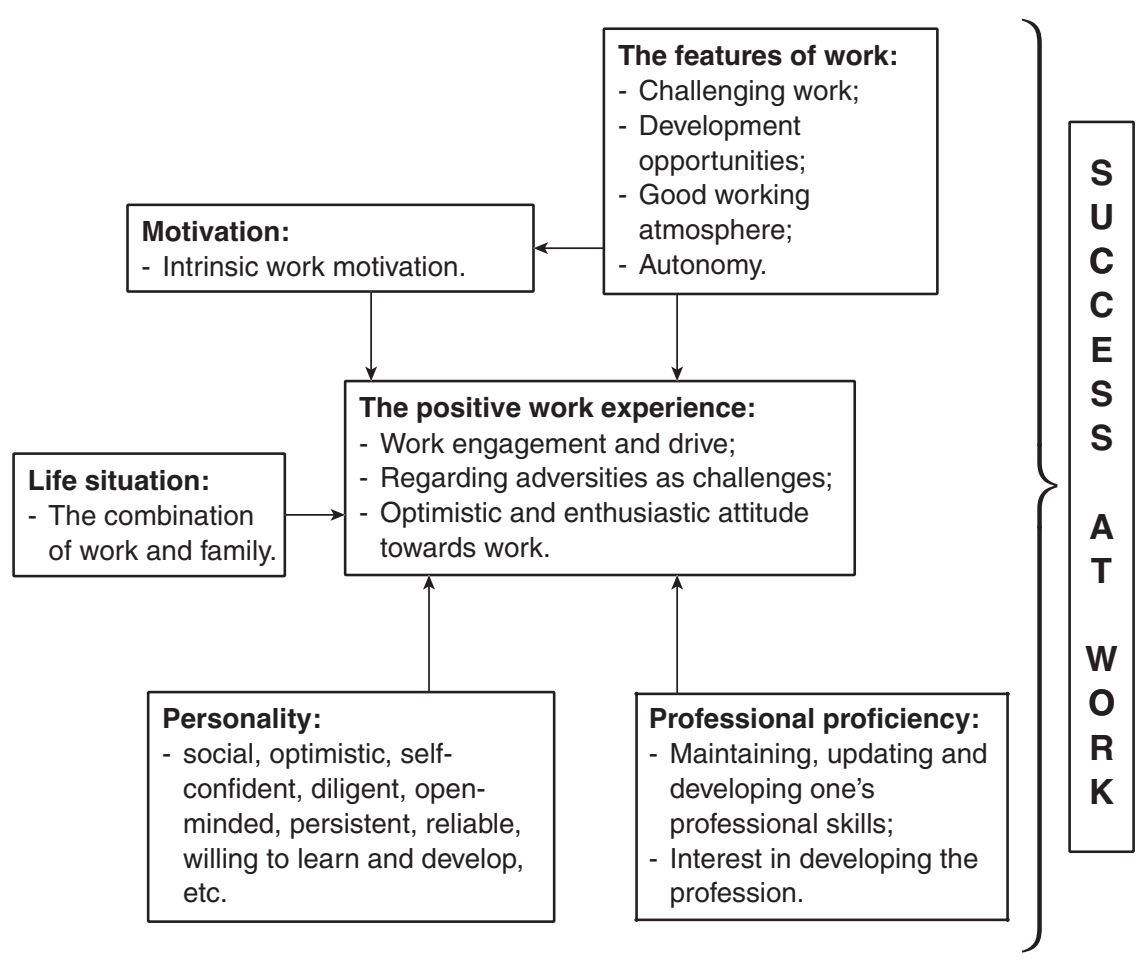

Figure 3.I The interconnectedness of the factors that explain success at work among Employee of the Year awardees (Uusiautti, 2008).

Although the findings are not generalisable as such, some recent research provides interesting guidelines regarding the types of attitudes that Finnish workers have toward work. For example, the National Research and Development Centre for Welfare and Health of Finland has studied working conditions and contentment (see, for example, Miettinen 2006) and has listed factors that employees value most about their work. Among employees who were mostly very pleased with their jobs, the factors that were most appreciated were the following: interesting content, autonomy, variation at work and social relationships with co-workers. Of these factors, autonomy and social relationships were also important to Employees of the Year. The difference between Finnish workers in general and the participants in this research was in relation to employees' attitudes toward opportunities for developing and educating themselves and the need for challenges at work. These were highly appreciated among Employees of the Year but not among workers in general.

The variation between top workers and the general pool can also be studied from another perspective. Among Finnish workers in general, two-thirds of managers, half of subordinate managers and one-third of workers reported considering education and development at work as very important (Aitta 2006). 
In our research, this kind of variation between different positions was not apparent. Instead, all Employees of the Year, regardless of their position, appeared to be extremely eager to educate themselves.

These results are in line with previous research. For example, Kinnunen et al. (2008) have found that increasing the rewarding aspects of work - instead of decreasing effort - could be especially efficient for increasing work engagement. Additionally, researchers have demonstrated that wellbeing is impacted by core concepts of positive psychology such as hope (see Snyder 1994), self-efficacy (Bandura 1997) and optimism (Carver and Scheier 2002). These characteristics were common to participants - especially the optimistic attitude toward work and life in general.

What can be learned from the experiences of Employees of the Year? It seems that having positive experiences is a key factor in success and wellbeing at work. Also, a lack of absenteeism and a willingness to stay in the same job engagement, so to speak - are significant. Employees of the Year could be described as true 'try-harders' because of their optimistic attitude both when confronting obstacles and when striving forward in their careers and other workrelated ambitions. According to Tugade and Fredrickson (2004), there are individuals who seem to 'bounce back' from negative events quite effectively, whereas others are seemingly unable to get out of their negative ruts. Our participants seemed to represent the former group. In addition, participants were passionate about working consummately. Indeed, it has been discovered that high work engagement magnifies emotional responses to perceived success or failure (Britt 1999).

Regardless of occupation or position, Employees of the Year appreciated wellbeing at work over hard values, such as making a good salary. In order to gain positive experiences from one's work, an employee has to be (intrinsically) motivated to do this particular work, to accomplish tasks and goals set. Work itself can motivate. However, in the present research, it was also discovered that when the work content lacked interest but its other characteristics, such as challenges, autonomy and work environment, appealed to employees, positive experiences were more likely to be achieved.

\section{Strengths and success}

Employees are human beings working in a certain job or occupation. As the previous findings show, success at work can be connected to challenging and inspiring work tasks but also to the intrinsic drive to work well. However, it is also interesting to think about the strengths that top workers possess and illustrate in their doings.

Indeed, recent research has paid increasing attention to studying human virtues (Magnusson and Mahoney 2006). Now, the research concentrating on human weaknesses has had to compete with a strong interest in human abilities, healthy aptitudes and virtues. Researchers have become conscious that people's 
experiences can be studied from this perspective as well and not just in a way that is oriented toward flaws and conditions (Mahoney 2002).

The concept of human strengths can be considered as contextually dynamic because the function of a specific behaviour depends on its context and its outcome. In addition, contexts are dynamic and change during an individual's life span. The concept of human strengths is also norm-dependent because the fundamental features of a society involve common knowledge about appropriate and appreciated behaviour (Baltes and Freund 2006).

According to Baltes and Freund (2006), the concept of human strengths is (1) dynamic and unbound to context from the point of view of adaptation or general mechanism, (2) represents the state of life-long learning and flexible lifemanagement, (3) regulates the direction of the goals in individual development as well as the ways in which the goals will be achieved, and (4) not only supports individuals' development but also makes them more efficient participants in creating the common good.

Virtues can be dissected from a variety of viewpoints. The synchronic perspective tries to explain an individual's behaviour on the basis of psychological and biological orientations at a certain moment, whereas the diachronic point of view is interested in those developmental processes that have led to the prevailing behaviour. This perspective focuses on the behaviour at a certain moment as part of an individual's developmental history. Diachronic models consider individual development and the timing and emergence of important happenings in one's environment, as well as the ways in which these factors interact in the course of time (Magnusson and Mahoney 2006).

We leaned on a universal idea of human strengths and asked about the strengths that top workers recognised in themselves. The list of strengths was originally developed by Professors Seligman and Peterson and their research group. After having read all kinds of categorisations about human virtues - starting from Aristotle and Plato, to the Old Testament, Talmud, Buddha, Bushido and the Boy Scouts - they managed to define six virtues that appeared common to all.

Their criteria for the strengths and virtues selected among the list were the following: first, a strength needs to be manifest in an individual's behaviour, including thoughts, feelings or actions consistently across time and situations. Second, a strength contributes to various fulfillments that comprise the good life. Third, although strengths can and do produce desirable outcomes, each strength is morally valued in its own right. Fourth, the display of a strength by one person inspires and encourages others rather than diminishes them. Strengths and virtuousness in this sense are not based on or evoke jealousy. Fifth, the wider society provides institutions and associated rituals for cultivating strengths and virtues. Sixth, it is possible to recognise people who are paragons of virtue. Seventh, strength is arguably one-dimensional and cannot be decomposed into other strengths (Peterson and Park 2004: 436-436).

The virtues listed were wisdom and knowledge, courage, justice, temperance, spirituality and transcendence, and love and humanity (Seligman 2002). Each 
virtue was complemented with strengths that illustrate the particular virtue. In other words, the idea is that one can reach a virtue and manifest it through special strengths, for example, the virtue of love and humanity can be shown through social intelligence.

The list of virtues and strengths is as follows (Seligman et al. 2005: 412):

1 Wisdom and knowledge (cognitive strengths that entail the acquisition and use of knowledge):

Creativity (thinking of novel and productive ways of doing things);

Curiosity (taking an interest in all of ongoing experience);

Open-mindedness (thinking things through and examining them from all sides);

Love of learning (mastering new skills, topics and bodies of knowledge);

Perspective (being able to provide wise counsel to others).

2 Courage (emotional strengths that involve the exercise of will to accomplish goals in the face of opposition, external or internal):

Authenticity (speaking the truth and presenting oneself in a genuine way); Bravery (not shrinking from threat, challenge, difficulty or pain);

Persistence (finishing what one starts);

Zest (approaching life with excitement and energy).

3 Humanity (interpersonal strengths that involve 'tending and befriending' others):

Kindness (doing favours and good deeds for others);

Love (valuing close relations with others);

Social intelligence (being aware of the motives and feelings of self and others).

4 Justice (civic strengths that underlie healthy community life):

Fairness (treating all people the same according to notions of fairness and justice);

Leadership (organising group activities and seeing that they happen);

Teamwork (working well as a member of a group or team).

5 Temperance (strengths that protect against excess):

Forgiveness (forgiving those who have done wrong);

Modesty (letting one's accomplishments speak for themselves);

Prudence (being careful about one's choices; not saying or doing things that might later be regretted);

Self-regulation (regulating what one feels and does).

6 Transcendence (strengths that forge connections to the larger universe and provide meaning): 
Appreciation of beauty and excellence (noticing and appreciating beauty, excellence, and/or skilled performance in all domains of life);

Gratitude (being aware of and thankful for the good things that happen);

Hope (expecting the best and working to achieve it);

Humour (liking to laugh and tease; bringing smiles to other people);

Religiousness (having coherent beliefs about the higher purpose and meaning of life).

\section{Top workers' strengths and virtues}

We asked the top workers to rank their strengths by giving three points to their best strength, two to their second best, one to their third best and half points to any other strengths they considered typical of them. When all the data were combined, the results were interesting. Three strengths stood out: open-mindedness came in first, social intelligence was ranked second and perseverance came in as the third important strength. We will now introduce the strength-based analysis in greater detail.

\section{Wisdom and knowledge}

The virtue of wisdom and knowledge consists of cognitive strengths (creativity, curiosity, open-mindedness, love of learning and perspective) that relate to the ability to acquire and use information. This virtue was the most important among the top workers. Based on their own perceptions, wisdom and knowledge as a virtue included those strengths that best described their passionate attitude toward learning new things, developing themselves and their occupation, as well as gathering versatile knowledge and skills. Therefore, their estimation also illustrated their attitude towards working.

The top workers were not always able to recognise their strengths, for example, when they spoke about creativity:

'I thought that I was not creative at all because I have always been really bad at drawing. But still, I compose music and write lyrics... and make up all kinds of gadgetries and apparatuses.'

Creativity was appreciated, but not all the top workers recognised themselves as creative. In fact, the concept of creativity is not as self-evident as one might think. Seligman et al. (2005: 412) state that creativity simply means 'thinking of novel and productive ways to do things' whereas Sternberg and Lubart (1999) have defined creativity as the ability to produce work that is novel and appropriate. Simonton's (2009: 262) definition follows that of Sternberg and Lubart. Creativity can be defined on the basis of two conditions: first, it must be original. This means that creative ideas are novel, surprising and unexpected; however, originality is not a sufficient criterion. Creativity must also be adaptive, which 
means that others should find the created thing adjustable or the creation should be adaptable. Sometimes, creativity is defined only as a feature that produces concrete results (for example, Carson et al. 2005). Furthermore, creativity can be defined only in terms of the so-called divergent creative reasoning. In divergent working, several options for solutions are kept open and flexible whereas the convergent way of working concentrates on one solution in order to achieve the right convincing result (Basadur and Hausdorf 1996; Runco 1993). From a psychological point of view, creativity is a very important human strength; it is most productive for those whose personality consists of features such as independence, strength, optimism, inner-direction, flexibility, tolerance of conflicts, energy, as well as perseverance and goal-orientation (Csikszentmihalyi 1990, 2000; Eysenck 1993; Maslow 1988).

Furthermore, creativity must not only be understood as a feature of an individual (a lone genius) but more often as a result of group work (see Nijstad and Levine 2007; Simonton 2009). Indeed, Anderson et al. (2004) have suggested that creativity and innovations should be studied more comprehensively and in a more routinised manner as the modern, constantly changing working life requires it - not to mention other areas of life.

Open-mindedness is associated with tolerance and courage to take part in new things. From the point of view of success at work, this is interesting because it can explain top workers' willingness to tolerate changes and seize opportunities. Usually, people tend to resist information that conflicts with their personal views - even if new information is shown to improve understanding (Correll et al. 2004). Interestingly, people seem to be motivated toward discounting both the source and the content of a challenging message in an effort to protect their existing beliefs and by striving for positive self-regard by drawing on successes in important domains in their lives (see also Cohen et al. 2000). For successful working, it is worth mentioning that research has shown that open-minded interaction leads to curiosity and information-seeking and the increasing likelihood of creative new knowledge emerging in work groups and teams (Mitchell and Nicholas 2006).

In particular, the Police Officer of the Year, the Psychologist of the Year and the Farmer of the Year considered open-mindedness as an important characteristic. According to the interviews, open-mindedness aptly described all the participants, as did love of learning (for example, Nurse of the Year considered this to be his greatest strength), whereas creativity and curiosity were not. Curiosity was considered rather negatively: as nosiness. This might be a culture-specific finding since the concept seemed to have a negative connotation among interviewees. Notwithstanding, according to an American-Japanese comparative research, curiosity was connected with subjective happiness (Shimai et al. 2006), thus representing a very important human strength.

Perspective was, to some extent, every top worker's strength. It was understood as a sort of wisdom gained through experience, i.e., the ability to look at things from different perspectives: 
'First, I thought of some tactics... The more experience you have the easier you notice that you have plenty of other options and tacks that you have to consider.'

Thus, the virtue of wisdom and knowledge described the top workers well, a point also supported by the fact that none of these workers thought that these strengths should be improved or that they lacked one or some of these strengths.

\section{Courage}

The virtue of courage was defined as an emotional strength consisting of the will to achieve goals regardless of inner or outer resistance. Putnam (1997) distinguishes three dimensions of courage: physical courage is characterised by overcoming a fear of death or physical harm. The goals to be achieved by the exercise of physical courage are traditionally defined by society or by the requirements of survival. Moral courage deals with loss of ethical integrity or authenticity and social disapproval. For example, it refers to situations in which a person adheres to his or her moral principles regardless of the group pressure of the people surrounding him or her. The third form of courage is psychological courage, which refers to fear centering on a loss of psychological stability. In the classification of virtues and strengths (Seligman et al. 2005) courage is analysed through the strength of authenticity, bravery, persistence and zest, which can all contain elements of the aforementioned three dimensions as well.

This virtue was evaluated as having secondary importance by the top workers, and they did not see any shortcomings in the strengths listed within this virtue. Nurse of the Year and Priest of the Year thought that authenticity was their most important strength, which is, indeed, especially crucial among professions that entail working closely with other people.

'So you certainly have to be genuine when dealing with people and at work in general and I think that I try to express that I am what I am and what I do...'.

Persistence is an interesting strength when it comes to success at work. The previous chapters have shown that, to some extent, success requires persistent and diligent work. Therefore, it could be assumed that persistence would score high among top workers. Furthermore, the strength itself is not as straightforward as it might appear. For example, Lent et al. (1984) have shown that high self-efficacy positively affects persistence. Likewise, motivation and outer surroundings can influence how persistently people keep on doing something. But when regarded as a personal strength, persistence appears more stable, a constant feature that one manifests in many areas of life. It is also a question of a certain kind of attitude, a mental map (Achor 2010), that leads people to strive and try over and over again or to approach any long-term goal step by step. 
Persistence as a strength was emphasised by Police of the Year, Psychologist of the Year and Priest of the Year and, according to the top workers, persistence was the third most important strength among them.

'I can say that if I agree to take care of something, I'll have a great need to do it; I rarely leave tasks unfinished.'

Every top worker also considered himself or herself to be typically zesty; however, bravery as a concept was difficult to grasp as many of them associated it with romantic images of brave heroes. Nonetheless, defined as everyday bravery, it seemed more familiar, and they described it as staying strong and sticking to one's principles when accomplishing daily chores and making daily choices.

\section{Humanity}

The third most important virtue among the top workers according to their assessments was humanity. Within this virtue, they also recognised their second most important strength, namely, social intelligence. The concept of social intelligence can be perceived from various viewpoints. Salovey et al. (2004) sums up four of them: (1) perceiving emotions, (2) using emotions to facilitate thought, (3) understanding emotions, and (4) managing emotions in a way that enhances personal growth and social relations. If success at work was previously associated with opportunist, cold-hearted mavericks, top workers in our studies proved the opposite.

Artisan of the Year, Priest of the Year, Police of the Year, and Nurse of the Year all thought that social intelligence described them extremely well. Of course, the later three are occupations for which social intelligence can be seen as one of the basic requirements to perform well. One of the top workers paralleled social intelligence with social skills, and he was of the opinion that his social skills were not perfect but should be improved. One interesting remark concerning social intelligence was made by Artisan of the Year who pointed out that social relationships are important for success at work:

'You don't create your success all by yourself; it's the others who create your success.'

However, those employees who lacked social skills can also be rewarded, but whether it is more likely that social personalities are rewarded is a different question altogether.

\section{Justice}

Among the strengths (fairness, leadership, teamwork) that describe the virtue of justice, the top workers named fairness as their most important feature, especially Farmer of the Year, as he considered it as a component of good leadership. Treating 
his employees fairly was important for creating and sustaining a good working atmosphere and trust in the workplace. Leadership can be defined as a leader's personal characteristics or behaviour, style and decisions (Arnold et al. 1993). The top workers regarded leadership merely as a skill, instead of a strength, that one should have. Indeed, leadership can be seen as an innate characteristic - or strength - that can be cultivated and that can flourish along with one's development (see, for example, Murphy and Johnson 2011). On the other hand, leadership can also be considered as a profession that can be taught and learned for the benefit of oneself and others (see, for example, Uusiautti 2013; Uusiautti et al. 2012).

One of the top workers recognised the shortcomings in her leadership skills whereas another considered it as one of his most important strengths.

'I want to be in the lead and take the group forward... Yet, I am not a dictator... but I consider myself as a leader and a trend-setter in order to make good for other people as well.'

Teamwork skills varied among top workers according to their assessments. Those who evaluated their social intelligence as good assessed their teamwork skills similarly, whereas two of the top workers who held managerial positions saw some deficiencies in their teamwork skills; one of them wanted to improve his skills.

\section{Temperance}

This virtue was not deemed very important, but downright distant, because of its connection with modesty and prudence. The top workers found it somewhat difficult to assess how this virtue and its associated strengths (forgiveness, modesty, prudence and self-regulation) would characterise them. However, after persistently defining them together during the interviews, the workers began to have an idea of which strength typified them and which did not.

Not surprisingly, the ability to forgive did depict all top workers to some extent. They also emphasised that one has to be able to apologise as well. According to the top workers, their forgiveness was tested by the social conflicts in the workplace.

'I am able to forgive and apologize... but it is hard if you are accused of something that you have not done.'

Modesty as a strength was considered paradoxical; on one hand, modesty is a desirable trait, but one has to be able to be genuinely proud of one's achievements without unnecessary or excessive modesty. Indeed, a study by Shimai et al. (2006) also showed that modesty had a strong negative correlation with happiness among both Americans and Japanese, which means that having modesty as a signature strength was associated with less happiness. The contradictory nature of this concept was also discussed in our studies. Although, traditionally, modesty 
in people has been appreciated, the top workers were critical. For example, some old proverbs were questioned:

"“Modesty makes you prettier" is not necessarily good for success at work but "you would foster your own achievements" would be.'

However, feeling proud assumes that one cannot be proud of something to which one has not contributed oneself (see also Varila and Ikonen-Varila 2002). Two of the top workers associated modesty with humbleness.

'I would like to be humble but do I want to be... "the one who reaches high ends up low" - this proverb has stumped us.'

In work life, unwritten emotional rules determine what emotions are approved and how, to whom, and in which situation one is allowed to express them, and how emotions are interpreted.

Half of the participants saw prudence as one of their strengths, and they explained it as their special skill in deliberating their actions and making justified decisions at work. Therefore, prudence merely resembled a professional skill or a work-related strength rather than a personal attribute, unlike self-regulation, which was seen as a strictly personal characteristic and as an aspect of temperament. Half of the top workers assessed that their self-regulation could be better.

'Still, there are many dimensions that could be smoothened... my nature can be stretched to many directions.'

\section{Transcendence}

Transcendence as a virtue was also considered paradoxical because they did not agree with all the strengths (appreciation of beauty and excellence, gratitude, hope, humour, religiousness) included in this virtue. For example, it was difficult to imagine religiousness as a strength - except for the Priest of the Year. However, the top workers did spend a significant amount of time contemplating how appreciation of beauty and excellence was manifested in working life. They explained this virtue as the ability to recognise good performances and achievements instead of using one's energy on envying. This had to do with their positive attitude and ability to understand achievements earned (Pajares 2001).

Gratitude is an important human strength that contributes to subjective happiness (McCullough et al. 2002; see also Otake et al. 2006). Gratitude was considered as gratefulness for being able to have rewarding and pleasing work.

'This lies deep in our culture; you cannot say when another does something good. We haven't had such a working culture either. I want to give feedback if I see that someone is seriously doing something really great.' 
One of the top workers saw hope as one of her most important strengths. Hope was seen as the foundation of an optimistic attitude.

'So that you believe that you'll cope with this although there are difficulties; that you'll just try again or some other route.'

Indeed, hope and optimism are neighbouring concepts, but Finnish people (Ojanen 2002), for example, are traditionally seen as optimistic rather than hopeful. Ojanen (2002) defines hope as realistic optimism which has trust at the center.

The top workers appreciated humour although some of them did not consider themselves very humorous. The ability to look at things from a distance and see humour in them was, however, considered important as humour helped to process problematic issues and handle tough situations. For example, the Police of the Year emphasised the meaning of humour in police work as a connective factor among police officers and when there is a need to confront the most difficult situations at work. The Priest of the Year saw similarities in humour and religion:

'They are at least cousins, if not downright siblings; both create hope in people.'

In addition, humorous people understand things widely and do not remain stuck on details; in his opinion, religion has the same dimension.

\section{Other virtues and strengths}

The top workers also named some other strengths that were not included in the CVS Model. Five of them highlighted the significance of their own personality; they allowed their strong personalities to surface in their work. Many of them associated this with authenticity or being themselves. This was important for Nurse of the Year, Priest of the Year and Police of the Year. But those who worked as supervisors also emphasised the significance of acting in a genuine way and bringing out one's personality. In this way, followers' trust can be achieved.

Another important characteristic that most of the top workers mentioned was diligence and dedication. They thought that success at work could be achieved through industriousness. This was also a trait that was mentioned when they were asked to identify one trait that they would like other workers in their work community to possess.

Half of the top workers emphasised their positivity and joviality. Positivity appeared as an optimistic attitude towards working. In addition, it was seen as providing resources to the entire work community. Indeed, optimism is one of the most salient concepts in positive psychology. It can be defined as a steady attitude and view of life and the future (Pajares 2001). 


\section{On the connection between virtues and strengths and success and wellbeing at work}

Arnold et al. (1993) state that awareness of one's strengths and weaknesses as well as values and interests is of primary importance for enhancing one's career. Optimism has a clear connection with success because, among other things, it involves the ability to set reasonable goals, to achieve these goals, and to use efficient learning strategies. According to Carver and Scheier (2002), optimistic people achieve their goals because they organise their actions in an intellectual way in order to achieve these goals. Furthermore, the top workers appeared to have proactive (Covey 2006), as opposed to reactive, attitudes. A proactive attitude embodies a way of thinking according to which people are able to change their behaviour, look at things from various perspectives, make choices by themselves, and know what they want. Proactive people concentrate on things that they can affect and thus, their action is positive and more efficient by nature.

This kind of attitude can also be dissected with the use of the concept of resilience. Being able to move on, despite hardships, demonstrates the resilience of those successful individuals. Therefore, psychological resilience refers to effective coping and adaptation when faced with loss, hardship or adversity - a common feature among the top workers.

The strengths that the top workers recognised most in themselves - openmindedness, social intelligence, persistence, optimism and authenticity - all relate to positive behaviour. If these features explain success at work, at least partly, wellbeing and happiness are most certainly not irrelevant to the workplace.

\section{Experiencing success alone and together}

Thus far, we have talked about the process of success or the phenomenon of success. We have referred to the idea of success as a (developing) state. However, the phenomenon of success at work also includes various experiences of success. Success is related to work and life in general and can be seen as a positive outcome of working.

What is an experience of success and what kinds of successes do top workers recognise in their work? This question was also posed to the top workers. They were eventually able to describe their experiences of successful situations or events at work in numerous ways. However, some categorisations could be made. The most fundamental categorisation concerned whether the experience of success was achieved alone or in a group. These are thus divided into personal experiences and communal, teamwork-based experiences. These two categories include various elements that illustrate the origin or nature of the experience of success.

Here again, the model of human strengths and virtues was applied for analytical purposes as it appeared that the two main categories could also be illustrated on the basis of personal strengths that are connected to the experience of success. 
In addition to individual strengths that can partly explain the origin of experiences of success, and that also appear on Seligman's list, teamwork-based experiences of success also seemed to necessitate human strengths that are social by nature. The categories somewhat overlap, but their purpose is to highlight the connection between individual strengths and experiences of success both at the individual and communal levels.

\section{Personal experiences of success}

\section{Persistence, bravery and hope: experiencing (concrete) accomplishments}

The list provided by Seligman et al. (2005) includes strengths that can be seen as relevant to accomplishing work-related tasks. Specifically, persistence as the ability to finish what one starts; bravery as not shrinking from threat, challenge, difficulty or pain; and hope as expecting the best and working to achieve it, appeared in the participants' descriptions. Firstly, the experience of success results from quite concrete accomplishments at work. On one hand, the top workers described their experiences of success as hands-on experiences such as, for example, performing well in some concrete task (for example, compiling a manual for guidance at work). On the other hand, these experiences could result from achieving a more high-level goal, sometimes through practical action. Furthermore, concrete successes may be born when some larger entity at work is directed in the right way. These kinds of experiences were described in the interviews as follows:

'So it is an orientation file. We began to compile this kind of bible.... The operation of our workplace is described in a very comprehensive manner, and all the practices are printed in it. Our boss always remembers to mention it. I think that our employees appreciate it as well. I think it is something that has been very useful.'

'I have thrown myself in new tasks. Supervisors have asked about my willingness, and I guess that they have seen in all their wisdom that I am able and capable of taking on new tasks. There [in the participant's work unit], it went like that, and I think it was something like one year since I had started as the section leader when my boss asked whether I was willing to change over to the duty officer's task. My boss thought that I would be good at that, so I took the duty officer's post... And I can tell that I had an excellent group at that time; it was this so-called car offence group. Many really good fellows worked in it and we really produced great results; the best of Finland at that time.'

'We created a new training program for occupational health psychologists...so that's my thing, you know... This task came to me at the end of the 1990s, and the head of department assigned me for it. And I have managed to create a team of it.' 
Moreover, the experience of success could result from such occasions in which employees were able to control or solve a situation at work. Therefore, accomplishment could be concrete but not always material in nature:

'There are phases when everyone flounder. So, I might have given a speech or address that solved that situation... When you hurl yourself into the situation and manage to reach the goal.'

'I have had the experience of "oh how good was it that I intervened the situation and was able to handle it".'

One way of achieving the experience of success is to work systematically and persistently. Therefore, daily practices and actions are not always that peculiar but the result may be:

'Then there are sort of exceptional crimes that I was allowed to help [solve]... I headed it here in the district. We quizzed people; and every time we had a small hint, we would start off, even at nights. And that is something immemorial and so exceptional that we could solve things like that.'

\section{Zest and love of learning: experiencing success through the joy of work and flow}

Seligman et al. (2005) define zest as the ability to approach life with excitement and energy, and love of learning as a desire to master new skills, topics and bodies of knowledge. These strengths surfaced in the top workers' interviews in the form of various positive emotional states toward their work. In this research, the top workers showed high levels of joy of work (Varila and Lehtosaari 2001) and flow (Csikszentmihalyi 2008) that resulted from putting their soul into work or learning new skills. When viewed from this perspective, the experience of success can also entail these positive feelings. The top workers described their moments of joy and flow in the following way:

'I am riveted by it and it is a blessing that you can be so wrapped up in your work so much.'

'Maybe the best feedback is those numbers and successes; in other words, we have good results to show the things that I want.'

\section{Curiosity and open-mindedness: experiencing success and expertise through challenges and new opportunities at work}

Top workers also emphasised the significance of challenges and new development opportunities in their work. Of the strengths categorised in the list by Seligman et al. (2005), this attitude especially resembled curiosity as workers 
were open-minded, were actively interested in ongoing experience, thought things through, and examined them from all angles. The experience of success could often result from a situation in which the outcome was not always clearly known beforehand or if worker had to learn or study something new. These events were described as follows:

'I always take up the gauntlet although a bit clueless... Huge challenges [I have accepted]. And then if you can contribute in a developing manner...'

'Then I considered criminal investigation challenging since I had worked [as a patrol officer] for two and half years, and I didn't know anything about criminal investigation. And I had so many questions on how I should handle this... So I thought I should put myself in criminal investigation for a couple of years so that I could learn it. And then I went, and I did not regret it. Of course, after a few months, I found working there quite awkward, but then it started to run smoothly.'

The experience of success is certainly closely connected to the experience of expertise. Top workers were extremely willing to educate themselves and gather knowledge either from various areas of their occupation or gain increasingly profound knowledge in their special field. The experience of success may thus consist of the self-efficacy and perceived feelings of capability and competence (see also Bandura 1997; Carver and Scheier 2005; Judge et al. 1997; Paloste et al. 2011):

'But then... as I qualified as a leader and had that training, it gave me such sources in a positive way, that I thought that someday I could go after that kind of position.'

'Oh yeah, I have taken all sorts of them [training sessions]. Of course, quite quickly, I reached the level that no one could teach me anymore.'

'And then, I have been developing quality work and pursued an auditing qualification, and then I was able to evaluate other units with my co-worker.'

At its best, work provides employees with opportunities to develop, find meaning in life and achieve social, emotional and mental wellbeing. Therefore, more attention should be paid on increasing employees' possibilities in workplaces (Snyder and Lopez 2002) since the opportunities to achieve experiences of success could also increase.

\section{Communal, teamwork-based experiences of success}

Seligman et al. (2005) allude to strengths that appeared especially important among top workers when they discussed teamwork-based experiences. They defined teamwork as working well as a member of a group or team; social intelligence as being aware of the motives and feelings of self and others; fairness as 
treating all people the same according to notions of fairness and justice; and kindness as doing favours and good deeds for others. Although the experience of success is a personal positive emotion, it may spring up after or while of working together with co-workers, clients or other people who are closely connected to the task at hand. When everyone in a team is excited and inspired by the task, developing successful outcomes may produce the most delightful experience of success (see also Losada and Heaphy 2004), as described in the following utterances:

'It is most fruitful when we all are excited about developing things.'

'What is most important is that you see together that something works, that the orchestra works and plays, and that everyone even plays the same melody.'

Furthermore, it is easier to carry out difficult work tasks when you are supported by colleagues and share ideas with them. According to the participants, when you have a good network or work community, you can succeed better than before. Naturally, however, one has to be willing to share and work for the team:

'It is a problem when you have to do it [make decisions] alone. When you think of whether you are blind to something or whether you have forgotten something crucial; it is a little bit harassing, but on the other hand, you'll find help from your network. I mean you can ask your colleagues.'

'Quite a few people come to talk to me about things and have the courage to say if there is something wrong or what they cannot take up in the negotiations by themselves. Many times I have been the channel through which the issues are discussed and thought over and their anxieties are released... It's one of those experiences.'

'But then I was called for this locum post, and it was something that I felt that I could work with real professionals, and somehow I worked well and felt supported and was in a really good team. The work was a regular nineto-five job, and it was a success even though I was a mother of a small child.'

The notion of the communal nature of the experience of success also highlights the fact that supportive and positive atmosphere at the workplace may be an important contributor to the experiences of success. Boreham (2004) uses the concept of collective competence to refer to making collective sense of events in the workplace, developing and using a collective knowledge base, and developing a sense of interdependency. Indeed, a common feature of the new ways of organising work is their emphasis on teamwork. Thus, the top workers' perceptions of teamwork and the support received from co-workers are essential from this point of view. It is important to notice that the experience of success can also be communal by nature. However, it requires strengths of a social character (see Seligman et al. 2005). 


\section{Experiencing work}

The experience of success is only one way of dissecting positive experiences at work. However, the top workers' experiences are also interesting because of their connection to overall success at work. In this research, the experiences of success were categorised in a data-driven manner, being aware that there are other ways of categorising these experiences. For example, Lutgen-Sandvik et al. (2011) used a more detailed categorisation structure when they studied American workers' experiences of success. However, some similar categories could be found in these two studies; for example, appreciation, challenge, success, opportunity, relationships, social support and teamwork, climate, supervisor/mentor, resources and triumphs were apparent in the participants' descriptions in both studies.

Based on the results, we constructed a model to illustrate the connection between individual and communal factors to the possibility of experiencing success at work (see Figure 3.2). Figure 3.2 includes the dimensions of both individual/communal and positive/negative. Next, we will introduce the four starting points for the experience of success at work in greater detail:

1 Firstly, there is the state in which both negative individual and communal factors are present. The employee is belittled not only by himself or herself but also by the work community. This situation is not likely to further the development of positive emotions at work - neither at the individual nor at the communal level. Instead, it can be considered as hindering the emergence of successes or other positive feelings.

2 Secondly, there is the possibility that the work community acts as a positive factor but the individual employee may still have low-esteem. Success as well as feelings of joy are difficult to achieve on the personal level as people usually tend to feel genuinely happy about achievement if they feel entitled to it (see, for example, Deci and Moller 2005).

3 The third part of the illustration describes a situation whereby the work community acts as a negative factor, but the individual has a positive perception. Therefore, the individual employee may have strong self-esteem, regardless of the work community's disregard - although the employee's self-regard in this situation may be low (Baumeister 1993; see also Baumeister et al. 1996).

4 The fourth section presents the so-called ideal situation whereby both the individual and communal factors are positive. This kind of starting point might be the core factor for the emergence of positively-toned experiences such as flow (see Csikszentmihalyi 2008) and joy of work (Varila and Lehtosaari 2001). Likewise, experiences of success, both alone and as a team, become more likely than in the other above-mentioned situations as it can, for its part, lead to maximal performances (see Avey et al. 2010; Kanfer and Ackerman 2005). Furthermore, for example, intelligent thought and social inclusion have also been seen to have a positive, direct relationship (Baumeister et al. 2002). Our idea is that this kind of combination of positive individual and communal factors will also lead to wellbeing at work. 


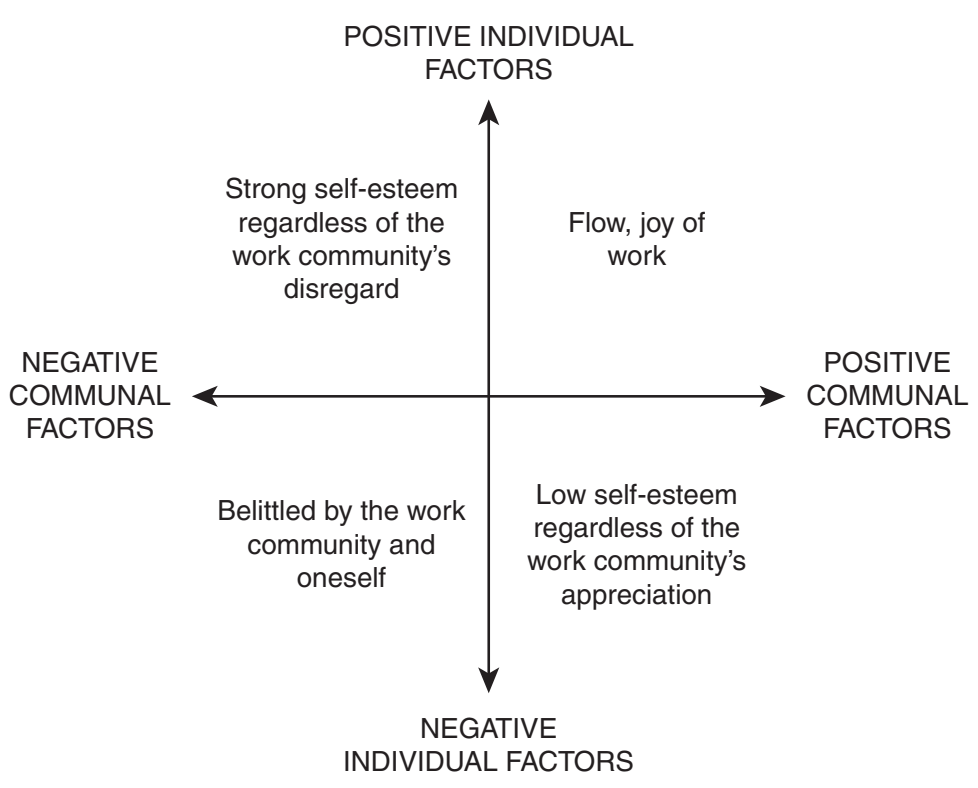

Figure 3.2 The connection of individual and communal factors with the perceived success at work (Uusiautti and Määttä, 20I3).

Employees of the Year found their jobs pleasing. Furthermore, finding a balance between an employee's skills and work-related expectations as well as opportunities and challenges leads to better performance at work, contentment, higher motivation and self-efficacy (Mäkikangas et al. 2005). As Myers and Diener (1995: 11) point out, 'Positive wellbeing is not just the absence of negative emotions'. Thus, no one has only positive experiences or experiences of success - one would not even know what these experiences are if one had not experienced the opposite. Employees of the year considered difficulties as challenges and moments for stocktaking. This behaviour resembles realistic optimism (see also Chapter 2). Schneider (2001) illustrates this way of thinking felicitously. According to her definition of realistic optimism and its beneficial consequences, the term 'problem' (with synonyms such as predicament, obstacle and difficulty) implies that the current state is negative and that actions must be successful to establish a satisfactory state. When this problem is seen as a challenge, the current state is considered acceptable, offering a potential opportunity for bringing about a beneficial change. Indeed, this framing can be quite powerful and explain the fundamental attitudes enhancing the process of success. Thus, they were able to eventually turn these situations into experiences of success - although it did not necessarily happen in an instant (see also Mitchell et al. 2004).

Bravery was not the only strength among the participants. Employees of the Year could tackle obstacles and strive forward in their careers and other workrelated ambitions. In addition, participants were passionate about working 
consummately. Indeed, it has been discovered that high work engagement magnifies emotional responses concerning perceived success or failure (Britt 1999). The positive attitude that Employees of the Year had toward work and life in general was the common factor among them. Their experiences of success can be seen as a salient factor in the perceived happiness at work. Of course, other features of work - professional proficiency, life situation, work motivation and personality - are also important for the positive experience. However, all factors affect each other to a certain extent. All special features together form the basis and prerequisites for success and wellbeing at work. In order to gain positive experiences from one's work, an employee has to be (intrinsically) motivated to do this particular work and to accomplish the tasks and goals that are set. Brown and Ryan (2003) suggest that mindfulness may also directly contribute to wellbeing and happiness. They define mindfulness as a pre-reflective state, which includes both self-focused attention and, for instance, experience. Furthermore, happy people are seen to possess adequate resources for making progress toward valued goals (Diener et al. 1999). This is interesting especially from the point of view of performing well and experiencing success at work because people who have a high perception of their self-efficacy tend to devote more to their work and are more persistent workers than those who make lower assessments of their abilities (cf. the second part of the model in Figure 3.2) (see Bandura 1997; Mitchell 1997).

The above-mentioned matters are important but, on their own, they are not enough. The results encouraged us to also consider success from the perspective of a work community. Therefore, the results of our study suggest that success is not only matter of a single employee; participants also highlighted the importance of a good working atmosphere and a supportive and healthy work community.

Quick (1999: 123) maintains that 'healthy work exists where people feel good, achieve high performance, and have high levels of wellbeing' - in other words, where people are happy. Could it be, then, that success could be enhanced by creating happy and functional work communities? It seems that feeling positive emotions toward work produces not only a quantitative improvement by increasing efficiency but also a qualitative one by making a better product or outcome that results from the virtue of pride, belief and commitment to one's job (Wright, 2004). Indeed, Arnold et al. (2007: 201) point out that 'it is possible that humanistic work values (the normative beliefs individuals hold about whether work should be meaningful) are an important influence on the likelihood of finding meaning in current work and psychological wellbeing.

\section{References}

Achor, S. (2010) The Happiness Advantage. The Seven Principles of Positive Psychology that Fuel Success and Performance at Work. New York, NY: Crown Business

Aitta, U. (2006) 'Ylemmät toimihenkilönaiset työ- ja aikapaineiden ristiaallokossa [Female managers in the riptide of work and time pressures]' pp. 17-35 in Lehto, A.-M., Sutela, H. 
and Miettinen, A. (Eds.) Kaikilla mausteilla. Artikkeleita työolotutkimuksesta [With All Spices. Articles Research at Working Conditions]. Helsinki: Statistics Finland

Anderson, N., De Dreu, C. K. W. and Nijstad, B. A. (2004) 'The routinization of innovation research: a constructively critical review of the state-of-the-science'. Journal of Organisational Behaviour, 25, pp. 147-173

Argyle, M. (1987) Psychology of Happiness. New York, NY: Routledge

Arnold, J., Robertson, I. T. and Cooper, C. L. (1993) Work Psychology. Understanding Human Behaviour in the Workplace. London: Pitman Publishing

Arnold, K. A., Turner, N., Barling, J., Kelloway, E. K. and McKee, M. C. (2007) 'Transformational leadership and psychological well-being: The mediating role of meaningful work'. Journal of Occupational Health Psychology, 12(3), pp. 193-203

Avey, J. B., Luthans, F., Smith, R. M. and Palmer, N. F. (2010) 'Impact of positive psychological capital on employee wellbeing over time'. Journal of Occupational Health Psychology, 15, pp. 17-28

Bakker, A. and Demerouti, E. (2007). 'The job demands-resources model: state of the art'. Journal of Managerial Psychology, 22, pp. 309-328

Baltes, P. B. and Freund, A. M. (2006) 'Ihmisen vahvuudet ja viisaus [The human strengths and wisdom]' pp. 34-46 in Aspinwall, L. G. and Staudinger, U. M. (Eds.) Ihmisen vahvuuksien psykologia [A Psychology of Human Strengths]. Helsinki: Edita

Bandura, A. (1997) Self-efficacy: The Exercise of Control. New York, NY: Freeman

Basadur, M. and Hausdorf, P. (1996) 'Measuring divergent thinking attitudes related to creative problem solving and innovation management'. Creativity Research Journal, 1(9), pp. 21-32

Baumeister, R. F. (1993) Self-esteem: The Puzzle of Low Self-regard. New York, NY: Plenum

Baumeister, R. F., Smart, L. and Boden, J. M. (1996) 'Relation of threatened egotism to violence and aggression: the dark side of high self-esteem'. Psychological Review, 103(1), pp. 5-33

Baumeister, R. F., Twenge, J. M. and Nuss, C. K. (2002) 'Effects of social exclusion on cognitive processes: anticipated aloneness reduces intelligent thought'. Journal of Personality and Social Psychology, 83(4), pp. 817-827

Binnewies, C., Sonnentag, S. and Mojza, E. J. (2009) 'Feeling recovered and thinking about the good sides of one's work'. Journal of Occupational Health Psychology, 14, pp. 243-256

Boreham, N. (2004) 'The theory of collective competence: challenging the neo-liberal individualization of performance at work'. British Journal of Educational Studies, 52(1), pp. 5-17

Britt, T. W. (1999) 'Engaging the self in the field: testing the triangle model of responsibility'. Personality and Social Psychology Bulletin, 25, pp. 698-708

Brown, K. W. and Ryan, R. M (2003) 'The benefits of being present: Mindfulness and its role in psychological well-being'. Journal of Personality and Social Psychology, 84(4), pp. 822-848. DOI:10.1037/0022-3514.84.4.822.

Carson, S. H., Peterson, J. B. and Higgins, D. M. (2005) 'Reliability, validity, and factor structure of the creative achievement questionnaire'. Creativity Research Journal, $17(1)$, pp. $37-50$

Carver, C. S. and Scheier, M. F. (2002) 'Optimism' pp. 231-243 in Snyder, C. R. and Lopez, S. J. (Eds.) Handbook of Positive Psychology. Oxford: Oxford University Press

Carver, C. S. and Scheier, M. F. (2005) 'Engagement, disengagement, coping, and catastrophe' pp. 527-547 in Elliot, A. J. and Dweck, C. S. (Eds.) Handbook of Competence and Motivation. New York and London: The Guilford Press 
Cohen, G. L., Aronson, J. and Steele, C. M. (2000) 'When beliefs yield to evidence: reducing biased evaluation by affirming the self'. Personality and Social Psychology Bulletin, 26(9), pp. 1151-1164

Correll, J., Spencer, S. J. and Zanna, M. P. (2004) 'An affirmed self and an open mind: self-affirmation and sensitivity to argument strength'. Journal of Experimental Social Psychology, 40(3), pp. 350-356

Covey, S. R. (2006) Tie menestykseen. 7 toimintatapaa henkilökohtaiseen kasvuun ja muutokseen [Road to Success. 7 Methods of Personal Growth and Change] (5th Ed.). Jyväskylä: Gummerus

Csikszentmihalyi, M. (1990) Flow: The Psychology of Optimal Experience. New York, NY: Harper and Row

Csikszentmihalyi, M. (2000) Beyond Boredom and Anxiety: Experiencing Flow in Work and Play. San Francisco, CA: Jossey-Bass Publishers

Csikszentmihalyi, M. (2008) Flow. The Psychology of Optimal Experience (10th Ed.). New York, NY: HarperPerennial

Deci, E. L. and Moller, A. C. (2005) 'The concept of competence. A starting place for understanding intrinsic motivation and self-determined extrinsic motivation' pp. 579597 in Elliot, A. J. and Dweck, C. S. (Eds.) Handbook of Competence and Motivation. New York and London: The Guilford Press

Diener, E., Suh, E. M., Lucas, R. E. and Smith, H. L. (1999) 'Subjective well-being: three decades of progress'. Psychological Bulletin, 125(2), pp. 276-302

Eysenck, H. (1993) Creativity and Personality. Suggestions for a Theory. Psychological Inquiry, 3(4), pp. 147-178

Judge, T. A., Locke, E. A. and Durham, C. C. (1997) 'The dispositional causes of job satisfaction'. Research in Organisational Behaviour, 19, 151-188

Kanfer, R. and Ackerman, P. L. (2005) 'Work competence: a person-oriented perspective' pp. 336-353 in Elliot, A. J. and Dweck, C. S. (Eds.) Handbook of Competence and Motivation. New York and London: The Guilford Press

Kinnunen, U., Feldt, T. and Mäkikangas, A. (2008) 'Testing the effort-reward imbalance model among Finnish managers: the role of perceived organisational support'. Journal of Occupational Health Psychology, 13, pp. 114-127

Lent, R. W., Brown, S. D. and Larkin, K. C. (1984) 'Relation of self-efficacy expectations to academic achievement and persistence'. Journal of Counseling Psychology, 31(3), pp. 356-362

Losada, M. and Heaphy, E. (2004) 'The role of positivity and connectivity in the performance of business teams: a nonlinear dynamics model'. The American Behavioral Scientist, 47(6), pp. 740-765

Lutgen-Sandvik, P., Riforgiate, S. E. and Flecther, C. V. (2011) 'Work as a source of positive emotional experiences and the discourses informing positive assessment'. Western Journal of Communication, 75(1), forthcoming

Magnusson, D. and Mahoney, J. L. (2006) 'Holistinen lähestymistapa myönteisen kehityksen tutkimuksessa [Holistic approach in research of positive development]' pp. 232-250 in Aspinwall, L. G. and Staudinger, U. M. (Eds.) Ihmisen vahvuuksien psykologia [A Psychology of Human Strengths]. Helsinki: Edita

Mahoney, M. J. (2002) 'Constructivism and positive psychology’ pp. 745-750 in Snyder, C. R. and Lopez, S. J. (Eds.) Handbook of Positive Psychology. Oxford: University Press

Maslow, A. (1988) 'Creativity in self-actualizing people' pp. 86-92 in Rothenberg, A. and Hausman, C. (Eds.) The Creativity Question. New York, NY: Kingsport Press 
McCullough, M. E., Emmons, R. A. and Tsang, J. (2002) 'The grateful disposition: a conceptual and empirical topography'. Journal of Personality and Social Psychology, 82, pp. 112-127

Miettinen, A. (2006) 'Työhönsä erittäin tyytyväiset [Employees that are very satisfied with their work]' pp. 275-290 in Lehto, A.-M., Sutela, H. and Miettinen, A. (Eds.) Kaikilla mausteilla. Artikkeleita työolotutkimuksesta [With All Spices. Articles Research at Working Conditions]. Helsinki: Statistics Finland

Mitchell, T. R. (1997) 'Matching motivational strategies with organizational contexts'. Research in Organizational Behavior, 19, pp. 57-149

Mitchell, R. K., Mitchell, J. R. and Smith, J. B. (2004) 'Failing to succeed: new venture failure as a moderator of startup experience and startup expertise' in Zahra, S. (Ed.) Frontiers of Entrepreneurship Research. Babson Park, MA: Babson College. Available online at: www.ronaldmitchell.org/publications/failing\%20to\%20succeed.pdf (last accessed 21 March 2014)

Mitchell, R. and Nicholas, S. (2006) 'Knowledge creation in groups: the value of cognitive diversity, transactive memory, and open-mindedness norms'. The Electronic Journal of Knowledge Management, 4(1), pp. 67-74

Murphy, S. E. and Johnson, S. K. (2011) 'The benefits of a long-lens approach to leader development: Understanding the seeds of leadership'. The Leadership Quarterly, 22(3), pp. $459-470$

Myers, D. G. and Diener, E. (1995) 'Who is happy?' Psychological Science, 6(1), pp. $10-19$

Mäkikangas, A., Feldt, T. and Kinnunen, U. (2005) 'Positiivisen psykologian näkökulma työhön ja työhyvinvointiin [Perspective of positive psychology on work and wellbeing at work]' pp. 56-74 in Kinnunen, U., Feldt, T. and Mauno, S. (Eds.) Työ leipälajina: Työhyvinvoinnin psykologiset perusteet [Work as Profession. The Psychological Basis of Wellbeing at Work]. Keuruu: Otava

Nijstad, B. A. and Levine, J. M. (2007) 'Group creativity and the stages of creative problem solving' pp. 159-172 in Hewstone, M. et al. (Eds.) The Scope of Social Psychology: Theory and Applications. New York, NY: Psychology Press

Ojanen, M. (2002) Elämän mieli ja merkitys [The Sense and Meaning of Life]. Helsinki: Kirjapaja

Otake, K., Shimai, S., Tanaka-Matsumi, J., Otsui, K. and Fredricsson, B. L. (2006) 'Happy people become happier through kindness: a counting kindnesses intervention'. Journal of Happiness Studies, 7(3), pp. 361-375

Pajares, F. (2001) 'Toward a positive psychology of academic motivation'. The Journal of Educational Research, 95(1), pp. 27-35

Paloste, A., Uusiautti, S. and Määttä, K. (2011) 'Through education and work experience toward professional competence - a phenomenographic study on some Finnish nurses' and midwives' perceptions'. Journal of Studies in Education, 1(1), pp. 1-21

Peterson, C. and Park, N. (2004) 'Classification and measurement of character strengths: Implications for practice’ pp. 433-446 in Linley, P. A. and Joseph, S. (Eds.) Positive Psychology in Practice. Hoboken, NJ: John Wiley and Sons

Putman, D. (1997) 'Psychological courage'. Philosophy, Psychiatry, and Psychology, 4(1), pp. 1-11

Quick, J. C. (1999) 'Occupational Health Psychology: The convergence of health and clinical psychology with public health and preventive medicine in an organizational context'. Professional Psychology: Research and Practice, 30, pp. 123-128 
Rousseau, V., Salek, S., Aubé, C. and Morin, E. M. (2009) 'Distributive justice, procedural justice, and psychological distress: the moderating effect of coworker support and work autonomy'. Journal of Occupational Health Psychology, 14, pp. 305-317

Runco, M. (1993) 'Divergent thinking, creativity, and giftedness'. Gifted Child Quarterly, 1(37), pp. 16-22

Ruohotie, P. and Honka, J. (2003) Ammatillinen huippuosaaminen. Kompetenssitutkimusten avaama näkökulma huippuosaamiseen, sen kehittämiseen ja johtamiseen [Professional Top-expertise. Perspectives of Competence Research on Top-expertise, Developing, and Supervising It]. Hämeenlinna: Hämeenlinna University of Applied Sciences

Salovey, P., Caruso, D. and Mayer, J. D. (2004) 'Emotional intelligence in practice' pp. 447-463 in Linley, P. A. and Joseph, S. (Eds.) Positive Psychology in Practice. Hoboken, NJ: John Wiley and Sons

Schneider, S. L. (2001) In search of realistic optimism. Meaning, knowledge, and warm fuzziness'. American Psychologist, 56(3), pp. 250-263

Seligman, M. E. P. (2002) Authentic Happiness. New York, NY: Free Press

Seligman, M. E. P. and Csikszentmihalyi, M. (2000) 'Positive psychology: An introduction'. American Psychologist, Special Issue on Positive Psychology. Available online at: http://www.ppc.sas.upenn.edu/apintro.htm (last accessed 21 March 2014)

Seligman, M. E. P., Steen, T. A., Park, N. and Peterson, C. (2005) 'Positive psychology progress. Empirical validation of interventions'. American Psychologist, 60(5), pp. $410-421$

Shimai, S., Otake, K., Park, N., Peterson, C. and Seligman, M. E. P. (2006) 'Convergence of character strengths in American and Japanese young adults'. Journal of Happiness Studies, 7, pp. 311-322

Simonton, D. K. (2009) 'Creativity' pp. 261-270 in Lopez, S. J. and Snyder, C. R. (Eds.) Oxford Handbook of Positive Psychology. Oxford: Oxford University Press

Snyder, C. R. (1994) The Psychology of Hope: You Can Get There from Here. New York, NY: The Free Press

Snyder, C. R. and Lopez, S. J. (2002) 'The future of positive psychology. A declaration of independence' pp. 751-767 in Snyder, C. R. and Lopez, S. J. (Eds.) Handbook of Positive Psychology. Oxford: Oxford University Press

Sternberg, R. J. and Lubart, T. I. (1999) 'The concept of creativity' pp. 3-15 in Sternberg, R. J. (Ed.) Handbook of Creativity. New York, NY: Cambridge University Press

Tugade, M. M. and Fredrickson, B. L. (2004). 'Resilient individuals use positive emotions to bounce back from negative emotional experiences'. Journal of Personality and Social Psychology, 86(2), pp. 320-333

Uusiautti, S. (2013) 'An action-oriented perspective on caring leadership: a qualitative study of higher education administrators' positive leadership experiences'. International Journal of Leadership in Education: Theory and Practice Available online at: doi: 10.1080/13603124.2013.770077 (last accessed 6 March 2013)

Uusiautti, S. and Määttä, K. (2013) 'Does success at work produce wellbeing and happiness or vice versa?' The International Journal of Interdisciplinary Organizational Studies, 7(3), pp. 11-25

Uusiautti, S., Syväjärvi, A., Stenvall, J., Perttula, J. and Määttä, K. (2012) “ “It’s more like a growth process than a bunch of answers". University leaders describe themselves as leaders'. Procedia - Social and Behavioral Sciences, 69, pp. 828-837

Varila, J. and Ikonen-Varila, M. (2002) Ylpeys ja ammattiylpeys tutkimuksen kohteeksi. Ylpeyden tunteen teoreettinen ja empiirinen tarkastelu [Pride and Professional Pride as 
Research Themes. Theoretical and Empirical Review on the Feeling of Pride]. Joensuu: University of Joensuu

Varila, J. and Lehtosaari, K. (2001) Työnilo - Ahkeruudella ansaittua, sattuman synnyttämää vai oppivan organisaation vaatimaa? [Joy of Work - Earned by Diligence, Caused by an Accident or Required by a Learning Organisation?]. Joensuu: University of Joensuu

Wright, T. A. (2004) 'The role of "happiness" in organizational research: past, present and future directions' pp.221-264 in Perrewe, P. L. and Ganster, D. C. (Eds) Exploring Interpersonal Dynamics. (Research in Occupational Stress and Well-being, Vol. 4). Oxford, UK: Elsevier 


\section{Success begins in childhood}

\section{Introduction}

Is success at work based on childhood and adolescent experiences? What is the influence of parents' expectations on one's career? The influence of childhood and adolescent experiences in relation to adult work success has not been widely studied. As such, we wanted to begin the process of drawing back the curtain on this theme through top workers' biographies.

We were interested in exploring those factors that Employees of the Year recognised from their lives, especially from childhood and adolescence, as having enhanced their success. This is important if our aim is help people with their opportunities to find a suitable occupation in which they can use their talents. Experiences and events taking place in childhood and adolescence can be crucial or can at least point people in the right direction.

The first part of the chapter focuses on the top workers' childhood memories and the factors they recall as having influenced their careers. The second part of the chapter then continues the analysis from the point of view of caring teacherhood. Findings from our leadership studies are also included in this chapter to show how caring leadership in education can be used for promoting students' successful study paths. This contributes yet another viewpoint to factors promoting success during children's and adolescents' school careers.

\section{Success starts from childhood?}

Magnusson and Mahoney (2006) have argued that positive development cannot be defined with reference to an individual person and that the person's characteristics, resources and limits, as well as the cultural, physical and historical context in which the person lives, also matter. As such, positive development is a holistic process. This means that developmental processes form an entity that affects all levels of the person-environment system. At the same time, all the elements within developmental processes interact. An individual's positive development depends on how well the inner and outer functions of the organism are synchronised. Inner processes are, for example, mental, biological and behavioural 
functions while outer processes cover opportunities, demands and rules provided by one's environment. Therefore, the developmental process also varies between society and culture (Magnusson and Mahoney 2006).

Numerous studies have focused on positive development, and they have often taken a specific stand or approach to the theme. There are singular studies researching various factors and relationships; for example, studies have found a positive relationship between adolescents' perceived autonomy and self-esteem together with a positive relationship with parents. Likewise, parents' socioeconomic status influences not only children's wellbeing but also intellectual attainment, such as education (for example, Bradley and Corwyn 2002). Furthermore, socioeconomic factors are shown to be indirectly related to children's academic achievement through parents' beliefs and behaviours (Davis-Kean 2005). Similar findings have been reported, for example, regarding parents' role in enhancing their children's acquisition of positive values, attitudes and behaviours towards sport hobbies (Côté 1999). However, current approaches to the theme have begun adopting more and more holistic foci concentrating on factors that affect both positive and problem youth development (Catalano et al. 2005).

Success is not just sunshine; it requires the ability to be flexible, adjust, make compromises and cope with failures and adversities. It is important to consider how the home teaches and supports a child, including in circumstances in which he or she does not achieve goals, i.e., the ways in which difficulties are handled and how they are understood as an inevitable part of life (Määttä and Uusiautti 2012a, 2012b, 2013), as well as how to develop a sense of oneself as an autonomous individual (Eccles 1999). Therefore, the influence of family and upbringing is far from simple when it comes to children's success in later life (see, for example, Aronson Fontes 2002; Elder et al. 1985; Rowe 1990). What might be the most crucial aspect for this study is the manner in which people learn to interpret their experiences.

Indeed, top workers do not develop independently; they are surrounded by their families, friends and relatives. According to Berscheid (2006), human behaviour and development should always be understood as the result of living within the network and context of human relationships. It is crucial to explore how these factors enhance the development of self and the use of human strengths (Caprara and Cervone 2006; Magnusson and Mahoney 2006). Indeed, love and attachment expressed in relationships that surround us are not simply about an affect or a passive inner emotion but an active aspiration to help the beloved grow and be happy (Maijala et al. 2012; Määttä and Uusiautti 2013).

Perhaps no one aims for an Employee of the Year award, but the road to success at work, from perspectives on childhood and adolescence, is likely to be something more indefinable and general. Despite this, some people do achieve success at work. Is their success traceable to their childhood, and what could be the role of their childhood and adolescent experiences? The purpose of this chapter is to discuss the childhood experiences of top workers awarded Employee of the Year and to explore what they regard as especially facilitating factors or 
obstacles in their childhood and adolescence that could explain their favourable growth and development toward success at work.

First, we discuss the factors that the top workers considered beneficial to their career development and success at work. As expected, many factors were highlighted, which were further categorised into (1) parents' support and upbringing, (2) idols, relatives and friends, and (3) careers counselling at school. Following this, we take look at the hardships and obstacles faced by the top workers in their childhood and adolescence.

\section{Childhood experiences as contributory factors in occupational choices}

Success at work can result from many factors. Snyder and Lopez (2002) discuss it as a process emphasising, for example, the influence of family, school, childhood development and good workplaces on the young people. The section will begin by analysing parents' influence on top workers' career choices and their attitude to life, successes and hardships, and many characteristics needed for success. Likewise, the role of idols, relatives and friends as bellwethers is discussed. Third, the significance of careers' counselling at school is studied in the context of the top workers' experiences.

\section{Parental support and upbringing}

Values and educational goals that form the basis of upbringing reflect an understanding of the meaning of life, in other words, what people want to achieve or do in order to live a certain kind of life. Home is the most important environment for children because every child is bound to a home and is under the influence of the home environment. Attitudes to life and other people are adopted from home. The influence of the home in upbringing is markedly significant and, therefore, the process of becoming a top worker can be traced to the childhood and adolescence of top workers.

In the interviews, top workers were asked to reminisce about events and factors that have affected their career choices in one way or another and whether their parents had influenced them. The first reaction was that their parents had not tried to influence them. However, according to Snyder and Lopez (2002), families do influence their children's behaviour in later life by exemplifying how to explain adversities, how to set goals for the future, and how they strengthen hope in children. Indeed, according to the interview findings, parents had influenced top workers' attitude toward work rather than than their actual career choices.

Top workers maintained that their parents emphasised the importance of having an occupation and earning one's keep during adulthood. Three of the interviewees reported that their parents had some ideas about what they might want their children to become, and two top workers stated that their parents' occupation had influenced their career choices. For example, a farmer had 
continued the family farm. However, this career choice was not clear from the beginning. The farmer described the situation as follows:

SU: 'Was it always clear that you would continue with the family farm?'

Employee of the Year: 'I don't know. It wasn't obvious... Of course, when relatives visited, they would always talk about the young farmer, or they would ask something else. But it wasn't clear to me... I think that it mattered that I was away for about ten years. It broadened my mind and thoughts, and everything, surprisingly lot when you look around and see what people do elsewhere in the world. My parents never put pressure on me. Rather, they have always asked about my situation. Certainly, these questions were asked more often when my father's retirement got closer.'

Another top worker was also given the opportunity to continue with his parents' farm, but this top worker was aware from an early age that this was not a suitable path. One of the interviewees spoke of hope quite concretely: the top worker's father had wanted his child to become a chemist (in Finland, chemists are entrepreneurs and own pharmacies), but the top worker was not interested in this field. The desire of the parents was primarily driven by the security and profitability of being a chemist.

One top worker stated that studying and having an occupation was strongly encouraged at home. Although parents did not influence this top worker's career choice, his father's occupation had affected childhood and adolescence hobbies and the career choices of siblings:

'My father was a musician... Being an artist, he downright demanded that we do music and almost every one of us children had to play the piano or whatever. You have probably heard these stories about compulsory hobbies. We did it, and some of my siblings, two sisters are cantors and my brother too is a musician.'

Other top workers did consider that their parents had much influence on their careers. The most important thing was to find a field that was pleasing and interesting, and parents did not try to restrict their children. Parents did not put pressure or demands on their children but helped them to think about the future, make their own choices in life, and perceive the possibilities, opportunities and wellbeing that life could offer. What is relevant for success is the capability to learn how to get excited, set new goals, and the propensity to receive positive feedback and thus enhance one's own learning.

Furthermore, disappointments are an important aspect of developing selfesteem and mental health (for example, Desjardins et al. 2008). In the safety of the home, children can learn about those means that help them to handle disappointments and failures. When necessary, parents can protect their children from feelings of anxiety and guilt. Successful rearing does not aim to rid hardships and obstacles but to help children learn how to confront, tolerate and conquer the inevitable difficulties (McRee and Halpern 2010). 


\section{Idols, relatives and friends}

Only a few of the interviewees could name an idol who had influenced their career choice. However, three top workers acknowledged someone or some people who had, in one way or another, helped them with their occupational choices. The police officer maintained that patriotism in the family had influenced his career dreams. Patriotism was based on respect for relatives who had gone to war and they were considered the police officer top worker's idols. Although the top worker realised that the police profession was not founded only on the basis of this ideology, it remained partially important.

The priest described how spiritual life was rooted in the family even if the priest's parents had had temporal occupations and there were no actual church employees in the family. Nevertheless, the top worker's grandmother had run Sunday school and the top worker had good memories of it.

These examples show that top workers' stories do not include absolute idols who they would have followed in their lives. Therefore, it is not about admiration with blind worshipping but, rather, that the factors influencing these idols were manifested in attitudes such as patriotism and religiousness. These kinds of positive experiences directed their career choices later in life.

Friends can also have an influence on careers, and their effects are not always foreseen. Hence, one of the top workers stated that the decision to apply to a business school was based on a discussion with a friend. They wanted to continue studying together. This is a good example of how powerful an influence adolescent friendships can have and that, therefore, the impact of the circle of friends should never be underestimated. In a situation in which choosing a place of study is uncertain or difficult, the decision can easily be made with friends.

\section{Careers counselling at school}

The previous sections have showed that top workers' career choices were not directed by their families; their upbringing was directed in the sense of enhancing their overall positive attitudes to study and work. Therefore, it was also interesting to explore whether their schools had guided them and whether careers counselling in school had helped them with their occupational choice.

The significance of school in upbringing becomes especially emphasised if the home and family resources are insufficient or if children and adolescents do not receive sufficient information or stimuli at home. Their development can be supported at school, too, by employing their strengths. The purpose of student counselling at school is to support students' personal, social, moral and occupational development, and therefore it is quite wide-ranging and holistic (SundvallHuhtinen 2007) in nature. In Finnish schools, students have careers counselling, and practical training periods in real workplaces are also important.

In the interviews, top workers were asked to describe their experiences of careers counselling at school. Their experiences varied from one extreme to the 
other. Every top worker remembered their school counsellor, but perceptions of how meaningful the counselling had been varied considerably.

Three top workers had experiences that could be regarded as positive. One remembered that various occupations were introduced to them, although this top worker attended school when Finnish schools did not yet have separate counsellors or practical training periods.

'I think careers counseling was appropriate. I cannot remember which one of the teachers had to do it. It provided information about certain occupations and such, so that we could ponder it a bit. So, it was beneficial at that moment.'

This top worker did not choose his occupation on the basis of careers counselling but did so later when performing army duties. However, the positive experience of careers counselling was based on the information provided about different occupations that many young people did not know beforehand.

Another top worker remembered that at school they had to familiarise themselves with occupations in which they were the most interested. They were asked to write about how to study for and become employed in these fields. This top worker stated that he was already thinking about his current occupation at that time. Thus, careers counselling equipped this top worker with the knowledge of how to enter that profession.

The third positive experience differed somewhat from the previous two. This top worker had sought professional careers counselling after graduating from general upper secondary education. Careers counselling thus supported this top worker's occupational choice.

Two top workers had quite similar negative experiences of careers counselling in school. Their counsellor had advised them about who could apply for vocational school and who could continue to general upper secondary education and then to higher education. While the first top worker's counsellor had not supported the top worker's decision to go to vocational school, the other top worker's counsellor remained doubtful of the top worker's capability to continue on to general upper secondary education. Therefore, careers counselling would have directed them in directions other than what they had chosen and in which they had succeeded. These two top workers were the youngest of the research participants and they also had practical training periods at school. Usually, they would go to familiar, neighbourhood enterprises to familiarise themselves with real work life.

'Yes, we had careers counseling in middle school. And I still remember what our counselor at the time told me, that my choice was a bad one. I tried to say that I did not agree and tried to give reasons. And the counselor strongly encouraged me to continue with general upper secondary education. I did not. I did not think it would be my thing. I really remember it, and we had quite a lot of that counseling during the ninth grade.' 
What is most interesting in the previous example, and in the one that follows, is that counsellors do not seem very interested in figuring out what the youth is interested in. At the very least, this was what the top workers remembered. Students were divided into two groups; based on their grades, they would be suitable for either general upper secondary education or vocational upper secondary education after their compulsory education.

Employee of the Year: 'Those careers counseling lessons! Those were about rest and so on. I don't know whether I was just a silly youngster that I didn't understand the idea of counseling or whether it was because of those counselors. I remember that they were all already approaching their retirement age, so they were so far away from...'

SU: '...yeah, the adolescents' life.'

Employee of the Year: 'Yes. And then he looked at my records and wondered whether I was really seriously going to pursue general upper secondary education.'

Two top workers reported that careers counselling had not been significant to them at all. They both remembered it but had not personally benefitted from it. In all, it can be concluded that the top workers had not found careers counselling very important and, therefore, it cannot be seen as one of the key factors directly contributing to their success, although, in fact, it could and should have the opposite effect.

Why did careers counselling not meet students' needs? One reason is probably that top workers who participated in this research went to school in the 1950s-1970s when careers counselling was completely differently organised than it is today. For example, Sundvall-Huhtinen (2007) points out that it was not until the 1970s that the school system started to become more flexible and personal study plans were developed. In addition to changes in the education system, changes in society and especially work life have influenced on the development of careers counselling (Numminen et al. 2002).

The need for counselling and guidance has increased. At the same time, attitudes about the future and future occupations have changed considerably; in the 1960s-1980s' Finland, the starting point of studying and work was to make a career decision, pursue studies, find a stable and secure career, and avoid making mistakes. This was also evident in the kind of advice that the top workers received at home from their parents. However, in the 1990s and 2000s, attitudes have changed and emphasis is on having many options, life-long learning, enjoying life, and learning from mistakes (Sundvall-Huhtinen 2007). Changes in the worldview, living in insecure times, and the demand for constant updating and learning at work necessitate efficient guidance that can support occupational development.

Top workers also mentioned other factors that they thought enhanced their careers. One talked about having a gap year between studies and after compulsory 
school. This top worker had no idea about a suitable occupation at the time. During that particular year, the top worker worked in a retirement home for eight months and became familiarised with nursing. Although this top worker did not apply for nursing education immediately afterwards, the top worker later realised that positive work experiences from the retirement home would pave the way. Eventually, the top worker studied and graduated as a nurse and has worked as one ever since.

\section{Hardships and obstacles}

Top workers were also asked to describe the kinds of hardships they faced in their lives and whether they considered these experiences as having impacted on their careers. Some specific events were mentioned. For example, the police officer did not get into cadet school, which was very disappointing. However, this top worker decided on the police profession and applied to police school, got in, and this is how a fine career as a police officer got started. The setback turned into an advantage, and plan B became a success story.

Various kinds of career-related hardships could be seen as mere sidetracks. This is also because top workers were once clueless youngsters trying to find their own paths. Two top workers experienced such sidetracks; after having acquired an education, they later realised that their pursued fields were misguided and unsuitable. Stories about sidetracks teach that one does not always decide upon the right occupation without some level of stray. As a matter of fact, wrong choices can even be considered advantageous as they may strengthen one's positive feelings toward finding the right path; under such circumstances, one can make solid comparisons between situations.

Every top worker had experienced turning points in which they had to decide where to go next. For example, two top workers had the opportunity to continue with their parents' farm, but only one of them eventually did. Both of them became Employees of the Year awardees. What seems most important is to listen to oneself and choose the direction according to one's own feelings, thoughts and values. One of the top workers expressed this as follows:

'I do not know about those situations when you have to choose, whether the road will go here or there, or will I take this or that. I have been wise enough to think of what I really want, what is worth investing in with my abilities and talents. And even if something could be really interesting but not quite what is most suitable. I have always discussed these profoundly with myself. When it comes to my occupation, I have certainly been thinking about what are the best use of my strengths. And that had led to such satisfaction and pleasure that cannot be measured by money or respectability in relation to work.'

This type of thinking reveals a multidimensional analysis of the mission, standards and performances expected in work (see also Gardner et al. 2001). 


\section{Imbibing brisk attitude and optimism from parents and educators?}

According to the results, top workers could not recall specific factors from their childhood that could have been crucial in finding the right occupation. However, one important notion can be raised from their childhood, which is the attitude toward education, work and life in general that was adopted from home. Although the top workers' parents did not make career decisions for their children, they had encouraged them to educate themselves, work hard, and have a positive attitude about the future. Indeed, it has been shown that childhood experiences do matter in later development and success in later life (for example, Hawkins et al. 2005; Larson, 2000).

How then can success be supported? Twenty years ago, Arnold et al. (1993) emphasised that awareness of one's own strengths and weaknesses, values and points of interest, and knowledge about different occupations are of primary importance for career enhancement. According to the results of this study, none of the top workers had found their occupation through the careers counselling provided at school, but some of them still appreciated the information about occupations given at counselling.

The latest research in the field of positive psychology has further advanced the importance of recognising one's strengths (Aspinwall and Staudinger 2006). There is not simply one road to success at work, and every top worker is an individual. What was common among them was their ability and courage to listen to themselves and be true to themselves. According to Gilligan (2000), childhoodrelated factors that promote self-directedness or self-efficacy include parents' belief in the child's own sense of control, responsiveness, consistency, warmth and praise, support, and encouraging the child to engage in his or her environment and surrounding people (see also Sroufe 2005; Young et al. 2001). Therefore, social skills learned from home can be crucial for the positive development in this sense (see, for example, Decovic and Janssens 1992).

It seemed that the most important criterion for success is to find a career that is suitable and in which a person can become fulfilled. Educators need imagination, courage, and even the ability to take risks so that they can help growing and maturing people test their own limits and abilities (Uusiautti 2008; Uusiautti and Määttä 2013). Careers counselling can play an important role and should be further researched. Students need information about various occupations and work tasks to be able to evaluate what they find interesting and what they want or can do. Therefore, personal careers counselling also has to help a student recognise his or her abilities and talents, but equally important is to find out which school subjects the student likes the best and what he or she likes to do. Questions related to career choice and occupational socialisation are surprisingly closely connected with free-time activities (Driver 1982; Duffy and Dik 2009; Maljojoki 1989; Middleton and Loughead 1993).

In addition, students have their own preconceptions of various occupations and thus it is crucial that the expectations in various professions are clarified to 
students. Abundant practical experiences and examples from real work life cannot be sufficiently emphasised. Furthermore, teachers and counsellors should be aware of their prejudices and stereotypical conceptions of valuable and notso-valuable occupations. Top workers who participated in this study attended school four to six decades ago, and careers counselling was not as systematic as it is today, since societal interest in adolescent choices emerged in the late 1960s and early 1970s (Petersen 1988).

It is also worth remembering that, regardless of whether a student is a straightA pupil or simply barely passes, every student needs careers counselling. Therefore, it is important to highlight the positive experiences of success and being capable - every student has and can have them. It would be interesting to know how the future Employees of the Year perceive the role of careers counselling in school today.

In all, it became evident that researching the secrets of success from people's childhood and adolescence was not straightforward. The phenomenon of success does not appear in the same way as failure and, therefore, it is not easy to think about reasons for success (Isen 2001; Uusiautti and Määttä 2011). However, the role of childhood experiences at school and at home should be interesting to educators. For example, Mäkikangas (2007) has found that a sensitive and childcentered upbringing was connected to optimism in later phases of life (see also Sroufe 2005). Top workers also displayed optimistic attitudes, which can be closely related to the overall satisfaction of life, including satisfaction with one's work and career choice.

Perceiving the phenomenon of success from this perspective is relevant to many areas of life, but especially remarkable is that the foundation of success can be laid from childhood. Positive psychology has been interested in exploring and creating optimal conditions for all children and students (Carruthers and Hood 2005). Success is not just something that, for example, gifted people are entitled to but the concept could be used for enhancing everyone's success. If students' mastery of information or skill leads to success, and if positive emotions are one of the cornerstones of successful learning, it would be reasonable to pay attention to this viewpoint in education (Chafouleas and Bray 2004). The purpose, therefore, is to research, define and specify the human strengths and capacities that individual people, families, communities and societies should aim to utilise. Positive human development should be encouraged (Dunn et al. 2008). Although the viewpoint presented in this review is very individualistic, it is also worthy to continue the discussion from the collective perspective and to think about whether these concepts can also be used for enhancing collective or communal success.

Educators should be ready to meet the challenge of providing children and students with such positive experiences of finding their own road and being able to fulfil themselves. Lerner et al. (2002) use the word 'thriving' to discuss the positive development of youth. They emphasise 'the five Cs of positive youth development: competence, confidence, character, social connection, and caring 
(or compassion)' (p. 23), which work toward enhancing positive youth development. Indeed, in addition to the personal benefits of happiness that are achieved through utilising one's strengths (Seligman 2002; 2011), they are also socially beneficial as balanced, satisfied people are also better citizens (Gilpin 2008).

\section{Caring teacherhood as a means to success}

As the childhood memories of top workers surfaced, it became evident that the connection between counselling at school and one's capability of finding the right occupation was not that simple. As such, we want to spend a moment to discuss the idea of caring teacherhood as a means to discovering pupils' strengths. We consider teachers as caring leaders who can employ love-based methods that enhance pupils' ability to spot their strengths and thus improve their self-knowledge.

\section{Can pupils and students be led toward goodness and happiness - and wellbeing?}

Authority is often addressed from pedagogical points of view and it has been studied a great deal (Delpit 1988; Deutsch and Jones 2011; Pace and Hemmings 2007). Nevertheless, it has been understood in a contradictory manner in relation to education and teaching (Langford 2010; Seidl and Friend 2002). Obviously, the relationship between a teacher and a student is asymmetrical because the teacher possesses something that the pupil does not. According to Hare, the teacher does not have to think that the student is presently his or her equal, but does need to see the student as a potential equal (Hare 1993). The purpose of the learning relationship is to make the pupil develop into an independent and responsible autonomous individual. However, students cannot achieve this goal independently; they need the educator's help and guidance and, therefore, the teacher is in a position of authority.

van Manen emphasised that an adult's ability to affect a pupil is genuine when the authority does not rely on power, but on love and affection (van Manen 1991). Harjunen also defines pedagogical authority through pedagogical interaction (Harjunen 2009). According to the author, pedagogical interaction consists of such characteristics as 'trust building', 'treating students as human beings', and the 'ethics of care and justice'.

We have defined the connection between pedagogical love and authority in the following manner:

If pedagogical love and pedagogical authority are based on expertise-based respect, the learning atmosphere is warm and encouraging. Mutual respect supports empathy; students respect the teacher because of his or her expertise and regard the teacher as a sort of safe mainstay that they can rely on. The teacher trusts and believes in the students' abilities, respects their individuality, 
and helps them to enhance their balanced development and find their own strengths.

(Määttä and Uusiautti 2011b)

What does this mean in the context of schooling and teaching? The existence of a good human being can be considered problematic or even impossible because 'good' is usually confused with 'perfect'. Being a good human being does not mean that one should be totally irreproachable, moral and faultless, that is, non-human and probably impossible to achieve anyway. We want to highlight love as the fundamental factor in raising children to be good human beings and that this particular aim is the ultimate purpose of all rearing. Love appears in teaching as guidance toward disciplined work, but also as patience, trust and forgiveness. The purpose is not to make learning fun, easy or pleasing but to create a setting for learning whereby pupils can use and develop their own resources, eventually proceeding at the maximum of their own abilities. A loving teacher takes care that the learner does not lose his or her trust in his or her own learning when faced with difficulties. Therefore, love appears as goal-oriented action: a teacher plans and implements learning situations that enhance learning. Furthermore, a loving teacher takes a pupil's personal situation into consideration (for example, Hatt 2005; van Manen 1991).

Pedagogical love is considered a working method that involves persistent interest and perseverance in supporting pupils' development for the sake of themselves and the whole society. In addition, teachers should find a balance between pedagogical love and pedagogical authority and combine them both in a studentspecific manner. Pedagogical tact is at its strongest in this ability. Dealing with various students requires flexibility and sensitivity in the teacher's pedagogical approach. Some students need more intimacy while some others consider expertise especially important. Moreover, the teaching content and learning objectives may necessitate different kinds of procedures from the teacher - in other words, a certain kind of tact (Määttä and Uusiautti 2011b). Taking this viewpoint further, van Manen points out that pedagogical tact is 'the language of surprising and unpredicted pedagogical action' that emerges from the genuine attachment to the pupil (van Manen 1991). At the core, it is the children's vulnerability and defenselessness that make the educator protect them.

\section{Tools for employing strength-based approaches in school}

The way we see it, the role of a teacher is primarily focused on encouraging and rewarding the multitude of talents and strengths a child has, by presenting opportunities for displays of these talents and strengths each day. In practice, the means are quite simple: linking strengths to specific festivals and events throughout the school calendar and activities such as the strengths-based classroom, victory logs and celebrations of 'what went well' (see Linley et al. 2009).

In practice, it is important that the teacher makes self-assessments. A teacher can reflect and observe his or her way of teaching and interacting with students 
and ask questions such as 'Do I listen to students' opinions in an open manner?', 'Do I encourage students to express their emotions or perceptions?', 'How do I handle divergent opinions and criticism or feedback from students?', and 'Do I treat students equally regardless of their background?' Becoming aware of one's own style and level of tact enables one to move from one quadrant to another, toward an ideal state. It is about the teacher's tact and the capabilities of recognising various learners and personalities and of having situational flexibility (see also Määttä and Uusiautti 2012b).

In addition to teachers' reflective practice, it is crucial to include positivelyoriented and wellbeing-promoting actions toward pupils and students. Seligman et al. (2009) describes simple exercises that aim to help students identify their signature strengths and increase their use of these strengths in daily life. Moreover, this intervention was aimed at promoting resilience, positive emotions and students' sense of meaning or purpose. All goals were achieved, which made Seligman's research group conclude that wellbeing should and can be taught at school. The positive focus seemed, according to the study by Seligman et al., to consist of relatively small things, such as changing speaking prompts (for example, instead of asking students to describe negative events, teachers asked them to give a speech about when they were of value to others; religious education teachers asked students to explore the relationship between ethics and pleasure and what gives life purpose and meaning; geography teachers asked students to consider how the criteria for wellbeing might differ between various countries; PE teachers focused on analysing the successes of past games before the next game or lesson). The point here was that wellbeing could be taught and, with the teacher's lead, students would not only learn about it, but their own wellbeing would increase as well.

It is important to discover one's signature strengths. In Seligman et al.'s (2005) study, long-term effects of increased happiness were perceived in exercises that aimed to employ signature strengths in a new way and in which pupils were asked to name and explain three good things about their daily lives.

Furthermore, the idea behind Appreciative Inquiry (AI) could also be employed in education by teachers who would like to utilise the idea of caring teacherhood. Appreciative Inquiry utilises a cycle of four processes that focuses on 'discover' (the identification of organisational processes that work well), 'dream' (the envisioning of processes that would work well in the future), 'design' (planning and prioritising processes that would work well), and 'destiny' (the implementation (execution) of the proposed design) (Cooperrider et al. 2008). Likewise, Ryan et al. (1999) have advanced that AI is a suitable strategy for initiating an affective and analytical micro-level reform within a single school. The fundamental notion is that instead of concentrating on what was done wrong, AI helps with discovering what is done well and what more could be done.

Furthermore, providing students with daily experiences of success is important. If the mastery of information and skills is to lead to success, and if positive emotion is one of the keystones of learning, it would be reasonable to pay 
attention to this viewpoint in teaching (Chafouleas and Bray 2004). Fredrickson's (2001) analysis on pride also falls into this category. By adjusting goals and objectives and planning learning tasks in a way that each pupil can have the experience of achieving a goal, this kind of experience of success can be promoted. Teachers try to find a balance between pupils' skills, work-related expectations and opportunities and challenges, which is likely to lead to better performance, contentment, higher motivation and a sense of self-efficacy.

The teacher as a caring leader or pedagogical authority has the capacity to help bring about the best in pupils. The process can then move forward - not only the process of learning and performing, but also the process of discovering and using pupils' signature strengths, and promoting wellbeing and happiness, not only in the current phase of life but also in prospective phases.

According to Hare (1993), pedagogical love, caring in the classroom, humility, commitment and hope are traits that constitute a 'good' teacher, although they are not always easy to adhere to in modern schools. Therefore, pedagogical tact is the key; this is because it, along with pedagogical goodness, illustrates the pedagogical relationship and the fundamental idea that the adult is primarily working for the benefit of the child in this context (Saevi and Eilifsen 2008). The ability to create happiness for life is an important skill for a good educator and teacher. Von Wright has stated that to love the world we have to accept it and, therefore, to love students we have to accept them and to refrain from wanting to change them and to prepare them for changing the world in a particular and predefined way (von Wright 2009).

\section{Enhancing students' study success through caring teacherhood}

Caring teacherhood can be the way of bringing out the best in children, but caring, strength-based leading of learning does not need to end in compulsory education. Similar guidance is needed also in higher education levels. Also, it is not just teachers working in the classrooms that is important but the overall study environment that is created by the way the school or education institution is led; whether the teachers are encouraged to focus on pupils' and students' strengths, whether they are provided with sufficient resources for teaching, and whether the students are appreciated at school. The school functions as an entity, and the student-centered, positively oriented approach is a pervasive element of education. Here, we introduce our findings from Finnish and American universities as an example of how school can enhance students' success. The perspective on university studies is not meant to overlook other education levels. Instead, we wanted to analyse our data and provide an example of the impact caring leadership can make in education institutions. Thus, we argue that this viewpoint could apply to, for example, vocational education schools and polytechnics as well as it seemingly does to the university-level education.

Especially at a time when increasing demands on efficient and productive higher education, high numbers of student drop-outs (see, for example, Kuh et al. 
2008; OECD 2010) and prolonged studies (OECD 2010; San Antonio 2008; Schoon et al. 2010) do not seem to point in the same direction, new ways of considering education are needed. How to make students' study paths smooth and have them succeed in their studies?

In this section we will discuss how the goal of success could be achieved by employing caring leadership in higher education. This section leans on the data obtained from Finnish and American university leaders. The ultimate idea of the study was that a particular positive and caring viewpoint could be something that today's higher education would need. For example, Cruce et al. (2006) suggest that good practices in education have a unique, positive impact on student development as they can affect, for example, student engagement, which can be seen as one of the main pillars of successful and meaningful study paths. Kezar and Kinzie (2006) have introduced features of a quality undergraduate education that has been associated with student engagement; quality begins with an organisational culture that values high expectations, shows respect for diverse learning styles, and has emphasis on the early years of study; a quality undergraduate curriculum requires coherence in learning, synthesising experiences, on-going practice of learned skills, and integrating education with experience; and quality undergraduate instruction builds in active learning, assessment and prompt feedback, collaboration, adequate time on task, and out-of-class contact with faculty (see also Kuh 2003). Likewise, Theilheimer (1991) has presented a detailed list of five factors that contribute to a positive learning environment: (1) comfort (creating a feeling of safety, accommodating errors, giving students the freedom of expressing themselves without constraints, creating the feeling of belonging to peer group); (2) clarity (providing clear instructions, breaking down material to smaller chunks to maintain the feeling of accomplishment, however small); (3) respect (mutual respect between students and the teacher); (4) relationships (particularly caring relationships between the teacher and individual students, teacher attending each student individually); and (5) responsibility (giving students a degree of control over decisions concerning their learning).

Here, our purpose was to analyse how caring leadership in higher education can be employed to enhance students' success and study achievements, and what its relationship with other factors affecting students' study success is like.

The leaders' perspective is interesting when considering the effect of caring that covers the institution, in this case, the university, through the select approach of the leader. Caldwell and Dixon (2010) have defined love, forgiveness and trust as organisational constructs that are freedom-producing, empowering and vital to enhancing followers' self-efficacy. When leaders consistently exhibit love, forgiveness and trust in relationships, their followers - whether they were students or employees - respond to these behaviours with increased commitment and loyalty. Moreover, happiness can be directly translated into engagement, productivity and satisfaction (Prewitt 2003; see also Rego et al. 2011). It has been argued that sensitive leaders develop a culture that demonstrates concern for individual needs (Fairholm and Fairholm 2000; Popper and Amit 2009). 
Happiness not only produces a quantitative improvement by increasing efficiency but also a qualitative one by making a better product or outcome by virtue of pride, belief and commitment. Emotions and emotional intelligence have even been considered as the heart of effective leadership (Goleman 2006). Furthermore, an ethic of caring establishes a moral touchstone for decision making (Hoyle 2002) as leaders' elicitation of love regards other people as the cause, target or third-party observer of these emotions (Fischer and van Kleef 2010).

Given this perspective on love and leadership, we were interested in researching how university leaders talk about the connection between caring leadership and students' study success. This viewpoint contributes to the overall knowledge about caring leadership practices, but specifically to the awareness of the multidimensional nature of higher education organisations and factors affecting the smoothness of university students' study processes. Finally, the purpose is to determine how the love-based aspect might be used in elaborating research models for re-thinking and designing caring learning environments, students' psychosocial wellbeing, and for developing the models of caring and love-based leadership in education context.

As the interviewees worked in universities, their work was closely connected to not only their followers but also to university students. Therefore, leaders discussed their leadership in relation to the study opportunities and conditions among students at their universities. We analysed how the university leaders actually perceived their role in promoting university students' study success and fluent study processes. All their perceptions were first categorised into themes according to the way leadership was discussed in relation to students (for example, leadership actions for the students, providing resources and quality teaching). Then, the perceptions were re-categorised into three main categories that best represented the leaders' perceptions: using caring leadership for (1) providing resources for quality education, (2) seeing students, faculty or staff, and themselves as equal groups, and thus promoting a sense of solidarity, and (3) treating students as customers.

\section{Caring leaders provide resources for quality education}

The first category refers to the relationship between outer factors affecting education and the way that the education is realised in practice and provided to students. The current educational policies regarding funding in universities were reflected by the university leaders. They were aware of the pressure of doing research and having students graduate:

'The pressure within the public university environment has really focused more and more around money. [Universities] have to be doing more research, they have to be taking more students, they have to be generating more programs.'

(American leader) 
'At this level, in a university, those kinds of push for excellence and productivity make it pretty difficult to be I think a loving leadership model.'

(American leader)

Although they realised that the demands of competition and productivity can make it more difficult to employ caring leadership in universities, the university leaders could see their position and opportunities to utilise their leadership. They seemed to consider themselves responsible for ensuring the high quality education and support for students.

'I mean, your [the leader's] job is to make life better for all the faculty and students so they can do what they need to do: their research, their teaching, and the students, so they learn and get their degree, go out there and make us all proud. To do that, you got to be a leader.'

(American leader)

'A lot of times, that requires that you're going to make sure that the quality of the education that the students get is going to be the highest possible.'

(American leader)

In practice, caring leadership appeared as a wish to guarantee as high a quality education for students as possible by using the available resources in a purposeful manner, reallocating it to activities that would benefit students' study processes (for example, by decreasing teachers' and professors' administrative work), and enhancing the spirit of everybody doing their share and their best for the students and the university.

'We have to guarantee such resources that the quality of education is considerably better than it is now, that the operation is meaningful, and that we can take the best possible care of students. That will also benefit work life.'

(Finnish leader)

'I find it surprising that we have so much administrative work at the university... Teachers have to send emails to various pupils, and they do a little bit of this and that? That's administrative work. And if we had an employee to do that work, it would be much more logical.'

(Finnish leader)

\section{Caring leaders promote the sense of solidarity among students and faculty}

The second viewpoint expressed by the university leaders was related to the atmosphere at the unit. They considered it important for the students' study success, commitment and overall satisfaction that the people at each unit and at the university would share the sense of togetherness and solidarity. 
'The caring that I have my organization, I got 700 employees, about 18,000 students, the caring I have is for all of them, and so, everybody gets treated that way.'

(American leader)

'You can have more family-orientation. We are only interested in our own research and we hardly ever collaborate. I think that at the individual level, you know, I think working with your own doctoral students, we can have more personal caring relationship. The stress of competition is not good but working with individual students and dissertations, that's more satisfying, working with students in the classroom.'

(American leader)

As the latter of the aforementioned data excerpts show, the sense of togetherness was also seen as the answer to the ever-increasing pressures of productivity and individual success. Working together could benefit not only students and the faculty but the whole organisation. Moreover, the university leaders named actual measures that they themselves used in practice in order to improve the spirit of collaboration at their units. The leaders talked about treating everyone equally and promoting open and informal interaction among the faculty and students.

'Our community; we have students who are equal members of this work unit in their own role, and we have the personnel... This [university] is quite a world of its own compared to the normal units.'

(Finnish leader)

'Management by walking around; and I think it is insane that teachers for example sit in a separate cabinet away from students or where leaders sit on a different table than employees. I can affect those daily situations in which I can mold in the community and stick together with them.'

(Finnish leader)

'We're trying to re-develop the area around the university to build more coffee shops, restaurants, bars, music places ... I think that leadership is all about getting people to feel connected and engaged... A research university should make a very clear connection with the practical world of the community and the faculty and the students.'

(American leader)

According to the findings, the students' study processes could be enhanced by increasing open interaction and collaboration in units. Caring leadership thus could be seen to be the means of setting an example by spending time with people, discussing problems, and initiating actual proposals for actions, be they small-scale collaborative actions such as the faculty and students having coffee at 
the same table, or larger scale measures, such as improving offerings within the overall education environment. Thus, caring university leaders pay attention to their followers' and students' overall wellbeing. They realise that a wellfunctioning unit with a good and inspiring spirit can offer the best premises for students' study success and, through this, the success of the whole unit and the university as well.

\section{Caring leaders perceive students as customers}

The previous category described how the sense of solidarity could support students' study paths. The third category develops this thinking to the personal level by seeing students as the customers. According to the results, the university leaders' way of perceiving students resembles a whole new way of defining customership. It is not just demands expressed by the customers but merely collaboration and desire to find out what is the best for them through reciprocal interaction: students as customers are simultaneously seen as partners too. From this point of view, caring leadership was considered a means of paying attention to students as individuals, taking care of them at the personal level, and respecting them as the most valuable part of the university. The university leaders expressed this idea as follows:

'In academics, you need to be very careful that the students should come first. And I think that's a big difference between academics, a leader in academics and a leader in industry. I really try to do what is best for the students first. And then I try to do what is best for the faculty and the college.'

(American leader)

'Here, where you don't necessarily have a product, per se. You are not making televisions, but the other thing is: What is the product of higher education? You might think the student, I'm saying, no. You can't claim another human being as your product. No, the curriculum is your product. I just refuse to think, if you use business analogy and you're a dealer, a car dealer. It's not the customer that's your product, it's your car. So, since when, if we look at that, why not students are our customers.'

(American leader)

The university leaders described that when students are perceived as customers of higher education, they can feel they are being supported and heard. Caring leadership was manifested in personal relationships with students:

'I have a good, direct, and open relationship with students. I hope, at least, and sense that I am easily approachable and they come to discuss their problems and studies, and quite openly have confided in me.'

(Finnish leader) 
In addition to direct interaction with students, some university leaders perceived their position as a possibility to support their followers, department chairs, professors and other faculty, in creating the favourable relationship with students and supporting them in their studies. Caring leaders thus could see their support and guidance they provide to their followers as the way of supporting students' study processes.

'[I want to] support the chairs really connecting with students.'

(American leader)

'From time to time, I've sent them [the faculty] reminders about why we are working here and how important it is to work together despite the fact that your work loads are heavier because of the financial times but remember why you're here: It's the students' smile when they leave your office. You know it's working and reminding them of that ultimate goal.'

(American leader)

The way caring university leaders can show their support to their ultimate customers, students, is to make sure that people working at the unit are aware of the purpose of their work. This was also related to the question of respecting students. One of the leaders described the situation by giving an example:

'If you have an office and you open at 8, it's not just good at all, not good for the students, not good for the whole college, if you're not there at 8 o'clock. If there is no one there, we are not respectful to them.'

(American leader)

The leader continued with the example that he considered that it is also the caring leader's task to make sure that not only are his or her followers aware of their responsibility for students and have accepted them as their customers, but also that they have to find meaning in their jobs. If they still do not find their work meaningful the leader's task, for the sake of the students and the employee himself or herself, is to help the employee find the meaning in the job or reconsider the job description.

'If you say I don't like my work, I'm just shuffling papers, then I can explain, OK, there's the reason why you're shuffling this paper, because the students need this, the students. Maybe there are some forms that students need. But sometimes people are not in the jobs. You have an opportunity to identify that like when you really explain why some things have to be done and still that individual does not find it meaningful, then I would engage in little better professional planning.'

(American leader) 


\section{Factors behind students' success}

The results of this study complement our previous studies of factors directing university students' study processes (see, for example, Määttä and Uusiautti 2011a). We have previously described the teacher/student's study process as a sum of factors at the student's personal level, the unit level and the overall regulations, values and cultural traditions that control education. Although they do not explain a successful study process alone, their development and significance should be paid more and more attention at universities.

Figure 4.1 illustrates the interconnectedness of students' study processes and factors affecting it. We consider caring leadership the fundamental enabling and empowering element influencing all levels of study processes.

We analysed caring leadership in relation to students' study success. At the personal level, students' study processes vary greatly depending on their backgrounds, starting points, study skills and the experiences they get during their education. Students have certain abilities and habits related to their learning history and experiences and that can strengthen their knowledge and self-efficacy. This conception is either strengthened or dashed at the university (Biggs 1987; Cassidy and Eachus 2000; Gettinger and Seibert 2002; Lindblom-Ylänne and

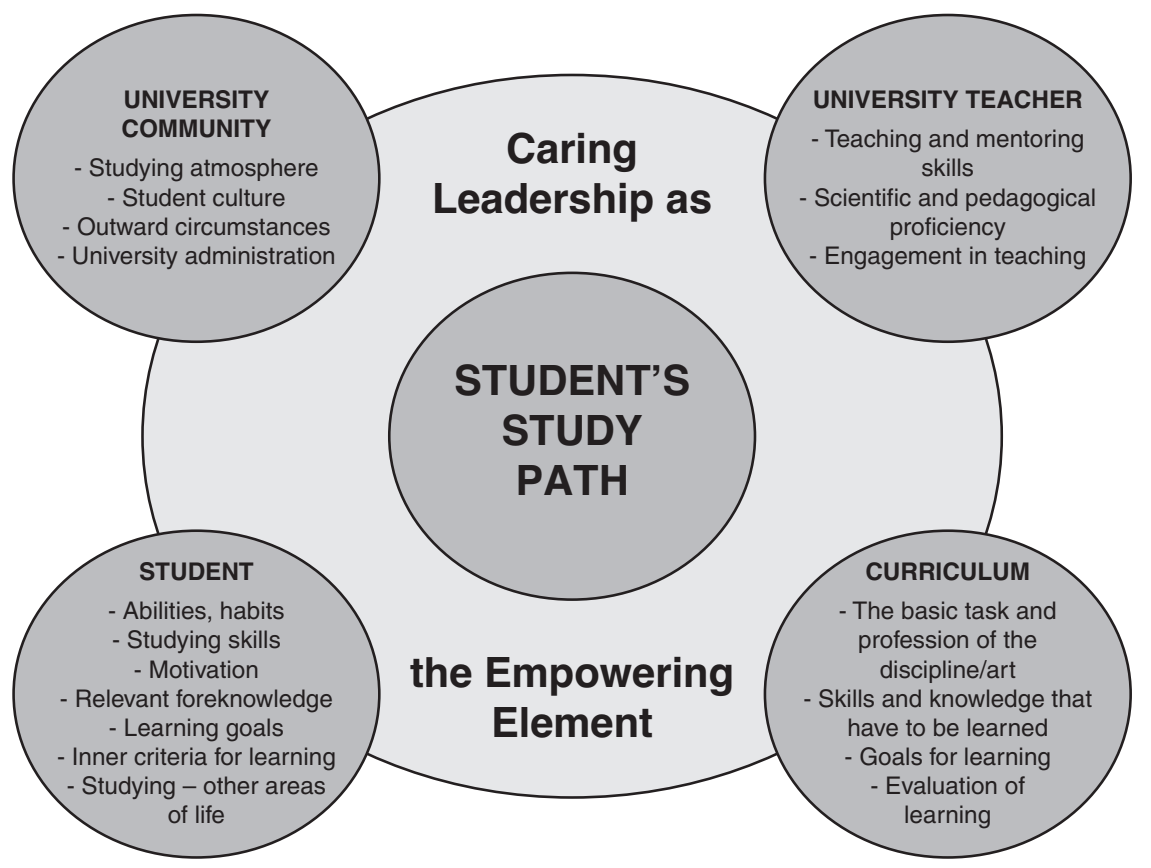

Figure 4.I Core factors affecting students' success (adapted from Määttä and Uusiautti, 201 I: 52). 
Pihlajamäki 2003). On the other hand, we want to emphasise students' motivation, which reflects in their way of seizing studies and persistence (Allen 1999; Mäkinen 2000). Certainly, outer rewards matter too. Receiving positive and encouraging feedback about one's own progress is important as it improves one's receptiveness to new learning experiences and tolerance of failures, whereas a perceived feeling of insufficiency and a poor performance level, as well as teachers' inadequate guidance and disinterest, decrease motivation (Pajares 2001).

The viewpoint presented here also included an interesting notion; namely, university leaders talked about considering students as customers. From the students' perspective, this means that they are valued and noticed at the university. They received support and guidance when needed and felt respected as an important part of the university. In addition to sufficient support and guidance, there are other means to enhance students' wellbeing too. Studies should also be in balance with other areas of life; interesting hobbies, good human relationships and family life, versatile and relaxing leisure time act as a good counterbalance to studying (see, for example, Lowe and Gayle 2007). Some university leaders talked about mutual free-time activities that could be provided at or nearby the campus. Participating in these kinds of activities would also increase student engagement. For example, Kuh's (2003) framework for student engagement is based on five benchmarks: level of academic challenge, enriching educational experiences, supportive campus environment, student-faculty interaction and active and collaborative learning. Therefore, it seems that engagement is one basic concept when considering successful studying.

Naturally, everyone also perceives success in studies subjectively and evaluates personal achievements in different ways (Maddux 2002). Expectations for the future affect greatly how people react on changes and challenges (Carver and Scheier 2002) and there are various strategies that lie behind the one that leads to active and meaningful studying. From the perspective of university students' success, it seems that caring leadership can function as a means to support students at their personal level and enable them to find and employ their personal characteristics, talents and strengths in the best possible manner during their studies.

The leaders in this research talked about the sense of solidarity and communality among the faculty and the students. At the unit level, the educators' pedagogical and scientific professionalism, curricula, and the atmosphere and conditions of the unit (see Määttä and Uusiautti 2011a; Uusiautti and Määttä 2013) can be named as the core factors. Consequently, if the students were regarded as customers, the curriculum was named the product. It should fulfill the promises of education and thus be cutting-edge. Basically, the curriculum provides both teachers and students with a clear goal. It answers the questions of what kind of expertise students will have after graduating from the training program and what kinds of courses are included in their studies.

Five stages can be distinguished in curriculum work (see Alaoutinen et al. 2009): (1) to define the basic task and profession of the education/discipline/art, to evaluate the need for education; (2) to define required competencies and 
general goals of teaching; (3) to define the model of curriculum; (4) to define the goals, contents, workload and methods for study entities and units; (5) to determine the communication in the curriculum; and (6) to evaluate the curriculum and the proficiency produced by it and its constant development. Learning goals in the curriculum tell what students are expected to know after taking a certain study unit and they also direct working and the way learning, teaching and studying are being evaluated.

When pursuing the valued outcomes, students need special support and guidance. What became highlighted here was the importance of equal and open interaction between the faculty and students. This is how the idea of perceiving students as customers was manifested in leaders' thinking; their customership implication appeared as a reciprocal relationship with students. Likewise, a positive atmosphere was emphasised as a crucial element.

More detailed lists of the nature of support and guidance have also been compiled (for example, Haapaniemi et al. 2001). Määttä (2012) has divided the resources of a good supervisor into four dimensions that constitute the four fundamental features of supervision: (A) Will: a supervisor's commitment to supervision; (B) Knowledge: substance knowledge and/or the mastery and ability to comprehend the overall structure; (C) Actions: ensuring that the contents meet the scientific quality requirements; and (D) Proficiency: positive and supportive supervision methods and personality. The emphasis that each element is given varies according to a supervision situation. Nor does the emphasis always remain the same. A supervisor can emphasise different features depending on his or her own style and on a student's work habits and needs. Supervision is not likely to succeed if one of the aforementioned resources is completely missing.

Many characteristics of a university community either enhance or hinder students' smooth processes. A study atmosphere can vary from open and vivid dealings between students and teachers and other personnel to distant, minimal and formal relationships between the above-mentioned groups. Indeed, the meaning of informal student-faculty contacts and learning outcomes has been noted already three decades ago (see Pascarella 1980). Finding studying meaningful is shown to have a positive relationship with students' perceptions of academic atmosphere at the unit (see, for example, Kezar and Kinzie 2006; Mayya and Roff 2004; Pimparyon et al. 2000).

Ultimately, the completion of an academic degree is a student's responsibility because even the most skillful teacher cannot learn on a student's behalf. Yet, teaching skills and teachers' abilities to be in an appreciating interaction with students and to guide students make a salient impetus in university education. This was also noted by the university leaders. Today's good university teachers bear the responsibility both for their disciplines and are concerned for their students' success.

An ideal education institution naturally covers the outward conditions as well, including studying facilities and their location, the number of teachers in proportion to the number of students, social, economic and health services, library services (the availability of books, opening times, etc.), ICT facilities and their 
sufficiency, the length of studying days, the accumulation of lectures versus even division by weekdays and time. It is a known fact (see, for example, Greenwald et al. 1996) that a broad range of resources are positively related to student outcome (see also Atjonen 2007). Indeed, this resembles the third perspective brought out by university leaders in this study. As the funding of universities strongly depends on the number of graduates, research programs and publications, in other words measurable outcomes, the pressures of productivity is high. The university leaders in this study considered these outer factors hindering the realisation of caring leadership but considered it as the basic principle for making decisions that would benefit the students the most and allocating money for purposes that would ensure them with as high-quality education as possible.

\section{Toward the adulthood success}

In the modern world student groups are more heterogeneous than ever (see, for example, San Antonio 2008; Zhao et al. 2008) and thus their study processes should be paid attention to more than ever. Consequently, university educators' work is demanding and important, and requires resources, time and concentration. Caring leadership in higher education can enhance the students' study processes by highlighting some fundamental principles of higher education.

Daniel Goleman (2006: 81) has wisely said: 'Leading a school to create a warmer and more connected school culture need not mean sacrificing academic rigor. Instead, socially intelligent leaders help schools better fulfill their main mission: teaching'. This concerns every level of education. Also, based on the results of our studies, we would like to continue Goleman's thought by adding that by using the leadership position for fulfilling the teaching mission, caring leaders also boost students' success. It can have a far-reaching influence on their consequent success as workers, too, when entering adulthood and work life. Indeed now it is time to turn eyes on the exogenous factors of success in adulthood.

\section{References}

Alaoutinen, S., Bruce, T., Kuisma, M., Laihanen, E., Nurkka, A., Riekko, K., Tervonen, A., Virkki-Hatakka, T., Kotivirta, S. and Muukkonen, J. (2009) LUT:n opettajan laatuopas [Quality manual for teachers in Lappeenranta University of Technology]. Lappeenranta: Lappeenranta University of Technology. Available online at: http:// www.lut.fi/fi/lut/introduction/quality/qualitybook/Documents/Opettajan_Laatuopas_ B5_final.pdf (last accessed 24 March 2014)

Allen, D. (1999) 'Desire to finish college: an empirical link between motivation and persistence'. Research in Higher Education, 40(4), pp. 461-485

Arnold, J., Robertson, I. T. and Cooper, C. L. (1993) Work Psychology. Understanding Human Behavior in the Workplace. London: Pitman Publishing

Aronson Fontes, L. (2002) 'Child discipline and physical abuse in immigrant Latino families: reducing violence and misunderstandings'. Journal of Counselling and Development, 80 , pp. $31-40$ 
Aspinwall, L. G. and Staudinger, U. M. (2006) 'Ihmisen vahvuuksien psykologia: kehittyvän tutkimuskentän kysymyksiä [Psychology of human strengths: questions from developing field of study]' pp. 21-33 in Aspinwall, L. G. and Staudinger, U. M. (Eds.) Ihmisen vahvuuksien psykologia [A Psychology of Human Strengths]. Helsinki: Edita

Atjonen, P. (2007) 'Educational technology and technology education for a better private and public life. Principles and practices from the Finnish viewpoint' pp. 91-110 in Jakku-Sihvonen, R. and Niemi, H. (Eds.) Education as a Societal Contributor. Frankfurt am Main: Peter Lang

Berscheid, E. (2006) 'Ihmisen suurin vahvuus: toiset ihmiset [The greatest strength of a human being: other human beings]' pp. 47-56 in Aspinwall, L. G. and Staudinger, U. M. (Eds.) Ihmisen vahvuuksien psykologia [A Psychology of Human Strengths]. Helsinki: Edita

Biggs, J. B. (1987) Student Approaches to Learning and Studying. Hawthorn: Australian Council for Educational Research. Available online at: http://eric.ed.gov/PDFS/ ED308201.pdf (last accessed 24 March 2014)

Bradley, R. H. and Corwyn, R. F. (2002) 'Socioeconomic status and child development'. Annual Review of Psychology, 53, pp. 371-399

Caldwell, C. and Dixon, R. D. (2010) 'Love, forgiveness, and trust: Critical values of the modern leader'. Journal of Business Ethics, 93, pp. 91-101

Caprara, G. V. and Cervone, D. (2006) 'Persoonallisuus toimivana, itsesäätelevänä järjestelmänä [Personality as functional, self-regulative system]' pp. 69-82 in Aspinwall, L. G. and Staudinger, U. M. (Eds.) Ihmisen vahvuuksien psykologia [A Psychology of Human Strengths]. Helsinki: Edita

Carruthers, C. and Hood, C. D. (2005) 'The power of positive psychology'. Parks and Recreation, Oct 2005, pp. 30-37

Carver, C. S. and Scheier, M. F. (2002) 'Optimism' pp. 231-243 in Snyder, C. R. and Lopez, S. J. (Eds.) Handbook of Positive Psychology. Oxford: Oxford University Press

Cassidy, S. and Eachus, P. (2000) 'Learning style, academic belief systems, self-report student proficiency and academic achievement in higher education'. Educational Psychology: An International Journal of Experimental Educational Psychology, 20(3), pp. 307-322

Catalano, R. F., Berglund, M. L., Ryan, J. A. M., Lonczak, H. S. and Hawkins, J. D. (2005) 'Positive youth development in the United States: Research findings on evaluations of positive youth development programs'. The ANNALS of the American Academy of Political and Social Science, 591, pp. 98-124

Chafouleas, S. M. and Bray, M. A. (2004) 'Introducing positive psychology: Finding a place within school psychology'. Psychology in the Schools, 41(1), pp. 1-6

Cooperrider, D. L., Whitney, D. and Stavros, J. M. (2008) 'Introduction' pp. xv-xxix in Cooperrider, D. L., Whitney, D. and Stavros, J. M. (Eds.) Appreciative Inquiry handbook. For Leaders of Change. San Francisco, CA: Berrett-Koehler Publishers

Côté, J. (1999) 'The influence of the family in the development of talent in sport'. The Sport Psychologist, 13, pp. 395-417

Cruce, T., Wolniak, G. C., Seifert, T. A. and Pascarella, E. T. (2006) 'Impacts of good practices on cognitive development, learning orientations, and graduate degree plans during the first year of college'. Journal of College Student Development, 47(4), pp. 365-383

Davis-Kean, P. E. (2005) 'The influence of parent education and family income on child achievement: the indirect role of parental expectations and the home environment'. Journal of Family Psychology, 19(2), pp. 294-304 
Decovic, M. and Janssens, J. M. A. M. (1992) 'Parents' child-rearing style and child's sociometric status'. Developmental Psychology, 28(5), pp. 925-932

Delpit, L. D. (1988) 'The silenced dialogue; Power and pedagogy in educating other people's children'. Harvard Educational Review, 58(3), pp. 280-298

Desjardins, J., Zelenti J. M. and Coplan, R. J. (2008) 'An investigation of maternal personality, parenting styles, and subjective wellbeing'. Personality and Individual Differences, 44, pp. 587-597

Deutsch, N. L. and Jones, J. N. (2011) "'Show me an ounce of respect": Respect and authority in adult-youth relationships in after-school programs'. Journal of Adolescent Research, 23(6), pp. 667-688

Driver, M. J. (1982) 'Career concepts - a new approach to career research' pp. 23-32 in Katz, R. (Ed.) Career Issues in Human Resource Management. New York, NY: Prentice-Hall

Duffy, R. D. and Dik, B. J. (2009) 'Beyond the self: external influences in the career development process'. The Career Development Quarterly, 58, pp. 29-44

Dunn, D. S., Uswatte, G. and Elliott, T. R. (2008) 'Happiness, resilience, and positive growth following physical disability' pp. 651-664 in Lopez, J. S. and Snyder, C. S. (Eds.) Oxford Handbook of Positive Psychology. Oxford: Oxford University Press

Eccles, J. S. (1999) 'The development of children ages 6 to 14'. The Future of Children, $9(2)$, pp. $30-44$

Elder, Jr. G. H., van Nguyen, T. and Caspi, A. (1985) 'Linking family hardship to children's lives'. Child Development, 56(2), pp. 361-375

Fairholm, M. R. and Fairholm, G. (2000) 'Leadership amid the constraints of trust'. Leadership and Organization Development Journal, 21(1/2), pp.102-109

Fischer, A. H. and van Kleef, G. A. (2010) 'Where have all the people gone? A plea for including social interaction in emotion research'. Emotion Review, 2(3), pp. 208-211

Fredrickson, B. L. (2001) 'The role of positive emotions in positive psychology: The broaden-and-build theory of positive emotions'. American Psychologist, 56(3), pp. 218-226

Gardner, H., Csikszentmihalyi, M. and Damon, W. (2001) Good Work. When Excellence and Ethics Meet. New York, NY: Basic Books

Gettinger, M. and Seibert, J. K. (2002) 'Contributions of study skills to academic competence'. School Psychology Review, 31(3), pp. 350-365

Gilligan, R. (2000) 'Adversity, resilience and young people: the protective value of positive school and spare time experiences'. Children and Society, 14, pp. 37-47

Gilpin, J. M. (2008) 'Teaching happiness. The role of positive psychology in the classroom'. Pell Scholars and Senior Theses, 12, pp. 1-23

Goleman, D. (2006) 'The socially intelligent'. Educational Leadership, September, pp. $76-81$

Greenwald, R., Hedges, L. V. and Laine, R. D. (1996) 'The effect of school resources on student achievement'. Review of Educational Research, 66(3), pp. 361-396

Haapaniemi, T., Voutilainen, U. and Ikäheimonen, K. (2001). 'Millä eväillä ohjauskokeiluihin? [With what provisions to mentoring experiments?]' pp. 97-112 in Voutilainen, U. and Haapaniemi, T. (Eds.) Ohjaus - opiskelun voimavara [Mentoring - A Resource for Studying]. Kuopio: University of Kuopio

Hare, W. (1993) What Makes a Good Teacher? Reflections on some Characteristics Central to the Educational Enterprise. London and Ontario: The Althouse Press 
Harjunen, E. (2009) 'How do teachers view their own pedagogical authority?' Teachers and Teaching: theory and practice, 15(1), pp. 109-129

Hatt, B. E. (2005) 'Pedagogical love in the transactional curriculum'. Journal of Curriculum Studies, 37(6), pp. 671-688

Hawkins, J. D., Kosterman, R., Catalano, R. F., Hill, K. G. and Abbott, R. D. (2005) 'Promoting positive adult functioning through social development intervention in childhood. Long-term effects from the Seattle Social Development Project'. Archives of Pediatric and Adolescent Medicine, 159, pp. 25-31

Hoyle, J. R. (2002) Leadership and the Force of Love. Six Keys to Motivating with Love. Thousand Oaks, CA: Sage

Isen, A. M. (2001) 'Some perspectives on positive affect and self-regulation'. Psychological Inquiry, 11(3), pp. 184-187

Kezar, A. J. and Kinzie, J. L. (2006) 'Examining the ways institutions create student engagement: the role of mission'. Journal of College Student Development, 47(2), pp. $149-172$

Kuh, G. (2003) 'What we're Learning about Student Engagement from NSSE. Benchmarks for effective educational practices'. Change, March/April/2003, pp. 24-32

Kuh, G. D., Cruce, T. M., Shoup, R., Kinzie, J. and Gonyes, R. M. (2008) 'Unmasking the effects of student engagement on first-year college grades and persistence'. The Journal of Higher Education, 79(5), pp. 540-563

Langford, R. (2010) 'Theorizing an early childhood educator's authority for the advancement of social goods'. The Alberta Journal of Educational Research, 56(3), pp. 291-303

Larson, R. W. (2000) 'Toward a psychology of positive youth development'. American Psychologist, 55(1), pp. 170-183

Lerner, R. M., Brentano, C., Dowling, E. M. and Anderson, P. M. (2002) 'Positive youth development: Thriving as the basis of personhood and civil society'. New Directions for Youth Development, 95, pp. 11-33

Lindblom-Ylänne, S. and Pihlajamäki, H. (2003) 'Adjusting law teaching to social change: an historical perspective to legal education'. Retfaerd, 101, pp. 5-19

Linley, P. A., Joseph, S., Maltby, J., Harrington, S. and Wood, A. M. (2009) 'Positive psychology applications' pp. 35-47 in Snyder, C. R. and Lopez, S. J. (Eds.) Oxford Handbook of Positive Psychology. Oxford: Oxford University Press

Lowe, J. and Gayle, V. (2007) 'Exploring the work/life/study balance: the experience of higher education students in a Scottish further education college'. Journal of Further and Higher Education, 31(3), pp. 225-238

Määttä, K. (2012) 'The pedagogy of supervising doctoral theses' pp. 143-160 in Määttä, K. (Ed.) Obsessed with Doctoral Theses. Rotterdam: Sense Publishers

Määttä, K. and Uusiautti, S. (2011a) 'How to enhance the smoothness of university students' study paths?' International Journal of Research Studies in Education, 1(1), pp. $47-60$

Määttä, K. and Uusiautti, S. (2011b) 'Pedagogical love and good teacherhood'. In Education, 17(2)

Määttä, K. and Uusiautti, S. (2012a). 'Parental love -irreplaceable for children's wellbeing'. Global Journal of Human Social Sciences, 12(10), pp. 1-8

Määttä, K. and Uusiautti, S. (2012b) 'Pedagogical authority and pedagogical love - connected or incompatible?’ International Journal of Whole Schooling, 8(1), pp. 21-39 
Määttä, K. and Uusiautti, S. (2013) Many Faces of Love. Rotterdam/Boston/Taipei: Sense Publishers

Maddux, J. E. (2002) 'Self-efficacy. The power of believing you can' pp. 277-287 in Snyder, C. R. and Lopez, S. J. (Eds.) Handbook of Positive Psychology. Oxford: Oxford University Press

Magnusson, D. and Mahoney, J. L. (2006) 'Holistinen lähestymistapa myönteisen kehityksen tutkimuksessa [Holistic approach in research of positive development]' pp. 232250 in Aspinwall, L. G. and Staudinger, U. M. (Eds.) Ihmisen vahvuuksien psykologia [A Psychology of Human Strengths]. Helsinki: Edita

Maijala, E.-L., Uusiautti, S. and Määttä, K. (2012) 'Grandparental love: a challenge or richness?' Early Child Development and Care, 183(5), pp. 627-642

Mäkikangas, A. (2007) 'Personality, wellbeing and job resources. From negative paradigm towards positive psychology'. Jyväskylä: University of Jyväskylä

Mäkinen, M. (2000). 'Mikä minusta tulee "isona"? Yliopisto-opiskelijan ammattikuvan kehittyminen [What will I become "when big"? The development of a university student's professional image]' pp. 77-90 in Tynjälä, P., Välimaa, J.And Murtonen, M. (Eds.) Korkeakoulutus, oppimine ja työelämä [Higher Education, Learning, and Working Life]. Jyväskylä: PS-Kustannus

Maljojoki, P. (1989) Ammatinvalinnanohjauksen taustoja ja kehityspiirteitä Suomessa [Background and Development of Occupational Guidance in Finland]. Joensuu: University of Joensuu

Mayya, S. S. and Roff, S. (2004) 'Students' perceptions of educational environment'. Education for Health, 17(3), pp. 280-291

McRee, A.-L. and Halpern, C. (2010). 'Parenting style and foregone health care as adolescents' transition to early adulthood'. Journal of Adolescent Health, 46, pp. 10-11

Middleton, E. B. and Loughead, T. A. (1993) 'Parental influence on career development: An integrative framework for adolescent career counseling'. Journal of Career Development, 19(3), pp. 161-173

Numminen, U., Jankko, T., Lyra-Katz, A., Nyholm, N., Siniharju, M. and Svedlin, R. (2002) Opinto-ohjauksen tila 2002. Opinto-ohjauksen arviointi perusopetuksessa, lukiossa ja ammatillisessa koulutuksessa sekä koulutuksen siirtymävaiheissa [State of Student Counseling 2002. Evaluation of Counseling in Basic Education, General and Vocational Upper Secondary Education]. Helsinki: National Board of Education OECD (2010) Education at a glance. Available online at: http://www.oecd.org/dataoecd/45/39/45926093.pdf (last accessed 24 March 2014)

Pace, J. L. and Hemmings, A. (2007) 'Understanding authority in classrooms: A review of theory, ideology, and research'. Review of Educational Research, 77(1), pp. 4-27

Pajares, F. (2001) 'Toward a positive psychology of academic motivation'. The Journal of Educational Research, 95(1), pp. 27-35

Pascarella, E. T. (1980) 'Student-faculty informal contact and college outcomes'. Review of Educational Research, 50, pp. 545-595

Petersen, A. C. (1988) 'Adolescent development'. Annual Review of Psychology, 39, pp. 583-607

Pimparyon, P., Roff, S., Mcaleer, S., Poonchai, B. and Pemba, S. (2000) 'Educational environment, student approaches to learning and academic achievement in a Thai nursing school'. Medical Teacher, 22, pp. 359-364

Popper, M. and Amit, A. (2009) 'Attachment and leader's development via experiences'. The Leadership Quarterly, 20(5), pp. 749-763 
Prewitt, V. (2003) 'Leadership development for learning organizations'. Leadership and Organization Development Journal, 24(2), pp. 58-61

Rego, A., Ribeiro, N., Pina, M. and Jesuino, J. C. (2011) 'How happiness mediates the organizational virtuousness and affective commitment relationship'. Journal of Business Research, 64(5), pp. 524-532

Rowe, D. C. (1990) 'As the twig is bent? The myth of child-rearing influences on personality development'. Journal of Counseling and Development, 68(6), p. 606

Ryan, F. J., Soven, M., Smither, J., Sullivan, W. M. and Vanbuskirk, W. R. (1999) 'Appreciative inquiry: Using personal narratives for initiating school reform'. Clearing House, 72(3), pp. 164-167

Saevi, T. and Eilifsen, M. (2008) "'Heartful" or "heartless" teachers? Or should we look for the good somewhere else? Considerations of students' experience of the pedagogical good'. Indo-Pacific Journal of Phenomenology, 8, pp. 1-14

San Antonio, D. M. (2008) 'Understanding students' strengths and struggles'. Educational Leadership, Apr/2008, pp. 74-79

Schoon, I., Salmela-Aro, K., Silbereisen, R. K., Eccles, J., Schneider, B., Trautwein, U. and Bergman, L. (2010) Pathways to Adulthood: Towards a Unifying Framework. Available online at: http://www.pathwaystoadulthood.org/docs/unifyingframeworkdoc.pdf (last accessed 25 March 2014)

Seidl, B. and Friend, G. (2002) 'Leaving authority at the door: equal-status communitybased experiences and the preparation of teachers for diverse classrooms'. Teaching and Teacher Education, 18, pp. 421-433

Seligman, M. E. P. (2002) Authentic Happiness. New York, NY: Free Press

Seligman, M. E. P. (2009) 'Positive education: positive psychology and classroom interventions'. Oxford Review of Education, 35(3), pp. 293-311

Seligman, M. E. P. (2011) Flourish. A Visionary New Understanding of Happiness and Wellbeing. New York, NY: Free Press

Seligman, M. E. P., Steen, T. A., Park, N. and Peterson, C. (2005) Positive Psychology Progress. Empirical Validation of Interventions. American Psychologist, 60(5), pp. 410-421

Snyder, C. R. and Lopez, S. J. (2002) 'The future of positive psychology. A declaration of independence' pp. 751-767 in Snyder, C. R. and Lopez, S. J. (Eds.) Handbook of Positive Psychology. Oxford: Oxford University Press

Sroufe, L. A. (2005) 'Attachment and development: a prospective, longitudinal study from birth to adulthood'. Attachment and Human Development, 7(4), pp. 349-367

Sundvall-Huhtinen, A. (2007) 'Tulevaisuusorientaation huomioiminen nuoren ohjauksessa [Considering the future orientation in the guidance of the young]' pp. 13-22 in Helander, J. (Ed.) Reunamerkintöjä ohjaukseen II - avauksia ja aavistuksia opintoohjauksen nykyisyydestä ja tulevaisuudesta [Marginal Comments on Guidance II Openings and Hints of the Present State and the Future of Counselling]. Hämeenlinna: Hämeenlinna University of Applied Sciences

Theilheimer, R. (1991) 'Involving students in their own learning'. Clearing House, 65(2), pp. $123-126$

Uusiautti, S. (2008) “"Tänään teen elämäni parhaan työn” Työmenestys Vuoden Työntekijöiden kertomana ["Today, I'll work better than ever". Success at Work Described by the Employees of the Year]'. PhD Dissertation, University of Lapland, Rovaniemi, Finland.

Uusiautti, S. and Määttä, K. (2011) 'Love for work as the way towards wellbeing'. Global Journal of Human Social Science, 11(9), pp. 63-68 
Uusiautti, S. and Määttä, K. (2013) 'Love-based leadership in early childhood education'. The Journal of Education Culture and Society, 1/2013, pp. 109-120

van Manen, M. (1991) The Tact of Teaching: The Meaning of Pedagogical Thoughtfulness. London: Althouse Press

von Wright, M. (2009) 'The shunned essentials of pedagogy: authority, love and mystery'. Nordic Philosophy of Education Network NERA Annual Meeting, Trondheim, 5-7th March 2009. Available online at: http://oru.diva-portal.org/smash/record.jsf?pid=diva2:212954 (last accessed 25 March 2014)

Young, R. A., Valach, L., Ball, J., Paseluikho, M. A., Wong, Y. S., DeVries, R. J., McLean, H. and Turkel, H. (2001) 'Career development in adolescence as a family project'. Journal of Counseling Psychology, 48(2), pp. 190-202

Zhao, C.-M., Kuh, G. D. and Carini, R. M. (2005). 'A comparison of international student and American student engagement in effective educational practices'. The Journal of Higher Education, 76(2), pp. 209-231 


\section{Success and the influence of exogenous factors in adulthood}

\section{Introduction}

This chapter continues the analysis of the top workers' biographies. We learned in the last chapter that many factors in childhood can lead to the right track in the light of the process of success at work. However, there are many elements in adulthood life too that can influence the process.

The first purpose of this chapter is to discuss the role of social relationships in success at work. Especially interesting is to make comparisons with research on happy and long-lasting marriages and solutions that top workers have considered functional. Are there commonalities between these groups?

Second, we glance at the significance of hobbies. In positive psychology the role of activities that provide refreshment and pleasure has been long acknowledged. In this book we will view how the top workers describe the importance of their hobbies for their success at work.

Finally, we will discuss the role of leadership. Can leaders enhance employees' chances of success at work? What if they themselves could also benefit from the capability of enhancing employees' chances of success?

\section{A successful combination of work and marriage}

When moving further from the school world, dating and romantic relationship begin to take place. In this section we will discuss how success at work is connected with family and marital life. The relationship between work and family life has been studied mostly from the perspective of negative conflict (Greenhouse et al. 1987). It is obvious that the interplay between these two areas of life has positive consequences (Barnett 2004; Leiter and Durup 1996), and the positive experiences and solutions are also worth studying (see, for example. Mahoney 2002).

The combination of work and family life has been increasingly studied since women started to work outside the home (Barnett 2004; see also Aryee et al. 2005). At the same time, in the past few decades, men have been spending more and more time attending to housework and childcare (Barnett 2004). In Finland, 
social policies have also been used to encourage the possibility of combining work and family (Salmi 2004b). Indeed, financial matters are essential to this phenomenon (see, for example, Barnett 2004; Barnett and Lundgren 1998).

Barnett and Lundgren (1998) illustrate issues that spouses need to solve when making work-related decisions. Fundamentally, the decisions are based on economic and social factors and, for example, on gender-related attitudes to work. In addition, the situation in a workplace (for example, the continuation of employment) and individual factors play their respective roles in decisionmaking. In an ideal situation, spouses reflect upon their own and each other's biological, psychological and economic needs. They may end up with an arrangement whereby (1) both work full-time, standard work schedules; (2) both work full-time, non-standard work schedules; (3) one works full-time, one works reduced hours; or (4) both work reduced hours (Barnett and Lundgren 1998). From the marital point of view, whether or not spouses work together (i.e., in the same workplace) is also significant.

However, the most significant issue, from our point of view, is to understand the question of combining work and family as related to wellbeing and overall happiness and success. Special attention was being paid to how the Employees of the Year solved this question as well as to the descriptions of the long-married couples' successful solutions. Salmi (2004a, 2004b) suggests that the most productive perspective would be the one that reflects the phenomenon from the perspective of the entirety of life.

\section{The interaction between work and family}

The interaction between individuals' work and family responsibilities has become a concern of practical as well as theoretical significance (Clark 2000). According to Berscheid (2006), an understanding of human behaviour has suffered because of the propensity to forget the fact that people live in a net of human relationships for their entire lives and that most behaviour takes place in the context of human relationships. When studying successful behaviour, it is important to examine how environmental factors and people's mutual relationships affect the development of self-concept (Caprara and Cervone 2006; Magnusson and Mahoney 2006).

In addition, Aspinwall and Staudinger (2006) note that many human strengths are based on the person's relationships with others; in other words, they are relational or collective by nature. For example, one's ability to understand and cope with various problematic life situations is strengthened if one has an opportunity to discuss the problem at hand with a close friend, swap opinions and reflect on the issues from new perspectives.

Social roles play a significant part in an individual's life. Frone (2003) refers to family-work balance in this matter. Imbalance between social roles may produce stress that further affects different areas of life as well as the individual's health and wellbeing. Most studies have focused on the work-family conflict; 
however, Frone (2003), for example, defines work-family balance as a lack of conflict or interference between work and family roles.

According to Clark's (2000) theory about work and family balance, people are daily border-crossers between the domains of work and family. The theory addresses how domain integration and segmentation, border creation and management, border-crosser participation, and relationships between bordercrossers and others at work and home influence work-family balance. Concepts, such as permeability, flexibility and blending are used to describe the border between work and family. Permeability refers to the degree to which elements from one domain enter the other. Flexibility is the extent to which a border may contract or expand depending on the demands of one domain or the other. When a great deal of permeability and flexibility occurs around the border, blending both work and family creates a borderland that cannot be called by either domain (Clark 2000).

In considerations of the connection between work and family, it is important to reflect both on how work influences family life and the kind of influence that family life has on work (Frone et al. 1992; Gutek et al. 1991), whether it is strengthening or conflicting (see, for example, Aryee et al. 2005). The hypothesis of the strengthening effect of multiple roles (see, for example, Rantanen and Kinnunen 2005) is of great contemporary interest as it concerns both genders - as well as other family members. Recent studies have shown that it is not just about making compromises but, for example, that positive paternal involvement influences the multiple domains of children's lives from birth through adolescence (see, for example, Hawkins et al. 2008).

We combine here the results of two independent studies in order to reflect the successful combination of work and family, and to discover the kinds of solutions that are adopted by couples who have been married for more than ten years (Määttä 2005) and by the top workers who have been nominated as Employees of the Year in their own occupation (Uusiautti 2008). By uniting these two perspectives, the purpose is to give a unique description of how both family and work roles can be combined in order to facilitate success both at work and in family life.

\section{The magnitude of shared worlds}

Crucial among solutions employed by happily married couples in relation to their time division between work and family was their willingness to make compromises in the face of different kinds of aspirations and foci. This can be defined as the magnitude of their shared world. It covers all the thoughts, feelings, activities and happenings that spouses share. The magnitude of this world depends on the extent to which spouses occupy the other worlds, and how much and in what way they appreciate and value their relationship compared with their other activities, such as their own friends and hobbies, and whether or not these activities are common between them. The solidity of a relationship derives from mutually 
shared activities; the stronger and more frequent the interaction between spouses, the more solid their relationship will be. Nevertheless, solidity does not result from activities that suppress or fail to appeal to either one of the spouses.

Shuttling between work and family was one of the salient issues disclosed by the Employees of the Year. Everyone had to make choices and come up with solutions of some kind in relation to this matter. The best situation was when a balance was found between these two areas of life. Thus, the Employees of the Year considered their intimate relationships and family as one of the most important factors enhancing their success at work. Some differences could be found in the top workers' experiences of how work and family could be successfully combined. These solutions depended a great deal on whether the couple had children or not.

\section{The balance between family and work according to long-lasting and happily married couples}

Married couples could be divided into three categories based on the time they spend together and the feeling of togetherness they share. The first one represents an intimate, family-oriented relationship that can be called 'Our Marriage'. The spouses had a strong affinity to each other; they were well integrated and spent their spare time with their family, made decisions together, and were willing to make the effort to solve and/or avoid disagreements. Their relationship was epitomised emotional intimacy; they enjoyed each other and being together.

'Our happiness is often based on work as we are surely able to collaborate.'

'The existence of the other is unquestionably important, and we are able to support each other.'

'A shared hobby makes us closer, and it is nice to discuss the subject at home with your spouse.'

This is in line with previous research as well. It has been found that the perceived superiority of one's own marriage is also strongly related to marital satisfaction (Buunk and van der Eijnden 1997).

The second category consists of couples that are happy together but as individuals. This kind of marriage of two individuals can be described as 'Our Marriage of Two Individuals'. They are integrated, but they tend not to avoid disagreements and do not endeavour to achieve a consensus. They spend a great deal of their leisure time together and have a high opinion of each other, but they also have personal interests outside of the family, such as their work. Despite being interdependent, they also emphasise their independence.

'We got married 12 years ago and being a wife of a traveling worker, I have to be strong-minded and believe, hope and love, forgive, and stretch, too... To be honest, sometimes it is nice for both of us to be alone from time to time.' 
The third relationship model represented a marriage that lacked interdependence or shared activities. This kind of relationship could be called 'The Marriage of Two Individuals'. There was no communication between the individuals, and they were unwilling to make compromises in conflict situations. These kinds of couples tended to stay together because of habit and convenience or because of their inability or reluctance to start divorce proceedings. They might have thought that this way of life would perhaps be better than living alone.

'My husband is a workaholic, whose home is his workplace - I am a mother whose home is her whole life. External issues, happenings, or people have not threatened our marriage; but time and everyday life have flattened and faded the flush of love. We have seldom been anywhere together because we have children and "we do not have time".'

\section{Work-family balance from the perspective of employees of the year}

Combining work and family is mostly instantiated through the organisation of schedules. In everyday life, this has to do with the number of hours that one works and how much time is being spent at home with family. The Employees of the Year alluded to various solutions based on their situation at home: whether they had children and of what age; whether their spouses worked; or whether they even had a spouse. The results introduce three categories with examples of the top worker's decisions concerning work-family balance.

Family-oriented top workers made decisions in relation to organising more time with their small children. One top worker had a brilliant career before having children but stayed at home while the children were very young. Returning to work was difficult and the emotions were inconsistent. The support and conversational companionship that her spouse provided was the most important factor enhancing her return to work. This top worker had also discussed her work openly at home, which had consciously made these two areas of life apparent to all of family members.

'I thought that both my work and being at home were important. The whole rigmarole, which lasted ten years when the children were small, is something that I do not even remember well. And eventually, it did not matter whether you were at work or at home. I think that my spouse's support and our communication were significant. He is smart and does not want to control my life. I allow every family member to become acquainted with my work because I wanted them to be part of it, and vice versa, in a way that my work would not be an area of life that my family knew nothing about. And I hope that this has enriched their knowledge of work life too.'

The other top worker had a business of his own and worked from home. The reason for this arrangement was that he wanted to be available for his children 
while also making a living. He became highly appreciated in his field, but his work never threatened his family as he always considered his family as the first priority. He emphasised that these two areas of life should be in balance. Of course, this negatively affected the family's incomes, but on the other hand, this top worker preferred having his life in his own hands and did not want to sell his principles for money.

'Basically, I have been at home all the time. When the children came home from school, I was here... But sometimes, it was financially tight. I have never wanted to work day and night. I can surely stretch but I do not want to sacrifice all my life for work. People should understand that too and not just strive for profits all the time. People should think about what they want to do with their lives.'

The relationship between work and family can also be described with the use of models that focus on multiple roles. The hypothesis of the burdening effect of multiple roles is based on an assumption of scarcity. Accordingly, the resources that an individual possesses are limited thus, multiple roles exhaust these resources. This implies that the resources spent at work diminish those that can be used at home and vice versa. On the opposite end of the spectrum is the hypothesis of the strengthening effect. According to this, an individual's resources tend to recur and increase particularly as a result of new roles. Consequently, both roles (work and family) are seen as enhancing capacity in both areas of life. This aptly describes the previous top workers' actions.

Two of the top workers had positive experiences with the combination of work and family - 'having them both'. Both of them were dedicated to a demanding job with irregular working hours. The solution to combine work and family was twofold: firstly, they wanted to give priority to their small children, and secondly, they planned their schedules in unison with their spouses. As they had irregular working hours, they tried to adjust their schedules with their spouses in a way that either one of them was at home with their children during their free time. Therefore, everything was based on mutual agreement, and they were strict about prearranged schedules.

'When my children were young, we had a system. They were in part-time day care, only ten days a month. I spent all my days off at home, as did my spouse, though not at the same time as I did. It went quite well like that. And we spent a lot of time with our children.'

'We made the effort to plan schedules together. I had irregular working hours but my spouse had standard ones. He was at home during my busiest seasons at work.'

Indeed, couples who value and strive for egalitarian relationships are often faced with new challenges upon the birth of their first child (Koivunen et al. 2009). 
Although combining work and family in this way may seem difficult, the Employees of the Year were content with their solutions because they enabled both spouses to work and take care of the home. Barnett and Hyde (2001) champion such solutions as they are of the opinion that versatile roles (i.e., work and family roles) benefit our psychological, physical and social health; and this is true for both sexes. A strong commitment in one role does not inhibit a similar commitment in the other.

Additionally, this solution has an effect on several other processes too: the family's income level increases, the experiential spheres of both spouses widen and the chances to succeed increase. Last, but not least, their work and family life experiences become similar.

Notwithstanding, some of the Employees of the Year wanted to keep these areas of life separate from each other; they were clearly 'work-oriented'. They had the possibility to concentrate on their careers and their spouses took care of the home. They emphasised that the solution was jointly agreed with their spouses and that their spouses understood the nature of their demanding job.

'I have not had any problems... My spouse is at home and this is a sort of a back rest for me, enabling me to work. And I have had support and encouragement from home and my spouse takes care of everything at home so well. I do not have to worry about whether everything is fine at home or not. I can concentrate on my work fully.

My family has been understanding; even the kids have, in their own way... I am married to my work as much as I am to my spouse.'

One of the top workers was in a similar situation but he had no children. He too had a demanding job with irregular working hours, which could have been be a strain on the relationship. However, that was not the case as his spouse was in a similar situation, having started a new business and being busy with that. The irregular rhythm of life was thus a matter of course for them and they did not consider it problematic or burdening to their relationship.

One of the top workers was single so he did not have similar experiences, nor did he have solutions to consider like his Employees of the Year counterparts. Instead, he found it occasionally difficult to separate work and leisure as his present circumstances meant that it was relatively easy to dedicate himself completely to work; work days tended to be prolonged and some tasks were done at home. This shows that spouses and families do not only demand time and effort but they also require balance and contentment that does not involve work.

\section{Ability to compromise}

One thing was certain; all Employees of the Year had succeeded in their work and were rewarded for excellence. Additionally, they considered consensus and concordance with their spouses more important than enhancing their careers as 
feelings of guilt frequently pervaded their thoughts when they worked long days instead of being at home. Further reflection on the data on married couples revealed that the only common feature was that they had been married for a long time, over ten years, whereas marital happiness and satisfaction varied according to their mutual appreciation and respect for their marriage and togetherness. This appreciation and respectful attitude toward each other and their relationship appeared to connect the two studies.

Whereas the married couples were categorised according to those who were tightly bonded to each other and those who lived together but as individuals, the top workers were located between the dimensions of family-oriented and workoriented individuals. In considerations of successful marriage, on the one hand, and a successful combination of work and family, on the other, one fundamental dimension comes to the fore namely, the ability to compromise.

It is not easy to draw conclusions of marital happiness from Employees' of the Year narratives. Who would not want to succeed at both work and family life? This is, however, easier said than done. The solutions may vary but fundamentally it is all about finding one that satisfies both spouses. There is no single model, however. It is crucial to determine the kinds of compromises that spouses are willing to make and whether one has different hopes and emphases than the other. The ability to be realistic is also relevant here; the understanding that one cannot have everything appears pertinent to success in both work and marriage. Thus, the ability to take pleasure in the achievements and best sides of work and family life eases the compromises. It is the ability to bend and adjust - without forfeiting anything of primary value. None of the top workers wanted to become a martyr in the process of making compromises. It was not about neglecting oneself but a realistic and practical weighting of the possibilities and promises of life. The level of intrinsic motivation that the Employees of the Year experienced in their work due to favourable working conditions (such as the experience of meaning, responsibility for outcomes and knowledge of results) may also have enhanced their ability to make compromises and appreciate the other at home and in the marriage (see, for example, Oh and Lewis 2009).

Combining work and family responsibilities is a topic of considerable current interest, which also concerned the Employees of the Year. Many theories describe career-related solutions more as individual decisions (Barnett and Lundgren 1998), not as shared with spouses or the family as a whole. Employees of the Year disagreed with this; they thought that it was crucial to make career-related decisions together with their families. All solutions were unique, varying from equal division of labour between spouses to a situation in which one was working and the other took care of the home. Regardless of the solution, the main point was that it was made jointly by considering the aspirations and situations of both so that neither partner had to sacrifice his or her career for the other. The same phenomenon can also be seen as a prerequisite for a successful marriage. Couples who made an effort to listen to each other and who tried to find a common ground appeared happiest. 
A study conducted in Sweden (Evertson and Nermo 2007) suggests that compromises relating to the sharing of housework remained unusual; despite the increasing involvement of women in work outside the home they continue to perform the majority of household tasks, and a woman's economic dependency on her spouse is related to her share of the housework - this may also lead to decreased levels of marital satisfaction (see also Koivunen et al. 2009). Furthermore, for men in the dual-earner couples, the relationship satisfaction was associated with positive family-to-work spillover whereas satisfaction with the housework arrangement was related to women's positive spillover. With both men and women engaging in more non-traditional gender roles in work and family domains, there is great need to understand the impact of these roles on each domain (Perrone et al. 2009).

Having a family does not prevent one from also having a successful career. It seems that more important is the readiness to make compromises and to take both spouses' hopes into consideration. According to our interpretation, the most plausible and successful solution is not necessarily to share all duties equally. Neither do the spouses have to always be together. Both spouses can maintain some level of individualism in marriage (see also Frisco and Williams 2003; Judkins and Presser 2008).

\section{Time for hobbies}

In considerations of wellbeing and success at work, hobbies and free-time activities often take the backseat. Leisure is not considered as important as other areas of life, such as work and family life. Moreover, Csikszentmihalyi (2008: 159) asks cleverly why people usually would like to work less and spend more time in leisure given that: 'on the job people feel skillful and challenged, and therefore feel more happy, strong, creative, and satisfied. In their free time people feel that there is generally not much to do and their skills are not being used'.

In this section, we want to analyse the importance of hobbies and leisure for success at work. Our fundamental assumption is that the pleasure of doing and positive emotions are quite important to one's holistic, daily wellbeing - and freetime activities offer an excellent context for these experiences. One reason for this is that activities done in free time are usually voluntary; people do what they find enjoyable (Carruthers and Hood 2005).

Likewise, positive psychology wants to pay more attention to the significance of hobbies from the point of view of deriving pleasure and positive emotions. Positive emotions are connected to physical health (for example, the prevention of physical stress symptoms), mental health (for example, positive coping strategies), and social health (for example, friendships and social support), which refers to the fact that happy people are more likely to build happy and reciprocal human relationships than unhappy people (Carruthers and Hood 2005).

The conclusion is that if one's hobby provides positive experiences and thus enhances happy and balanced life, it will also promote success at work - indeed, physical, mental and social health are needed in work life too. This is also 
acknowledged in many workplaces internationally, as McGillivray's (2005) shows that health and fitness programmes, for example, now make up a significant component of wider organisational wellness or workplace wellness programs - although their positive influence seems to focus more on physical health than on mental health (see, for example, Griffiths 1996). Instead, Tuomi et al. (2001) find that in addition to favourable work characteristics (such as autonomy and opportunities for personal development), support for physical activities and hobbies, as well as possibilities for development and training both at work and during leisure, influence higher work ability and, furthermore, higher quality of work and the enjoyment of staying in one's job. Among older workers, these features were also connected to active and meaningful retirement.

Myers and Diener (1995: 15) remind us in their study on 'Who is Happy?' that while work provides this 'sense of pride and belonging to a group', which helps 'people construct their social identity', work is not always satisfying; people can become overwhelmed or underwhelmed. The type of flow described in earlier chapters of this book is not always guaranteed in top workers' jobs either. Therefore, a life-balancing hobby can become an important part of the life of successful people.

\section{Hobbies provide counterbalance}

However, the significance of leisure was not completely absent from top workers' narratives. The Employees of the Year tried to unwind from their arduous work schedules and emphasised the significance of a good hobby. Hobbies were seen not only as a counterbalance to work but also as an activity that provided resources for work. Notwithstanding this, counterbalance was no less important; in fact, a positive relation between feeling recovered during leisure time and job performance over time has been proven (Binnewies et al. 2009).

For one top worker, a hobby turned into a profession; he was a handicraft artist. In this case, his hobby had considerably influenced his career choices. According to this top worker's interview, he had never been interested in studying and schooling. Instead, he enjoyed practical stuff. Therefore, after compulsory education, he found it natural to have his artistic hobby as a profession.

'Basically, I chose my occupation after somehow finishing basic education. Not then however, who, at least not I, would think that handicraft could be or become a profession. You know, I did not like going to school, so I saw an opportunity there. I could have a better occupation by entering this side door without studying. I did not want to go to school at all. I had been doing this ever since my early childhood, because my dad had a small hobby carpenter's shop. I did quite a lot of work there.'

Three other top workers described their hobbies and recognised the importance of these hobbies in their lives. Those who mentioned their hobbies seemed to take them seriously. Hobbies can enrich work, offer a balance to demanding work or become an option for an alternate profession. 
For example, the priest enjoyed reading and writing both novels and poems in his leisure time. This also enhanced the writing skills needed for his work, such as writing sermons, speeches, articles, etc. In addition, the priest found that reading both professional and fiction works was very important for his profession. However, writing was the priest's most important hobby. It also offered a loophole in case a change of profession felt sensible at some point.

Another top worker described her long-term commitment to voluntary work. She considered this hobby as a counterbalance for work. Furthermore, as her retirement age was quite close at the time of the interview, she also regarded voluntary work as her prospective substitute for paid work. After retirement, she was planning to devote her time to voluntary work.

A third top worker had a different kind of hobby; he sang and played in a band, even gigging. However, this hobby had benefitted his work too because it had brought him publicity and coverage. Through his band, he participated in the planning of the theme year for his union; he composed a theme song, etc. Partly, he thought that all this activity could have played a role in him being rewarded Employee of the Year. At the same time, he recognised all the other benefits, some more important than others (such as wide social networks), for his day job.

'2005 was the theme year. And I participated quite a lot in the planning. So I was very visibly a part of this thing. And I have this band too. Our band composed the theme song...'

\section{Hobbies can expand your competence}

The aforementioned descriptions seem to speak to the importance of good hobbies as a component of success at work. A good hobby does not only help to relieve work-related pressure or direct thoughts away from work; it can have other, even surprising, benefits for work and life outside work. Hobbies provide resources for coping, but they can also help create and maintain social relationships and networks, as the third example above gives reason to believe.

In addition, hobbies may provide a way of increasing one's competence, skills or knowledge in a pleasant manner. As with any other employees, top workers' expertise develops incrementally and skills learned in leisure can eventually boost learning and development at work in a considerable manner. Achor (2010) talks about a 'Zorro circle', referring to ways in which we can achieve goals in jobs, careers and personal lives. By first limiting the scope of efforts and accumulating resources, knowledge and confidence to expand the circle, success can be achieved. This progress is similar in all hobbies; even if you jog as a hobby, you will have to gradually build your physical stamina, learn how to regulate your speed and select suitable clothes so that it can become pleasant and rewarding. The same behaviour can be adapted for work and, if the hobby employs similar skills used at work, it seems natural to think that the benefits are multiplied.

Hobbies also help to regulate negative emotions and moods as they ignite and strengthen positive emotions. In addition, hobbies are often social in nature and 
are usually enjoyed with other people. Therefore, they strengthen social relationships and provide support from a social perspective (Reed and Buck 2009). Perhaps relating to the point of view of success at work, it is important to note that employees can adopt new useful skills, widen awareness and self-knowledge, or even create better social networks. All these can help them face and seize challenges and opportunities at work and in life in general (Carver et al. 2009).

\section{Caring leaders encourage employees to succeed}

Next, we want to turn our attention to leaders and their chances of enhancing or supporting employees' success. We argue that leaders have the possibility of creating such work conditions and atmosphere as enhance positivity in workplaces. This viewpoint is based on our studies on the ideology of love-based leadership; but in this section we will focus on it from the particular viewpoint of success.

The role of emotions in the leadership process has attracted increasing interest in recent years and leaders' emotional expressions are typically more important to followers than the objective content of their communication (see Glasø, and Einarsen 2008). Emotions and emotional intelligence can even be considered as the heart of effective leadership.

Furthermore, an ethic of caring establishes a moral touchstone for decisionmaking as opposed to guiding principles that one blindly follows (Hoyle 2002). It has also been argued that when leaders consistently exhibit love, forgiveness and trust in relationships their employees respond with increased commitment and loyalty.

Bass (2000) describes the important role that emotions play in contemporary leadership by contrasting 'transactional' leaders with 'transformational' leaders. Traditional transactional leaders focus more on mutual transactions and the exchange of rewards for performance and efforts between the employee and the employer instead of considering affective experiences. Transformational leaders project a vision that their followers believe in, inspire and support the followers, and make them feel wanted and valuable to the organisation. The latter leadership type corresponds to our conception of a loving leader.

Current understanding that wellbeing is not only valuable because it feels good but also because it has beneficial consequences makes a loving management imperative in the workplaces. According to Rego et al. (2011), fostering organisational virtuousness (for example, through honesty, interpersonal respect and compassion; combining high standards of performance with a culture of forgiveness and learning from mistakes) improves employees' affective wellbeing and promotes a more committed workforce. Considering these findings and mirroring the growing contributions of positive psychology (for example, Buss 2000; Gable and Haidt 2005; Seligman et al. 2005), it seems clear that a 'positive-people-management' perspective should be considered internationally by both practitioners and scholars (see Calori 1995). 
Sensitive and loving leaders develop a culture that demonstrates concern for individual needs in the workplace (Fairholm and Fairholm 2000), but consider and support their followers' personal lives as well (Ransford et al. 2008). Yet, an organisation in which employees are happy should also make a profit in the economic sense. However, these two factors are not mutually exclusive. It has been shown that effective leaders are sensitive and responsive to their followers' needs by providing advice, guidance, as well as emotional and instrumental resources, by supporting employees' creativity, initiative, autonomy and the desire to meet new challenges and develop and acquire new professional skills, thus enhancing their self-worth and self-efficacy (for example, Popper and Amit 2009).

Happiness not only results in a quantitative improvement by increasing efficiency but also a qualitative one by making a better product or outcome by virtue of pride, belief and commitment to one's job. Happy employees exhibit higher levels of job-related performance behaviours than do unhappy employees (Wright 2004).

Therefore, emotions are also given prominence in leadership (Campbell 2007). It has also been stated that authentic leaders are 'as guided by the qualities of the heart (passion and compassion) as by the qualities of the mind' (Avolio et al. 2004: 805).

Love in leaders' work can also be considered from the perspective of the interpersonal nature of emotions. According to Fischer and van Kleef (2010), it is indisputable that emotions are mostly reactions to other people, that emotions take place in settings where other people are present, that emotions are expressed toward other people and are regulated because of other people: therefore, the elicitation of love by understanding other people as the cause, target or third-party observer of these emotions is necessary for leaders.

\section{How do leaders describe love-based leadership?}

Finnish and American university leaders (for example, deans, department heads, etc.) were interviewed as a part of the Love-Based Leadership research project. They maintained that their role in turning a vision about the state or future of the organisation or work unit into reality was very satisfying when they could attain a caring leadership style. On the other hand, the process of attaining caring leadership did not necessarily have to be that lengthy or be related to a vision. Some university leaders found positive experiences in their daily work, and derived a feeling of success from the smallest accomplishments:

'I think that I get plenty of positive experiences, and they keep me going as an employee. Without these experiences, I couldn't do this job, really. At times, I'm quite frustrated ... so sometimes you can enjoy the simplest successes.'

(Finnish leader) 
Likewise, they described taking active and prompt action when they saw something that should be done or corrected:

'Three people were emailing each other quite blood-and-thunder messages, and so I intervened. It seemed to me that I had to solve it and we did, at least for a while.'

(Finnish leader)

'It's action, all right. You don't just sit there and ponder, like, oh my God, what am I going to do? You just go over there and say, hey, what's wrong, what are we doing wrong? ... and say, this is what I understand we're doing wrong. You go and make it right. It's all about action. So I think that's the thing I probably did best.'

(American leader)

Leaders' actions brought about the types of positive feelings that one may experience after active, motivated and engaged effort. In addition, when a leader handles issues in an active way, he or she simultaneously sets an example for followers who may find the action energizing. One of the leaders noted this as follows:

'When I was a dean at XXX University, I actually had breakfast in XX, lunch in the middle of the state, and dinner at the far end of the state. And I came back that night. Once my staff knew what I was doing that day, it energized them.'

(American leader)

The third category covers experiences of success that relate to working for others or for the common good. Leaders can consider their position as an opportunity to enhance work conditions and employees' positive development and thriving - this can improve their own wellbeing too, not to mention the efficiency of work units.

'I was the person in this faculty who attended every meeting and brought out the faculty's and students' voices. I noticed that afterwards everything turned out as I had hoped, so I could say I succeeded in that way.'

(Finnish leader)

'I guess the greatest successes that come to mind first have something to do with organizational development and the handling of conflicts among staff. Having discussions with people and reorganizing duties within the organization, I have made at least half a dozen people so happy that they are never absent. And they sort of find their work valuable and meaningful and feel that they are being heard and treated well, and they feel good. I think these things make me proudest.' 
What was emphasised in these interviews was a sort of humane, caring leadership, the core of which was the leader's authenticity and self-knowledge. One of the US interviewees talked about servant leadership; another referred to caring leadership; and a Finnish leader described it as dialogic leadership. However, this kind of leadership was seen as a means of achieving benefit for all.

\section{Employees' success is the leader's success as well}

The findings here are in line with those of Kinnunen et al. (2008) who maintain that increasing the rewarding aspects of work is an effective means of both reducing staff turnover and increasing engagement among leaders. Moreover, Schunk and Pajares (2005) have noted that a positive perception of one's efficacy improves one's performance and wellbeing in numerous ways. The positive experiences of leadership reported in this study can also be compared with those described in a study by Hakanen et al. (2008). They find that job resources (for example, autonomy, immediate feedback and rewards) are crucial to true wellbeing and motivation at work, or work engagement, as it is sometimes called.

When everyone in a team is excited and inspired by the task and reaches for a common goal, a successful outcome may produce the most delightful experience (see also Losada and Heaphy 2004). Naturally, workplaces are replete with problems and conflicts, and the purpose is not to turn a blind eye to these facts. Rather, we seek to highlight the power of positive experiences. Seligman (2002: xi-xii) has wisely stated: 'There is not a shred of evidence that strength and virtue are derived from negative motivation.... Experiences that induce positive emotion cause negative emotion to dissipate rapidly. The strengths and virtues function to buffer against misfortune and against psychological disorders'.

The leaders in our study emphasised working for the good and the use of reciprocal feedback practices that enhance positivity in others (see also Avey et al. 2011). This view shows the significance of caring leadership in action; it may be directly connected to productivity among followers as a result of leaders creating a positive and encouraging working environment; it may also have this effect among leaders themselves (see, for example, Hoyle 2002).

'I try to empower my team of chairs. They're the ones that I really want out there leading... So I try to work through them, and I've spent a lot of time pruning that group, developing that group, trying to coach those people. And I see their success as really my success.'

(American leader)

\section{Leaders' flow as the booster of everyone's success}

Mihaly Csikszentmihalyi (2008) begins his comments on flow at work by saying that 'Like other animals, we must spend a large part of our existence making a 
living' (p. 143), but continues 'Because work is so universal, yet so varied, it makes a tremendous difference to one's overall contentment whether what one does for a living is enjoyable or not' (p. 144). He is talking about an ultimate phenomenon that can occur in various areas of life; that is an autotelic experience; a total feeling of becoming absorbed by one's doing and which contributes to one's perception of satisfaction with life.

The concept of flow starts to be quite a familiar one among researchers of behavioural sciences, and yet, it is extremely adjustable with new positively toned research trends such as, for example and especially, under the umbrella paradigm of positive psychology (Hakanen et al. 2008; Isen and Reeve 2006; Snyder and Lopez 2002). In this section, we discuss the phenomenon in workplace environments through a new leadership concept, love-based leadership, and analyse the connection between flow and success at work. The viewpoint is unique; here, we address the state of flow through leaders' experiences. The ultimate purpose is to view how the positive work conditions can occur in workplaces, how leaders can enhance this kind of absorption to work, and how leaders' flow is connected to the overall satisfaction and wellbeing at workplaces.

Our purpose here is to analyse the concept of flow from the point of view of positive psychology and its core concepts, happiness, wellbeing and positivity. This particular study focused on the positive experiences and the manifestation of flow as a part of love-based leadership. Csikszentmihalyi's (2008) list of the eight elements of flow was used when analysing the leaders' positive experiences because it also provides illustrative examples of the multidimensional nature of flow; being absorbent in one's doing consists of many factors and flow can occur for numerous reasons. In order to be called flow, one or more of the following elements should typify the experience.

\section{Challenging activity that requires skills}

In flow it is important that one's skills and abilities match the work at hand. It has been shown that the optimal work experience can lead to high motivation and activity in work. A leader's work is something that obviously has high psychological demands (Kinnunen et al. 2008) and, as a result, it can provide numerous varied opportunities for high-level use of one's skills. However, not everyone is a leader instinctively but one has to find the position suitable to oneself. This fit was emphasised by the leaders.

'Well, I think some people don't really like the political dimension of leadership. And I think your reason for going into leadership has a lot to do with that. But I think that some people don't feel comfortable in the political role. They don't feel comfortable in the public eye.' 
'You as a leader have to have quite a strong self-esteem with what you are doing. Always when leading other people you face the fact that everyone is not satisfied and you have to make difficult decisions. That is your job.'

(Finnish leader)

Indeed, leadership is a strength (Seligman et al. 2005) that is more peculiar to some people than others. The leaders interviewed in our study referred to the political nature of leadership and that one being in such a position has to feel comfortable in it. From this perspective, the position can be seen as a combination of leadership strengths, categorised by Rath and Conchie (2008) as execution (making things happen), influence (selling ideas inside and out of the organisation), relationship building (being the glue that holds teams together), and strategic thinking (focusing on the big picture and the future). When the leader's skills match with these kinds of challenging activities involved in leadership work, flow can occur.

\section{Merging of action and awareness}

As mentioned earlier, flow occurs as experiences of being absorbed. This means that one concentrates fully on what one is doing instead of thinking about something else; the level of the focus of attention at work is the key in this element of flow (see, for example, Gardner et al. 1989). Clarity of goals and immediate feedback, which will be discussed next in this section, lay the foundation of this experience.

'It's action, all right. You don't just sit there and ponder, like, oh my God, what am I going to do?'

(American leader)

University leaders described events like this by talking about processes they had followed persistently or about the nature of their action as leaders. Their workload is, naturally, heavy, which means that they have to consciously focus on their tasks at hand. The leaders in this study described taking active and prompt action when they saw something that should be done or corrected. At their best, these actions provided leaders with satisfactory work experiences.

'I was really happy that I handled that issue so quickly.'

(Finnish leader)

\section{Clear goals}

In flow, one always knows what has to be done, and an enjoyable job always has clear goals (see also Maier and Brunstein 2001). The work leaders doing is special by nature when it comes to the goals of their work. Often they are the ones 
who have to define or have the possibility of defining the goals not only of their own work but for that of their followers too.

'I have a particular vision of what a research university should be like. I've tried to invest in activities that will make the vision more real.'

(American leader)

The university leaders in the data described situations that had successful endings or outcomes due to them having used their leadership skills. They were able to give many examples of such situations or chains of events in which the foci or goals of the action were at the center. These kinds of positive experiences were described as follows:

'It is a long process finding the right direction. When we are able to discuss and change course in a direction that leads to a good outcome and we are all satisfied with it; those are the best experiences of success.'

(Finnish leader)

\section{Immediate feedback}

In addition to the fact that one knows what has to be done (the goals), flow always requires information about how well one is doing. Immediate and clear feedback should be, therefore, received usually from the activity itself, allowing the person to know he or she is succeeding in the set goal (see, for example, Jackson and Marsh 1996), whereas maintaining flow in an unresponsive work unit can be difficult or impossible. Positive feedback received from others was very much appreciated. However, regardless of how positive or negative the feedback provided by co-workers was, more important is that it should be given in context and related to their actions. The university leaders liked positive feedback because it boosted intrinsic motivation (see also Isen 2001; Isen and Reeve 2006; Ryan and Deci 2000).The fact that feedback had to correspond the university leaders' intrinsic conception of their work tells us that the leaders could also provide feedback to themselves. Actually, this is in line with the conditions of flow too.

'So, I had almost hundred percent positive feedback all the way. It's flattering; they don't even know what they're talking about.'

(American leader)

\section{Concentration on the task at hand}

After the merging of action and awareness, distracting issues do not bother when doing the task at hand. Leaders emphasised the ability to focus on the person coming to talk to you or on the event they have to handle as leaders. The ability 
to exclude distractions was seen as important in leader's work, especially when it came to the love-based action. This means that leaders wanted to show their concern and willingness to understand and to see the employee's perspective by being present in the situation of talking with others.

'You have to be able to be present in situation.'

(Finnish leader)

The leaders also expressed their willingness to do their share and raise the spirit at the work unit by showing the way through their own work:

'Once my staff knew what I was doing that day, it energized them.'

(American leader)

On the other hand, the process of attaining caring leadership can emerge from very small accomplishments in leaders' work:

'It doesn't have to be anything more than just finishing some paper or email.'

(Finnish leader)

All of the afore-mentioned examples show the range of elements in leaders' work requiring concentration. In addition, they show that if the leaders find the pleasure from accomplishing these tasks, and if they openly show their excitement to their followers, the positive state can contribute to the work spirit of the workplace. Perceiving this positive outcome can act as a significant component of flow as well.

\section{The paradox of control}

The most enjoyable experiences allow people to exercise a sense of control over their actions. This means that rather than thinking of the actual doing, they feel the possibility of control. In a leadership position, it can manifest itself as a leader's perception of how action can influence in the big picture; the feeling of power can even become addictive. The leader's feeling of capability and being in the right job assures about the leader's proficiency - and the feeling of control.

'So, we' $\mathrm{d}$ meet and talk about how things are to move and I don't go on down and telling people that this is the way it's gonna be. You know, I want them to know that the whole pattern needs to flow through the organization.'

(American leader)

\section{Transformation of time}

One of the most common descriptions of optimal experiences is the perception of time and how it does not seem to pass in a way that it ordinarily does. Many 
people have experienced these changes in time. This was common to the university leaders too, but merely through the realisation that leadership was something demanding and time-consuming, and that in order to be a good leader one has to become free 'from the tyranny of time' (Csikszentmihalyi 2008: 67).

'Good leadership takes time. You just can't do it, you can’t be on a clock.'

(American leader)

This notion was also manifested through negative leadership experiences. The leaders reported how they would like to have more time to do their work properly, especially in people management.

'I think a good leader needs to spend time and talk with people and also listen to them. You know, not just talk at them.'

(American leader)

\section{The loss of self-consciousness}

The loss of self-consciousness is an interesting part of flow because it eventually leads to increased self-awareness. The foundation of the loss of self-consciousness is in the clear goals, stable rules and suitable challenges and, therefore, they involve a low risk of the self being threatened.

'I think every leadership position that I've had just made me feel more alive.'

(American leader)

At the same time, when being wrapped up in one's doing, flow requires a very active role for the self. This means that in order to fully employ one's abilities, and even exceed one's skills, one has to have a good self-conception, a profound understanding of one's self (see also Mäkikangas 2007). When considered from the point of view of leadership, this idea actually comes close to the concept of authentic leadership. The university leaders described the meaning of authenticity and self-awareness as follows:

'You lead people more or less with your personality.'

(Finnish leader)

\section{Could leaders' flow be spread among employees?}

Why is it necessary to study flow and, better yet, why study leaders' flow? The first reason is that whenever people are in flow, they report it as a much more positive experience than the times they are not in flow (Csikszentmihalyi 2008). In addition, Csikszentmihalyi (2008) reports that managers and supervisors would experience flow at work more frequently than, for example, clerical or 
blue-collar workers. Therefore, our leader data functioned well as the foundation of analysing flow states from the point of view of success at work. However, we also wanted to expand the perspective and contemplate whether leaders' flow could also contribute to the success of others at work.

The reason is that we wanted to analyse its manifestation in relation to the caring leadership. As the previous descriptions of flow-like leadership experience showed, as the leaders surfaced caring leadership practices and their experiences, they also described enjoyment in leaders' work.

Earlier in this chapter, we defined caring leadership as 'a process accomplished successfully through the exercise of one's leadership; individual successful events and the accomplishment of everyday duties; the leader's own actions that promote mutual good; and timely feedback given in context' (see also Uusiautti 2013). This all leads to the 'perceived meaningfulness', one of the basic tenets of positive psychology (Seligman 2002), and one connected to flow as well, enhancing people's productivity, engagement (Hakanen et al. 2008), problem-solving skills (Carver and Scheier 2005), wellbeing (Judge et al. 1997) and stability (Kinnunen et al.2008).

Most importantly, flow is also involved with one's skills, which is also closely connected with the sense of meaningful doing. Actually, the connection between the finding of one's strengths and perceived happiness is based on the feeling of meaningfulness (Seligman 2002).

Furthermore, the emergence of flow is dependent on how well one has recognised one's strengths, thus being a question of self-awareness and authenticity. To find pleasure from leadership and act in a love-based manner as a leader, one has to be ready for self-disclosure and increasing self-awareness (Gardner et al. 2005). Love-based leadership might contribute to leaders' work by providing them with positive experiences, initial excitement and perceived successes as well as a positive means to contribute, for example, to the work unit performance, employee retention and job satisfaction as was shown in Peterson and Luthans's (2003) study on hopeful leaders. Such positive action described in this section can, at its best, enhance optimism, hope, perseverance, wisdom, happiness and creativity - and flow.

The salient conclusion is, however, that love-based leadership might contribute not only to leaders' optimal performances, but also to employees' work by providing them with positive work experiences, initial excitement and perceived successes. These enhance positive feelings in the workplace (see also Isen and Reeve 2006), which are vital for the emergence of flow states.

Through this kind of leadership, leaders set an example at the workplace; they can encourage employees to seize new challenges boldly and not back away from the challenges (see, for example, Diener, Oishi, and Lucas, 2009) in order to find the meaning in their work. According to the ideology of love-based leadership, leaders can enhance employees' ability to utilise their own strengths through various love-based leadership practices in the workplace. The fundamental assumption is that leaders can act as guides, motivators and examples, as well as 
organisers of meaningful and enthusiastic doing at work (see also Rutledge 2009). This is how everyone can achieve top performances and the sense of using their abilities to the fullest.

Our viewpoint here also offers one way of analysing the positive impact leaders may have on performance challenges facing today's organisations (see also Peterson and Luthans 2003). Caring leaders try to find the road to better work conditions, development, performance, contentment, higher motivation, and the sense of self-efficacy in themselves and their employees - because success is also about a sense of meaning and pleasure, the best manifested by the state of flow.

\section{References}

Achor, S. (2010) The Happiness Advantage. The Seven Principles of Positive Psychology that Fuel Success and Performance at Work. New York, NY: Crown Business

Aryee, S., Srinivas, E. S. and Hoon Tan, H. (2005) 'Rhythms of life: Antecedents and outcomes of work-family balance in employed parents'. Journal of Applied Psychology, 90(1), pp. 132-146

Aspinwall, L. G. and Staudinger, U. M. (2006) 'Ihmisen vahvuuksien psykologia: kehittyvän tutkimuskentän kysymyksiä [Psychology of human strengths: Questions from developing field of study]' pp. 21-33 in Aspinwall, L. G. and Staudinger, U. M. (Eds.) Ihmisen vahvuuksien psykologia [A Psychology of Human Strengths]. Helsinki: Edita

Avey, J. B., Avolio, B. J. and Luthans, F. (2011) 'Experimentally analyzing the impact of leader positivity on follower positivity and performance'. Leadership Quarterly, 22, pp. 282-294

Avolio, B. J., Gardner, W. J., Walumba, F. O., Luthans, F. and May, D. R. (2004) 'Unlocking the mask: A look at the process by which authentic leaders impact follower attitudes and behaviours'. Leadership Quarterly, 15, pp. 801-823

Barnett, R. C. (2004) 'Women and work: where are we, where did we come from, and where are we going?' Journal of Social Issues, 60(4), pp. 667-674

Barnett, R. C. and Hyde, J. S. (2001) 'Women, men, work, and family. An expansionist theory'. American Psychologist, 56(10), pp. 781-796

Barnett, R. C. and Lundgren, L. (1998) 'Dual-earner couples and the decision to work less: A conceptual model'. Community, Work and Family, 1, pp. 273-295

Bass, B. M. (2000) 'The future of leadership in learning organizations'. Journal of Leadership Studies, 7, pp. 18-40

Berscheid, E. (2006) 'Ihmisen suurin vahvuus: toiset ihmiset [The greatest strenght of a human being: Other human beings]' pp.47-56 in Aspinwall, L. G. and Staudinger, U. M. (Eds.) Ihmisen vahvuuksien psykologia [A Psychology of Human Strengths]. Helsinki: Edita

Binnewies, C., Sonnentag, S. and Mojza, E. J. (2009) 'Feeling recovered and thinking about the good sides of one's work'. Journal of Occupational Health Psychology, 14, 243-256

Buss, D. M. (2000) 'The evolution of happiness'. American Psychologist, 55(1), pp. 15-23

Buunk, B. P. and van der Eijnden, R. (1997) 'Perceived prevalence, perceived superiority, and relationship satisfaction: most relationships are good but ours is the best'. Personality and Social Psychology Bulletin, 23, pp. 219-228

Calori, R. (1995) 'Management in Europe: Learning from different perspectives'. European Management Journal, 13(1), pp. 58-66 
Campbell, C. R. (2007) 'On the journey toward wholeness in leader theories'. Leadership and Organization Development Journal, 28(2), pp. 137-153

Caprara, G. V. and Cervone, D. (2006) 'Persoonallisuus toimivana, itsesäätelevänä järjestelmänä [Personality as functional, self-regulatie system]' pp. 69-82 in Aspinwall, L. G. and Staudinger, U. M. (Eds.) Ihmisen vahvuuksien psykologia [A Psychology of Human Strengths]. Helsinki: Edita

Carruthers, C. and Hood, C. D. (2005) 'The power of positive psychology'. Parks and Recreation, Oct 2005, pp. 30-37

Carver, C. S. and Scheier, M. F. (2005) 'Engagement, disengagement, coping, and catastrophe' pp. 527-547 in Elliot, A. J. and Dweck, C. S. (Eds.) Handbook of Competence and Motivation. New York, NY: Guilford Press

Carver, C. S., Scheier, M. F., Miller, C. J. and Fulford, D. (2009) ‘Optimism’ pp. 303-311 in and Snyder, C. R. and Lopez, S. J. (Eds.) The Oxford Handbook of Positive Psychology (2nd Ed.). Oxford: Oxford University Press

Clark, S. C. (2000) 'Work/family border theory: a new theory of work/family balance'. Human Relations, 53, pp. 747-770

Csikszentmihalyi, M. (2008) Flow. The Psychology of Optimal Experience. New York, NY: Harper Perennial/Modern Classics

Diener, E., Oishi, S. and Lucas, R. E. (2009) 'Subjective well-being: The science of happiness and life satisfaction' pp. 187-194 in Snyder, C. R. and Lopez, S. J. (Eds) Oxford Handbook of Positive Psychology. Oxford: Oxford University Press

Evertson, M. and Nermo, M. (2007) 'Changing resources and the division of housework: a longitudinal study of Swedish couples'. European Sociological Review, 23(4), pp. 455-470

Fairholm, M. R. and Fairholm, G. (2000) 'Leadership amid the constraints of trust'. Leadership and Organization Development Journal, 21(1/2), pp. 102-109

Fischer, A. H. and van Kleef, G. A. (2010) 'Where have all the people gone? A plea for including social interaction in emotion research'. Emotion Review, 2(3), pp. 208-211

Frisco, M. L. and Williams, K. (2003) 'Perceived housework equity, marital happiness, and divorce in dual-earner households'. Journal of Family Issues, 24(1), pp. 51-73

Frone, M. R. (2003) 'Work-family balance' pp. 143-162 in Campbell Quick, J. and Tetrick, L. E. (Eds.) Handbook of Occupational Health Psychology. Washington, DC: APA

Frone, M. R., Russell, M. and Cooper, M. (1992) 'Antecedents and outcomes of workfamily conflict: testing a model of the work-family interface'. Journal of Applied Psychology, 77, pp. 65-78

Gable, S. and Haidt, J. (2005) 'What (and why) is positive psychology?' Review of General Psychology, 9, pp. 103-110

Gardner, D. G., Dunham, R. B., Cummings, L. L. and Pierce, J. L. (1989) 'Focus of attention at work: construct definition and empirical validation'. Journal of Occupational Psychology, 62(1), pp. 61-77

Gardner, W. L., Avolio, B. J., Luthans, F., May, D. R. and Walumbwa, F. (2005) '“Can you see the real me?" A self-based model of authentic leader and follower development'. The Leadership Quarterly, 16, pp. 343-372

Glasø, L. and Einarsen, S. (2008) 'Emotion regulation in leader-follower relationships'. European Journal of Work and Organizational Psychology, 17(4), pp. 482-500

Greenhouse, J. H., Bedeian, A. G. and Massholder, K. W. (1987) 'Work experiences, job performance, and feelings of personal and family wellbeing'. Journal of Vocational Behaviour, 31, pp. 200-215 
Griffiths, A. (1996) 'The benefits of employee exercise programmes: a review'. Work and Stress: An International Journal of Work, Health and Organisations, 10(1), pp. 5-23

Gutek, B. A., Searle, S. and Klepa, L. (1991) 'Rational versus gender role explanations for work-family conflict'. Journal of Applied Psychology, 76, pp. 560-568

Hakanen, J., Perhoniemi, R. and Toppinen-Tanner, S. (2008) 'Positive gain spirals at work: From job resources to work engagement, personal initiative and work-unit innovativeness'. Journal of Vocational Behaviour, 73, pp. 78-91

Hawkins, A. J., Lovejoy, K. R., Holmes, E. K., Blanchard, V. L. and Fawcett, E. (2008) 'Increasing fathers' involvement in child care with a couple-focused intervention during the transition to parenthood'. Family Relations, 57, pp. 49-59

Hoyle, J. R. (2002) Leadership and the Force of Love. Six Keys to Motivating with Love. Thousand Oaks, CA: Sage

Isen, A. M. (2001) 'Some perspectives on positive affect and self-regulation'. Psychological Inquiry, 11(3), pp. 184-187

Isen, A. M. and Reeve, J. (2006) 'The influence of positive affect on intrinsic and extrinsic motivation: facilitating enjoyment of play, responsible work behaviour, and selfcontrol'. Motivation and Emotion, 29, pp. 297-325

Jackson, S. A. and Marsh, H. W. (1996) 'Development and validation of a scale to measure optimal experience: the flow state scale'. Journal of Sport and Exercise Psychology, 18, pp. $17-35$

Judge, T. A., Locke, E. A. and Durham, C. C. (1997) 'The dispositional causes of job satisfaction'. Research in Organizational Behaviour, 19, pp. 151-188

Judkins, B. and Presser, L. (2008) 'Division of eco-friendly household labor and the marital relationship'. Journal of Social and Personal Relationships, 25(6), pp. 923-941

Kinnunen, U., Feldt, T. and Mäkikangas, A. (2008) 'Testing the effort-reward imbalance model among Finnish managers: the role of perceived organizational support'. Journal of Occupational Health Psychology, 13, pp. 114-127

Koivunen, J. M., Rothaupt, J. W. and Wolfgram, S. M. (2009) 'Gender dynamics and role adjustment during the transition to parenthood: current perspectives'. The Family Journal: Counseling and Therapy for Couples and Families, 17(4), pp. 323-328

Leiter, M. P. and Durup, M. J. (1996) 'Work, home and in-between: a longitudinal study of spillover'. The Journal of Applied Behavioural Science, 32, pp. 29-47

Losada, M. and Heaphy, E. (2004). 'The role of positivity and connectivity in the performance of business teams: a nonlinear dynamics model'. The American Behavioural Scientist, 47(6), pp. 740-765

Määttä, K. (2005) Kestävä parisuhde [The Secrets of Long-lasting Marital Relationships] Juva: WSOY

Mäkikangas, A. (2007) Personality, Wellbeing and Job Resources. From Negative Paradigm towards Positive Psychology. Jyväskylä: University of Jyväskylä

Magnusson, D. and Mahoney, J. L. (2006) 'Holistinen lähestymistapa myönteisen kehityksen tutkimuksessa [Holistic approach in research of positive development]' pp. 232250 in Aspinwall, L. G. and Staudinger, U. M. (Eds.) Ihmisen vahvuuksien psykologia [A Psychology of Human Strengths]. Helsinki: Edita

Mahoney, M. J. (2002) 'Constructivism and positive psychology' pp. 745-750 in Snyder, C. R. and Lopez, S. J. (Eds.) Handbook of Positive Psychology. Oxford: University Press

Maier, G. W. and Brunstein, J. C. (2001) 'The role of personal work goals in newcomers' job satisfaction and organizational commitment: a longitudinal analysis'. Journal of Applied Psychology, 86(5), pp. 1034-1042 
McGillivray, D. (2005) 'Governing working bodies through leisure'. Leisure Sciences: An Interdisciplinary Journal, 27(4), pp. 315-330

Myers, D. G. and Diener, E. (1995) 'Who is happy?' Psychological Science, 6(1), pp. 10-19

Oh, S. S. and Lewis, G. B. (2009) 'Can performance appraisal systems inspire intrinsically motivated employees?' Review of Public Personnel Administration, 29(2), pp. 158-167

Perrone, K. M., Wright, S. L. and Jackson, Z. V. (2009) 'Traditional and nontraditional gender roles and work-family interface for men and women'. Journal of Career Development, 36(1), pp. 8-24

Peterson, S. J. and Luthans, F. (2003) 'The positive impact and development of hopeful leaders'. Leadership and Organization Development Journal, 24(1), pp. 26-31

Popper, M. and Amit, A. (2009) 'Attachment and leader's development via experiences'. The Leadership Quarterly, 20(5), pp. 749-763

Ransford, C. R., Crouter, A. C. and McHale, S. M. (2008) 'Implications of work pressure and supervisor support for fathers', mothers' and adolescents' relationships and wellbeing in dual-earner families'. Community, Work and Family, 11(1), pp. 37-60

Rantanen, J. and Kinnunen, U. (2005) 'Työn ja perhe-elämän vuorovaikutus [The interaction between work and family life]' pp. 229-264 in Kinnunen, U., Feldt, T. and Mauno, S. (Eds.) Työ leipälajina. Työhyvinvoinnin psykologiset perusteet [Work as Profession. The Psychological Bases for Wellbeing at Work]. Keuruu: Otava

Rath, T. and Conchie, B. (2008) Strengths-based Leadership. Great Leaders, Teams, and why People Follow. New York, NY: Gallup Press

Reed, J. and Buck, S. (2009) 'The effect of regular aerobic exercise on positive-activated affect: A meta-analysis'. Psychology of Sport and Exercise, 10(6), pp. 581-594

Rego, A., Ribeiro, N., Pina, M. and Jesuino, J. C. (2011) 'How happiness mediates the organizational virtuousness and affective commitment relationship'. Journal of Business Research, 64(5), pp. 524-532

Rutledge, L. (2009) Teacher leadership and school improvement: A case study of teachers participating in the teacher leadership network with a regional education service center. PhD Dissertation, Texas State University-San Marcos, USA

Ryan, R. M. and Deci, E. L. (2000) 'Self-determination theory and the facilitation of intrinsic motivation, social development, and wellbeing'. American Psychologist, 55, pp. 68-78

Salmi, M. (2004a) 'Arkielämä kokoaa yhteen työn ja perheen [The everyday life combines work and family]' pp. 11-28 in Salmi, M. and Lammi-Taskula, J. (Eds.) Puhelin, mummo vai joustava työaika? Työn ja perheen yhdistämisen arkea [Telephone, Granny, or Flexible Working Hours? The Everyday Life of Combining Work and Family]. Helsinki: Statistics Finland

Salmi, M. (2004b) 'Työn ja perheen yhteensovittamisen kentät [The fields of combinations of work and family]' pp. 1-9 in Salmi, M. and Lammi-Taskula, J. (Eds.) Puhelin, mummo vai joustava työaika? Työn ja perheen yhdistämisen arkea [Telephone, Granny, or Flexible Working Hours? The Everyday Life of Combining Work and Family]. Helsinki: Statistics Finland

Schunk, D. H. and Pajares, F. (2005) 'Competence perceptions and academic functioning' pp. 85-104 in Elliot, A. J. and Dweck, C. S. (Eds.) Handbook of Competence and Motivation. New York and London: The Guilford Press

Seligman, M. E. P. (2002) Authentic Happiness. New York, NY: Free Press

Seligman, M. E. P., Steen, T. A., Park, N. and Peterson, C. (2005) 'Positive psychology progress. Empirical validation of interventions'. American Psychologist, 60(5), pp. $410-421$ 
Snyder, C. R. and Lopez, S. J. (2002) 'The future of positive psychology. A declaration of independence' pp. 751-767 in Snyder, C. R. and Lopez, S. J. (Eds.) Handbook of Positive Psychology. Oxford: Oxford University Press

Tuomi, K., Huuhtanen, P., Nykyri, E. and Ilmarinen, J. (2001) 'Promotion of work ability, the quality of work and retirement'. Occupational Medicine, 51(5), pp. 318-324

Uusiautti, S. (2008) "Tänään teen elämäni parhaan työn” Työmenestys Vuoden Työntekijöiden kertomana ["Today, I'll work better than ever" Success at work described by the employees of the year]'. PhD Dissertation, University of Lapland, Rovaniemi, Finland.

Uusiautti, S. (2013) 'An action-oriented perspective on caring leadership: a qualitative study of higher education administrators' positive leadership experiences'. International Journal of Leadership in Education: Theory and Practice, 16(4), pp. 482-496

Wright, T. A. (2004) 'The role of "happiness" in organizational research: past, present and future directions' pp.221-264 in Perrewe, P. L. and Ganster, D. C. (Eds.) Exploring interpersonal dynamics. Oxford: Elsevier 


\section{The road to success - why pursue success at work?}

\section{Introduction}

Every human being's life abounds with promises and opportunities, and strengths and positive resources are not attributable only to certain people. Happiness and satisfaction must be understood as the outcome of a process of interaction between individual characteristics and aspirations on the one hand, and social relations and macro-social structures on the other hand (Haller and Hadler 2006).

In this chapter, we will sum up the offering of the book. First, we want to introduce the narratives of top workers. The purpose is to highlight the processual nature of success: to determine the core human resources and how to use human strengths and resources for one to develop into an expert. We will introduce the main characteristics of participants' careers (an analysis of their narratives). After that, we present the meta-narrative of Employees of the Year on the basis of narrative analysis. We will conclude the processual viewpoint by looking at the connection between resources and expertise development in the light of success at work.

In previous chapters we introduced our viewpoints, which focused on the phenomenon of success. The analysis has proceeded from childhood to adolescence, and from school to work life, not forgetting life outside work. Our outlook has shown the fundamental positive approach to human development and the meaning of recognising strengths. In this final chapter, we want to highlight two important concepts related to all previous viewpoints. Firstly, what can be done with love when considered as one of the fundamental tenets of positive psychology and flourishing, and how is it related to the process of achieving success? Secondly, how can we connect the idea of love with success and happiness?

We will recollect the main ideas of the previous chapters in the conclusion; we will take a glance at the role of love in the human being's lifespan and various areas of life and show the connection with successful development. Following this, we will move on to happiness and wrap up the analysis on the connection between success and happiness. 


\section{How to describe successful career processes?}

The careers of successful employees can be described on the basis of different career models and types. By considering Driver's (1982) divisions (linear, steady state and spiral), it became clear that career types among the top workers were quite dissimilar. One has had a linear career, similar to climbing up a ladder. Someone else's career appears to have been steadier, as his or her career-related choices presented more like a long-term commitment to his or her occupation and work, as well as diverse areas of mastery, and less striving for promotion. Some of the top workers' careers were both spiral and linear, that is, careers that thrive on alteration and new tasks and, at the same time, have a forward-moving trajectory.

The police's, priest's, psychologist's and artisan's careers exemplified a linear progression, even though they had proceeded without any major side-tracks in their professions (cf. Inkson and Amundson 2002). It appeared that they had educated themselves into their profession, enhanced their professional skills through various in-service educational opportunities, and worked in positions that were relevant to their profession. On the other hand, the nurse and farmer had either educated themselves for a different occupation or previously worked in a different field and ended up in their present occupations through various life phases. However, all top workers could be described with the metaphor of growth whereby a career is understood as something organic, and one is constantly developing and learning (Inkson and Amundson 2002).

\section{An optimistic attitude is the most essential factor in success at work}

\section{Finding an occupation that fits}

In terms of actual career-enhancing factors, the top workers were able to point to several considerations that they believed were salient. Interestingly, these factors did not vary much between occupations. In the process of achieving success at work, willingness to accept new challenges appeared to be an important factor. Additionally, top workers kept their professional knowledge up to date by in-service education and especially by voluntary education, often in their leisure time.

Still, not all of them aimed for a higher position in the hierarchy, but they could pursue developing their professional skills, getting more diverse work tasks, or learning entirely new fields of know-how. Additionally, these matters were considered to enhance their work motivation and ability to cope. At its best, a workplace provides employees with the possibilities to develop, find meaning for life, and achieve social, emotional, and mental wellbeing (Snyder and Lopez 2002; see also Sennet 2004). 


\section{Obstacles and misjudgments}

Above all, the most special characteristic among Employees of the Year was their positive attitude, a characteristic common to all informants. In the face of conflict, they did not give up. Instead, they saw such situations as a good time to reassess their occupational skills and, if necessary, to become further educated and develop. Thus, conflict situations were seen as problems that had to be solved.

Major obstacles were represented as conflicts experienced in the workplace. Employees of the Year emphasised the importance of good relationships in the workplace - not only between co-workers but also vertically between employees and employers. Other more concrete obstacles, such as fire on the firm's premises or not passing an entrance examination, were confronted more realistically and with an optimistic attitude.

Misjudgments were mainly specific to the period of their youth. These kinds of sidetracks could be, for example, studying for an occupation that later turned out to be unsuitable. With the aid of relevant counselling, educators may wish to consider whether these misjudgments could be avoided. On the other hand, misjudgments of this kind can often be useful; it is not always a waste of time because the perspective gained from travelling on byways can actually be a valuable experience.

To sum up, top workers' career processes were not characterised by actual failures per se; rather, it was all about acting in a constructive way and considering those situations as opportunities for skills development.

\section{Metaphors as analyzing tools}

In order to aptly describe someone's experience, it is necessary to find ways of expressing this experience. This can be, for example, by using a metaphor to describe the experience by contrasting it with something familiar. Random, multidimensional or ambiguous phenomena can be transformed into conscious constructions that crystallise experiences into a culturally understandable form. A metaphor can be defined as a manner of speech in which a certain concept can be used for clarifying the meaning of some other concept (Inkson and Amundson 2002). Therefore, the use of metaphors in research resemble a high-level analysis of the nature of the research target.

As the Employees of the Year were also interviewed through the narrative method, their life stories formed narratives. Narratives and metaphors function as the foundation of creativity in language and thinking - this idea can be employed to represent phenomena in a new light. In a metaphor, a phenomenon is named with a familiar word. While in poetry metaphors are merely used as aesthetic tools, in science metaphors are used for the purpose of explaining research targets. 
Naturally, there are certain limits; it is relevant to consider when a metaphor helps one to see the phenomenon in a new and fruitful manner. The danger is that a metaphor simplifies and presents a stereotypical picture of the phenomenon.

Next, we will introduce the process of becoming a top worker with a metaphor of a road. The purpose is not to try to fit top workers' lives into one mould but, instead, to present various illustrations of possible roads that all lead to success.

Metaphors can be divided, for example, into four categories. The first category concerns metaphors that are connected to the passing of time (the past, present and future). In these metaphors, people can, for example, imagine themselves at various points on the time continuum.

Second, archetypical metaphors represent common metaphoric images. Inkson and Amundson (2002) name ten archetypical metaphors that describe careers:

1 Journey: seeing the career as a passage on the career path leading to a certain destination;

2 Heritage: committing to a career as something inherited from one generation to another;

3 Fit: thinking that work life and people have certain forms and the purpose is to find a fit;

4 Seasons: the career is seen as a series of carefully defined phases, such as spring, summer, fall and winter;

5 Growth: the career is seen as something organic that includes constant development and learning;

6 Creative work: the career is seen as something that is self-built or constructed, a sort of work of art;

7 Network: the career is seen collectively, closely connected to the norms of the group;

8 Resource: this way of seeing the career originates from the concepts of management of human resources; careers are connected to economic and organisational planning;

9 Story: when the career is seen as a story, the narrative form and the creation of meaning are emphasised;

10 Cultural phenomenon: the career is seen as the reflection of our cultural context.

Third is theatre metaphors in which people are regarded as the actors in the drama of work life. The fourth type is role metaphors, which make it possible to try various roles and find the most suitable ones for descriptive purposes.

For example, one Finnish researcher used the metaphor of the patchwork quilt to describe the biographies of her research participants. Here, the metaphor of the road describes the process of becoming a top worker; the road goes uphill and downhill, it contains curves and straightaways, intersections, rest areas and sidetracks. It is also quite common to compare life to a journey. 
The ups were relatively easy to track from the stories of the Employees of the Year. These could be divided into factors showing direction in one's occupation and development in one's work. Nevertheless, finding differences between downs and sidetracks was more challenging. For example, many of us have encountered problems that put us in difficult situations. Usually, the situation necessitates some sort of decision to be made. Crossroads, therefore, are not always related to downs, setbacks or problems but can occur in the middle of a straight, good journey. Moreover, an uphill can turn into a downhill after finding a solution proves successful and choosing the right direction at the intersection.

Amundson (2005) has also used metaphors in problem-solving. He highlights that a metaphor is a very efficient means of separating the problem from the person himself of herself; the metaphor externalises the problem and moves it to a new level. Metaphoric images help with understanding what the situation is really about. The same concerns research; metaphors help with interpretations of the nature of the phenomenon studied.

\section{Four roads to success at work}

Success at work is not a temporary state but, rather, a process. This process will now be described through the narratives of the Employees of the Year. The road to success begins from childhood and then branches into four separate roads before uniting again at the end.

\section{Employee of the year: the journey begins}

The journey begins from the childhood and adolescence of the Employee of the Year. His parents encourage him to study and work, and support his choices. They do not want to force him to choose a certain occupation but give important advice: keep a resilient attitude towards work. How does the story continue? We enter a crossroads that leads in four directions.

\section{Road I: straight ahead}

At school, different occupations are introduced to our employee, but he does not make his decision based on that. Instead, as a youngster, he has already formed an idea about his field of interest, mostly due to his admiration of his relatives' career examples and life choices.

After completing compulsory education, he applies to a school that could prepare him for his dream occupation. However, things do not always go according to plan and he does not get into his desired school. Along the road, he finds traffic signs that lead him to an alternative path: he discovers a different road leading to the occupation corresponding to his dream.

The road takes him on to working life. This is a very significant phase in his life, although getting used to work schedules and the requirements of different 
tasks takes some time. He is an enthusiastic worker with a great desire to learn. He looks for more and more responsibilities in order to enhance his career. To advance and meet his challenges he continually educates and develops himself.

He appreciates work that provides opportunities to develop his workplace and himself. New challenges keep him interested and he constantly seeks opportunities to take on additional responsibilities. Transitions into positions and taking on new tasks are important road signs on his road to success.

However, his road is not always like a smooth highway; he encounters some bumpy gravel when he confronts obstacles and failures. He has a special way of managing this situation; he sees these difficulties as challenges. The desire to work well and engage with work lie in his attitude. He wants to be totally dedicated to his work and feels driven to accomplish all the tasks he has started.

Naturally, his dedication is shown in long work days and total concentration at work. This is possible since his spouse takes care of the family. While the decision on this division of labour has been made jointly, he still experiences some compunction; surely, he realises that the more time he spends at work, the less time he has to spend with his family.

Hobbies are important to this Employee of the Year. He may also make professional use of skills acquired in his leisure time; a hobby may even offer an alternative occupation. However, being aware that there is an option might be more important than actually using that option.

The road of the Employee of this Year clearly goes straight ahead. He has become an innovative and enthusiastic leader or supervisor in his professional field, wanting to devise new solutions and to develop work for the benefit of all. This is why he has been nominated Employee of the Year. His work has been valued.

After this reward, the Employee of the Year continues along the same way; he seeks new challenges or possibilities to get promoted. He is not likely to change his occupation.

\section{Road II: driving on all the lines}

This employee has determined his occupational field early on. He gets into a school of his choice and applies himself. He even goes to his local career counselling office to be sure of his occupational choice. Moreover, he takes up work in places that prepare him for his dream field, and this confirms to him that he is going in the right direction.

After his studies, he receives the position of his dreams and is an extremely diligent and devoted worker. His transition from school to work is not easy, but it is made easier by a mentoring system in the workplace as well as a supportive and open-minded work community. The employee advances in his career from one project to another and faces challenges that seem overwhelming afterwards. 
This suits his way of working. He also studies during his career, both at work and during his leisure time. Opportunities for further education are considered 'ups' in his road whereas conflicts between co-workers are seen as 'downs'. He finds these situations particularly stressful but still tries to work persistently because he likes his area of work. Changing jobs may, however, be the only option because he needs to be surrounded by a good work atmosphere. Openness and giving and receiving feedback are important to him. However, he thinks that positive feedback is believable only if it is consistent with his own perceptions.

One of the most crucial decisions concerns combining work and family life because he wants them to be in balance. This is challenging because of his demanding work. The spouses often adjust their schedules in a way that allows both to work and to be at home, especially when their children are small.

As a result of his dedication the employee climbs the ladder to higher and higher positions. He is then nominated Employee of the Year. This is an important leg in his journey, confirming that he has chosen the right road.

His hobby represents both a counterbalance to work and a valuable leisure activity. At the end, when he retires, a good, long-term hobby could turn out to be surprisingly significant because it might offer a way to direct his energy to things he is interested in.

\section{Road III: choosing the safe mid-way}

At school, this Employee of the Year received some career counselling, but it was not of much help to him. He is not at all sure of what he wants to do and goes to vocational school after deliberating with his friend. After a few sidetracks, he finds a route to the right way in military service.

At the beginning of his career he works in different positions. He is interested in his field and eagerly learns new skills. After a few years, he lands himself a position that seems to be right for him. Being promoted is less important to him than working autonomously and developing himself and his work. He enjoys working and is good at it. He also thinks that good social relationships are valuable at work. He likes to brainstorm with colleagues. In addition, he reveres giving and receiving feedback.

This Employee of the Year also invests in his family life. He wants to combine work and family, especially when children are young. Thus, successful scheduling with his spouse brings plenty of joy and enhances his success.

This top worker thinks that the Employee of the Year nomination results from his diligence and appreciation for his work, but he also recognises the significance of social relationships behind the nomination.

Following his nomination, his road goes on as it did before. He has never considered a career change and is unlikely to do so in the future. He has found the right way; by obtaining new skills and proficiency, the rest of his journey remains interesting. 


\section{Road IV: from byways to the interstate}

After compulsory education this employee finds himself at a fundamental crossroads. He does not have a clue where he should be heading when he is already supposed to have made a decision about his vocational education. In career counselling, the only assistance he receives is to select between general upper secondary education and vocational school, which is of no help. He has to do something, so he goes to vocational school. Soon, he realises that he does not fit into his field of study. He travels on several byways until, at some point, he finds a signpost that leads him to the right direction. This kind of signpost could be found during non-military service, a gap year or summer job.

Driving on byways is not a complete waste of time because he matures and gains a better perspective on life along the way. Critically, he must have enough strength to search within and listen to himself. Finding the right road is important; ultimately, however, this can be the result of coincidence or happenstance.

Finally, the employee begins work in a job that he feels is most suitable. He enhances his professional skills with various courses and further education. He is also anxious to participate in in-service education. Keeping his work content interesting is of great importance to him. He approaches his work systematically and deepens his knowledge by gaining new areas of expertise.

Good social relationships enhance his career journey and he considers a supportive work environment and the open flow of information important to work satisfaction and coping. Still, conflict situations can occur and he sees them as especially stressful and motivation-diminishing. Other obstacles might present themselves too. The time might come to think about what would be the best solution and way forward.

The employee does not have children; work plays such a major role in his life that distinguishing between work and leisure time sometimes seems impossible. Hobbies present a way to concentrate on something other than work.

His road has come to the point where he is nominated Employee of the Year because of his talents and dedication. He will continue along this path, because he has found - after wandering aimlessly in his early life - a field that really suits him and that allows him to use his talents and act innovatively.

\section{The remainder of the journey}

The career of the Employee of the Year does not end with this nomination; nor does this mean that there is nothing left to achieve. Instead, this top worker continues to seek new challenges and develop his professional skills. He will not change his occupational field although working is not always a bed of roses. He has found the right way.

Therefore, seeing the finishing line looming up could represent a difficult phase for the Employee of the Year. Letting go of the work to which he has been devoted and that has played a major role in his life will not be easy. Firstly, he 
has to admit that he is getting older. As retirement nears, one has to cut back on work tasks and start planning for life after work. If there were no life outside work, retirement could appear intimidating and seem like the end of the journey. But as an Employee of the Year he will know how to deal with life after work; he will regard it as a challenge and an opportunity to find another successful road for the rest of his journey.

\section{What do the stories reveal to us?}

Success at work is not a temporary state but, rather, a process; the top workers' careers were not equally logical, organised, controlled and phased. Instead of career planning, the concept of career skills could be relevant in describing the career journeys of these rewarded employees. This means that their careers are seen as expedient and built on the basis of a process in which they have been active and innovative in their search for the most suitable routes to proceed (Amundson 2005).

There are a number of felicitous ways of describing and analysing the top workers' career processes. For example, according to Baltes and Freund's (2006) selection-optimisation-compensation (SOC) model, development through the whole lifespan has three fundamental processes. The combination of these processes is an efficient and versatile mechanism that individuals, groups and societies can use in order to achieve higher action levels and to control future challenges. The rewarded Employees of the Year had selected an occupation that was the best fit for them, they had optimised their talents and professional skills, and when it came to compensation, they were able to, for example, change their plans in order to successfully handle challenging or conflict situation.

Gardner et al. (2001) encourage people to look at their work from three perspectives: the mission (the nature of the work and why society pays for doing this particular work - what the work's meaning is), the standards (what kind of performance is expected for this particular work and what kind of employee can best perform this work), and the identity of the work (what the ethical and moral features of the work are and how they are justified). This is precisely the kind of reflection in which the Employee of the Year nominees constantly engaged during their careers.

Then again, the ability to consciously control behaviour when needed has been seen to be an essential prerequisite for the functioning and wellbeing of human beings. People with this ability, such as the Employees of the Year, are persistent, flexible, and are more prone to positive emotions than negative ones and to handle the stressful situations in life efficiently (Baltes and Freund 2006).

In many ways, the Employees of the Year were quite different from each other as we would expect from people with unique characteristics. All things considered, the core success factor is that you have an optimistic attitude toward work and to life in general, as well as toward yourself; without faith in yourself, there is no point in trying to succeed. Maddux (2002) sums up the recipe for success in 
the following brilliant way: 'This truth is that believing that you can accomplish what you want to accomplish is one of the most important ingredients - perhaps the most important ingredient - in the recipe for success'.

\section{On the connection between human resources and expertise}

The careers of top workers appeared process-like, similar to the development of expertise. No doubt, all top workers participating in our studies were also experts in their fields. Expertise is a concept that generally refers to the special know-how of different professions (Sim and Kim 2010), although the understanding of the nature of expertise is shown to vary, for example, by nationality (Boudreau et al. 2001; Germain and Ruiz 2009). Experts are people who possess the ultimate skills and knowledge of their own field. They usually have long working experience and are able to apply their professional ability in practice. Thus, a certain amount of education and work experience is usually required to become an expert.

Although becoming an expert is an individual process, common features in that process are the pursuit of employing topical information about how to develop one's own work, a reflective approach to work, strong self-direction and selfassessment. For example, Marie-Line Germain's Generalized Expertise Measure (see, for example, Germain and Ruiz 2009) includes 16 items that describe the core of expertise. There are five objective items that are categorised as evidencebased items, while the remaining 11 items are subjective in nature and are categorised as self-enhancement items because of their behavioural component.

The emphasis on self-enhancement or subjective items seems clear and this is the core of our discussion. There are many reasons, and various elements of expertise, such as a sense of coherence, strong self-esteem and a sense of competence, which seem to prevent employees from burning out; instead, the path to wellbeing, according to Kalimo et al. (2003), is based on strong internal personal resources and challenging work.

However, development toward expertise does not consist only of the use of human and social resources. According to Luthans et al. (2004) knowing 'who I am' is as equally important as 'what I know' and 'who I know'. The researchers call it 'positive psychological capital' and claim that by focusing on personal strengths and good qualities, employees' confidence, hope, optimism and resilience can be developed. Self-confident and optimistic employees are open to development and focused on gaining higher levels of expertise, and are thus able to perform more effectively.

When the aim is to analyse people's opportunities for achieving success, happiness and positive work experiences, human resources are one possible way of approaching the issue. They also form the basis of developing expertise. Our understanding is that the basis of success and wellbeing at work can be illustrated as four fundamental human resources, each considered valuable and important 
keys to happiness and wellbeing at work and life and the development toward greater expertise and success:

1 Positive feelings enhance intellectual thinking and problem-solving skills, decrease defensive attitudes, deliberate, improve memory and helpfulness. Therefore, they function as an employee's emotional resources at work.

2 Good interaction skills such as empathy, flexibility, patience, care and interest are significant social resources that support the creation and preservation of good and close relationships.

3 Features such as willpower, self-regulation, self-appreciation and inner motivation are regarded as cognitive resources.

4 The fourth dimension is action. At its best, employees may experience joy of work, work drive, empowerment and reach the experiences of flow when they are riveted by tasks where their expertise is employed, where they have the possibility to develop on a level where they are ready to work to the limits of their talents. Here, these kinds of resources are referred to as functional resources.

When a human being is able to get the most of his or her resources, he or she is likely to get positive feedback and recognition from others, succeed and experience heightened self-appreciation. The employee wants to develop and strives in order to perform better. Through this kind of professional development, the employee notices his or her success and abilities and can become an active expert who expects good things to happen - in other words, this employee is optimistic. We claim that this kind of positive cycle lays the foundation for finding happiness at work as it represents the true opportunity of self-fulfillment at work and a positive path.

Happiness and satisfaction must be understood as outcomes of an interactive process between individual characteristics and aspirations, on the one hand, and social relations and macro-social structures, on the other hand (Haller and Hadler 2006). Kinjerski and Skrypnek (2006) have listed factors that are associated with individuals' experiences of spirit at work. These factors can also be considered essential in definitions of love for work:

1 Leaders and senior members who inspire employees through their leadership and example;

2 A strong organisational foundation that includes a shared vision, mission, purpose and an intention to contribute to the overall good of society;

3 Organisational integrity and work that is aligned with its mission and purpose;

4 Positive workplace culture, including a positive physical space for employees to work in;

5 Positive connections between all members and a sense of community in the organisation; 
6 Opportunities for members to pursue professional and personal growth and to fulfil their own personal mission through work; and

7 Appreciation and regard for the contributions made by its members (Kinjerski and Skrypnek 2006: 290-291).

Kinjerski and Skrypnek's description is interesting as it presents only one reference on physical working conditions (the positive physical space for employees to work in) while the others refer to inspiration, mission and purpose, good intention and integrity, as well as to positive culture and inter-worker connections, including appreciation. Opportunities to develop oneself professionally and personally, for their part, also strengthen positive feelings toward work.

The use of resources and development and positive experiences at work can develop into 'love for work'. Love for work resembles voluntary altruistic or helpful acts that have the potential to enhance organisations, otherwise referred to as organisational citizenship behaviour. Individuals may make voluntary contributions that go beyond specific task performance or the psychological contract with the employer and these behaviours are intended to help people and the organisation.

But how do you find love for work? How do you enjoy work so much that you can honestly say that you love it? From where can we draw this positive state - or better yet, where does this love come from? How can one grow into such a person who knows his or her weaknesses and strengths and believes in his or her opportunities and talents? We will now sum up our findings from our love research.

\section{Love - the greatest of all}

In previous chapters, we referred to love in many connections throughout this book. Our fundamental assumption is that love, in the sense we represent here, is a manifestation of balanced development, satisfaction and acceptance of oneself, and of an optimistic attitude toward the others and the surrounding environment.

The very first form of love in a child's life is parental love expressed by the child's parents (Määttä and Uusiautti 2012). Parents have the main responsibility for rearing their children but they can do it in a way that enhances positive development. Parental love secures children's wellbeing and positive development in at least two ways: 1) by setting safe boundaries and 2) constructing self-esteem. Children need experiences of success, appreciation and encouragement, but equally important is that children have distinct and safe limits. Parental love appreciates the child and does not abandon the child even when his or her behaviour causes disappointment and trouble. Successful rearing does not clear the obstacles of life but helps children learn to confront, tolerate and overcome the inevitable difficulties. Parental love prepares the child for the future and attitudes toward the world - all people and phenomena in it - are learned from home. This was very apparent in top workers' autobiographical narratives as well. Every parent can be loving and thus provide their children with the first requisites for 
finding their strengths, appreciating themselves, and being open to the opportunities the world offers them.

Along with parental love, children may receive care and support from their grandparents (Maijala et al. 2012). In many families, a grandparent is an important member of the family and the family network (see, for example, Harper and Ruicheva 2010; Johnson 1998). Grandparenthood involves various roles and dimensions that affect how grandchildren are raised and nurtured. Grandparenthood is part of the lifespan whereby grandmothers and grandfathers receive a significant amount of resources from their grandchildren and create a good and harmonious life. Grandparenthood can be dissected into the supporters and connectors of intergenerational relationships. Usually, grandparenthood is perceived positively (Powdthavee 2011) although grandparenthood itself has changed dramatically over the decades (Sciplino et al. 2010). Grandparenting can enrich life in a way that enhances the wellbeing of grandparents themselves and promotes their successful ageing. Furthermore, grandparents' roles are also developmentally beneficial, not only to grandchildren and their parents but also to grandparents themselves (see Thiele and Whelan 2006). Fundamentally, the most important task in grandparenting is the ability to act as a grandparent - in other words, to love as a grandparent (Maijala et al. 2012).

Indeed, top workers talked about parents and grandparents who had encouraged them, supported them, or acted as role models along their paths to success at work. In addition, their stories showed that other types of close relationships were crucial to their development such as, for example, friendships.

Plato (see Irwin 1979) and Aristotle (1981) contemplated what friendship was all about and what characteristics a friend should possess. The phrase 'platonic friendship' harks back to Ancient Greece and refers to a non-sexual friendship (Leone and Hawkins 2006). As friendship is based on free choice, there have to be reasons that people are encouraged to build friendships and reasons that make them worth cherishing (Schmalenbach 1977/1922). Overall, friendship has acquired a whole new meaning in modern everyday life (Lindgren 2012; Pahl 2000).

In psychology, special attention has been paid to the selection of friends (for example, Van de Bunt 1999), how friendship is born (for example, Hallinan 1979), and what kind of people become friends (Fisher 1982). There are several theories about selecting friends. According to reinforcement theory, we like people who reinforce us and our behaviour (Patterson 2007) whereas the investment models say that we enjoy being with people we can benefit from (Rusbult et al. 2007). Friends share, for example, the same age and similar attitudes and basic values. Friendship offers companionship and support that can be emotional, practical and material (Allan 1989) - and therefore, friendships and love from a friend can enhance one's success and happiness in numerous ways.

We spend a great part of our lives in school, at various education levels. Also, success processes described by top workers included rich and diverse memories from school years. We have paid much attention to the role of caring teacherhood 
on the road to success and, indeed, the love manifested by teachers cannot be underestimated. The ethics of caring concerns teaching (Gilligan 1982) and, in fact, caring has been discussed as the central aim and method of education (see Burns and Rathbone 2010; Noddings 1988). A teacher's ethical caring means genuine caring, aspiring to understand and make an effort in terms of pupils' protection, support and development. Because of this pedagogical caring, a teacher especially pursues pupils' potential to develop and thus help them to find and use their own strengths.

For decades, this kind of pedagogical love has been considered the core factor in the definition of good teacherhood, though the characteristics of a good teacher have always included various features. Features such as the ability to maintain discipline and order, set a demanding goal level, and the mastery of substance have been especially emphasised (see, for example, Davis 1993; Hansen 2009; Zombylas 2007). Consequently, even teacher education has focused more, for example, on teachers' didactic skills, as well as the ability to teach subjects and maintain social order (see, for example, Jakku-Sihvonen 2005). However, education and teaching aimed at bringing out personalities cannot succeed without a loving attitude (Haavio 1948). Indeed, Haavio (1948) has highlighted the moral nature of pedagogical love; pedagogical love is addressed to every learner regardless of his or her various outer abilities, features, appearance, behaviour or personality traits. Pedagogical love is a way of teaching. Love appears in teaching as guidance toward disciplined work, but also as patience, trust and forgiveness. The purpose is not to make learning fun, easy or pleasing but to create a setting for learning whereby pupils can use and develop their own resources and proceed at the maximum of their own abilities. A teacher's love for a pupil embodies the continuous trust that there is more to a learner than is shown on the surface. For instance, in situations in which a learner's progress is slow or tangled, a loving teacher takes care that the learner does not lose trust in his or her own learning in times of frustration (see, for example, Hatt 2005; van Manen 1991; Äärelä 2012).

In adulthood, partner selection and mutual life after finding a suitable life companion are topical. The form of love changes to romantic love. Seligman (2002) distinguishes the capacity to love from the capacity to be loved. People with a secure love style find it relatively easy to get close to others, and they do not worry about being abandoned or someone getting too close (Seligman 2002). Myers and Diener (1995: 15) point out that 'Throughout the Western world, married people of both sexes report more happiness than those never married, divorced, or separated'. Seligman (2002) claims that romantic love is more of a potential factor of happiness than is job satisfaction, for example. This is also important for the analysis of success. In Chapter 4, we showed that regardless of solutions, people did not want to achieve success at the expense of other. This does not feel right; but it has nothing to do with true happiness either.

We now come to work. All previous forms appear to set the foundation for love for work (Uusiautti and Määttä 2011). Love for work invokes conflicting emotions. Because of love for work, people stretch and enjoy the results of their 
diligence. However, love for work can become enervating and can completely consume one's energy. Work, joy of work and success at work are, at best, the spice of life and the most satisfying feeling.

Love for work provides the means for individual and societal development. Positive concepts that describe wellbeing and happiness at work are relevant highlights in discussions of the positive effects of work. Thus, work can become not only the most satisfying element in life (Csikszentmihalyi 2008) but also add focus and purpose in life - and is thus closely connected to happiness.

In all, successful development does not only mean success at work, but we want to highlight the holistic nature of success thinking, especially from the point of view of happiness. Still, love and happiness are quite personal matters. According to our studies, love ultimately appears as actions: giving, caring, responsibility and respect. Love can become an important source of satisfaction, a creator of vigour and energy, and the footing of success.

\section{Not just survival then, but flourishing!}

Shawn Achor (2010: 3) started his book on finding success and performance at work by criticising the common belief: 'If you work hard, you will become successful, and once you become successful, then you'll be happy'. As the previous chapters have shown, success does seem to require hard work. Yet, it is possible to see the connection between success and happiness. Achor argues that happiness comes first, which then leads to success. He bases his viewpoint on results from many other studies that happy people work more and better, are more efficient and, by being happy, they are also friendly and helpful; consequently, they help the whole organisation to succeed.

While his conclusions are correct, this is not quite the same viewpoint we want to offer. Our studies show that success and happiness go hand in hand. We will discuss this in detail at the end of this chapter. But the key point is that the discovery of human strengths, a balanced life, satisfaction and support can lead a person to a path that is not only filled with feelings of happiness and a meaningful life but also shows the way to success.

In Chapter 2, we presented a theoretical introduction to the elements of success. The selection of certain concepts, such as (intrinsic) motivation, work engagement, self-efficacy and positive strategies, was deliberate as the purpose was to explore the possible connection between success at work and human wellbeing.

More than four decades ago, Hall and Lawler (1970: 272) stated that: 'Successful integration of the individual with the organization can come about where the job behaviors that lead to satisfaction of such higher-order needs as autonomy, achievement, esteem, and self-fulfillment also lead to high performance'. Fostering organisational virtuousness (for example, through honesty, interpersonal respect and compassion; combining the high standards of performance with a culture of forgiveness and learning from mistakes) improves 
employees' affective wellbeing and promotes a more committed workforce (Rego et al. 2011). In practical terms, this is illustrated in the phenomenon 'the joy of work' (Varila and Lehtosaari 2001). It is a state experienced when an employee works as an engaged subject who can actively and comprehensively use his or her skills. In addition, the feeling of having found work that is suitable for oneself is essential. It is possible to define two kinds of joy of work: the passive one can be described as contentment with the relationship between one's actions and reality. Thus, the joy of work is like an assessment. The active joy of work results from active behaviour and is merely an inner feeling. The joy of work can be a steady state, an overall happiness. However, it can also be experienced as a captivating emotion when it actually resembles the experience of flow.

\section{Is there a connection between success and happiness?}

First, we want to highlight an interesting theory of personal happiness. Dr Seligman (2002) distinguishes three levels in happiness: 1) pleasure and gratification, 2) embodiment of strengths and virtues, and 3) meaning and purpose. He (Seligman 2002: 160) states that:

while the pleasant life might bring more positive emotion to one's life, to foster a deeper, more enduring happiness, we need to explore the realm of meaning. Without the application of one's unique strengths and the development of one's virtues towards an end bigger than one's self, one's potential tends to be whittled away by a mundane, inauthentic, empty pursuit of pleasure.

The point suggested by Seligman is profound and far-reaching. He argues that through the use of signature strengths, people can have a meaningful life. Having a meaningful life is therefore connected to authentic happiness. Why are people happy when they utilise their strengths? The answer is because they have a sense of ownership and authenticity, and feelings of excitement, invigoration, joy, zest and enthusiasm (Seligman 2002). When people experience such positive emotions and have the desire to employ these strengths, they also feel happy.

Likewise, instead of focusing on problems and stress-factors of today's work life, we wanted to focus this conceptual review on the positive sides of human behaviour, development and success (see also Almost and Spence Laschinger 2002; Spence Laschinger et al. 2004). Figure 6.1 illustrates the interconnectedness of the elements introduced above.

The fundamental idea of this illustration is that success is 1) dependent on certain factors, 2) necessitates action, and 3) manifested through certain outcomes.

The first section of the diagram means that success in any area of life can consist of various elements that can be roughly divided into individual-bound factors and context-bound factors. They form the preconditions of success. However, success is not a state that will miraculously materialise; it requires 


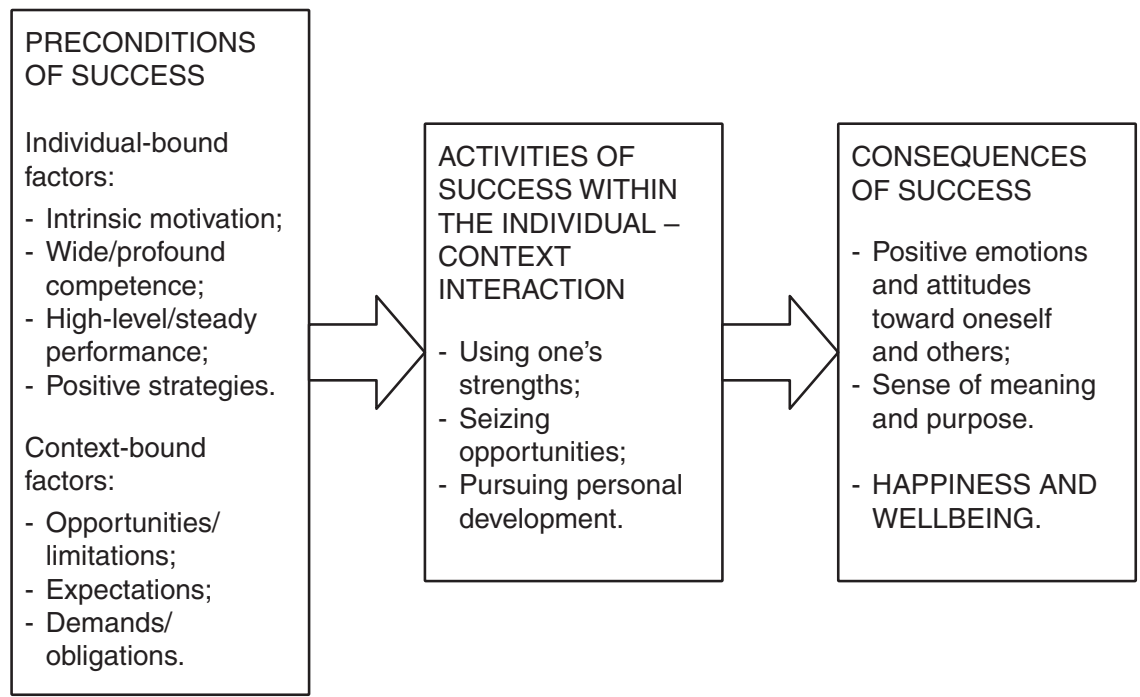

Figure 6.I The elements of success and their interconnectedness (Uusiautti, 20I3).

action. Likewise, certain motivational and contextual factors play a salient role in the process as they are also closely connected to a sense of capability or selfefficacy (see for example, Duda and Nicholls 1992). When it comes to positive development and the background factors of success, we have concluded that 'experiences and events taking place in childhood and adolescence can be crucial, or at least, direct people in a right direction' (Uusiautti and Määttä 2013: 69). So the push toward to success can be a sum of many factors engendering a sense of purposeful doing and, consequently, a sense of finding the right path. It means that when the individual-bound and context-bound features are synchronised (see also Magnusson and Mahoney 2006), the individual can seize the opportunities, use his or her strengths, and actively pursue personal development. What then is the result? Success in this perspective is manifested as positive emotions and attitudes, which means a good feeling of oneself, one's capability, and one's place in the world. This kind of sense of purpose and meaning are the core of happiness (see Seligman 2002).

In sum, success is considered a combination of feelings of expertise, competence, accomplishments, top performances, and the use of positive strategies (see Uusiautti 2008, 2013; Uusiautti and Määttä 2010, 2011) within a particular context. Therefore, success is not defined as the achievement of a certain goal or position in life (for example, becoming a top pianist or a CEO). It is achievable by anyone who discovers his or her strengths, finds the motivation to use them, applies positive strategies, but also realises the opportunities and limitations of the context. This viewpoint does not turn a blind eye to mistakes, hardships or poor conditions. The question is merely about the realisation that success can be 
understood positively as a means of positive development and a route to wellbeing and happiness at their fullest; moreover, success requires action and personal effort. Although success has context-bound features, it is also quite individualistic when seen as a manifestation of personal growth, effort and good outcomes.

Let us take an example. In order to be able to examine someone's success, one has to be competent in that particular area - for example, school mathematics. Competence and the ability to learn are not sufficient; one also has to have the motivation to learn and use mathematics. Then, in order to be successful at mathematics, one has to perform well in that area. The fourth dimension adds a longitudinal aspect to success, that being positive strategies. In order to be successful in mathematics one has to possess the necessary skills to optimise one's development by aiming to learn as widely as possible to become a straight-A student in maths or in order to figure out a difficult task. All this happens in context; the person can be encouraged, supported, taught and mentored by parents, friends, relatives or teachers. The school can apply a mathematics curriculum that enhances the mathematics enthusiast's skills, and he or she seizes the opportunities to utilise this maths talent. Success in maths can eventually lead to positive feelings about oneself as a whole and ignite an optimistic attitude toward one's chances and the future; mathematics could also be something one can continue to work with in later life. This is the foundation of success. When these areas overlap, the individual can develop and grow to his or her fullest, use his or her strengths, have positive experiences and have a sense of purpose in life. For the aforementioned mathematics enthusiast, being able to learn about maths and using mathematical talents, finding pleasure and joy from learning and working with maths, and then finding it important and meaningful, can provide him or her with positively-toned success that becomes a source of happiness that can be found by finding strengths and interests and actively applying them in life.

\section{Happiness as the by-product of the pursuit of success}

It seems, therefore, that from the viewpoint presented here, success is connected to happiness. Why is it important to talk about happiness? Happiness is not only important to individual people themselves, but it also benefits society as a whole (Gilpin 2008). According to numerous studies on happiness, happy people have been shown to be open, courageous, trusting and helpful (Seligman et al. 2005; see also Gilpin 2008); friendly and non-materialistic (see, for example, Fishbach and Labroo 2007; Otake et al. 2006; Polak and McCullough 2006); and cooperative, pro-social, benevolent and 'other-centered' (Lyubomirsky et al. 2005). The positive feeling of using one's strength is ultimately connected to authenticity. This is where strengths and authentic experiences are connected to happiness and wellbeing. But they are also connected to another phenomenon, namely, success.

Evidence suggests that happy people perform better at work than those who report low wellbeing. Furthermore, happy workers are better organisational citizens because they help other people at work in various ways (see Diener and 
Seligman 2004). Happiness can be directly translated into engagement, productivity and satisfaction - the wide definition of productive work (see Prewitt 2003). Likewise, according to Lyubomirsky et al. (2005), positive affect is associated with multiple positive outcomes, including better performance ratings at work, higher salaries and improved health.

Like happiness, success is a subjective, personal experience, and personal achievements are evaluated in different ways (Maddux 2002). However, this theoretical analysis on success sought to highlight that we need to understand the cognitive and motivational processes that maintain and even increase positive spirits and emotions important for, for example, problem-solving skills, innovative action (Isen 2001; 2003) and happiness (see also Lyubomirsky 2001; Ojanen 2001).

Luthans et al. (2004: 49) call for the recognition of the full force of the importance of human factors in meeting the tremendous challenges faced in work life now and in the future. Germain and Ruiz (2009) point out that an expert is not only someone who knows information but also someone who is able to apply and transfer knowledge. Moreover, the goal of today's occupational education should at least be the development of the expertise of trainees. We agree with Mikucka (2013: 259) that 'good work, work that fits human needs, does not have to be the luxury of the rich classes and the rich developed societies'. Indeed, our purpose is to contribute to this discussion by highlighting the significance of various human resources to the singular employee's abilities to not only confront the challenges set by work today, as well as in the future, but also to develop, experience expertise, success and, consequently, to find fulfillment in his or her work. Better yet, on the basis of what we have learned from the top workers, the ability to express oneself as one really is can be seen as crucial when work becomes a labour of love.

\section{References}

Äärelä, T. (2012) “ “Aika palijon vaikuttaa minkälainen ilime opettajalla on naamalla” nuoret vangit kertovat peruskouluajoistaan ["The teacher's look means a great deal" young prisoners tell about their school times]'. PhD Dissertation, Acta Universitatis Lapponiensis 242, University of Lapland, Rovaniemi, Finland

Achor, S. (2010) The Happiness Advantage. The Seven Principles of Positive Psychology that Fuel Success and Performance at Work. New York, NY: Crown Business

Allan, G. (1989) Friendship, Developing a Sociological Perspective. Hemel Hempstead: Harvester Wheatsheaf

Almost, J. and Spence Laschinger, H. K. (2002) 'Workplace empowerment, collaborative work relationships, and job strain in nurse practitioners'. Journal of the American Academy of Nurse Practitioners, 14(9), pp. 408-420

Amundson, N. E. (2005) Aktiivinen ohjaus. Opas uraohjauksen ammattilaisille [An Active Guidance. A Guide to Career Counseling Professionals]. Juva: WS Bookwell

Aristotle (1981) Nikomakhoksen etiikka [The Ethics of Nikomakhos] (S. Knuuttila, Transl.). Helsinki: Gaudeamus 
Baltes, P. B. and Freund, A. M. (2006) 'Ihmisen vahvuudet ja viisaus [The human strengths and wisdom]' pp. 34-46 in Aspinwall, L. G. and Staudinger, U. M. (Eds.) Ihmisen vahvuuksien psykologia [A Psychology of Human Strengths]. Helsinki: Edita

Boudreau, J. W., Boswell, W. R. and Judge, T. A. (2001) 'Effects of personality on executive career success in the United States and Europe'. Journal of Vocational Behavior, 58(1), pp. 53-81

Burns, D. P. and Rathbone, N. (2010) 'The relationship of narrative, virtue education, and an ethic of care in teaching practice'. In Education, 16(2)

Csikszentmihalyi, M. (2008) Flow. The Psychology of Optimal Experience. (10th Ed.) New York, NY: HarperPerennial

Davis, B. G. (1993) Tools for Teaching. San Francisco, CA: Jossey-Bass Publishers

Deci, E. L. and Ryan, R. M. (2008) 'Facilitating optimal motivation and psychological wellbeing across life's domains'. Canadian Psychology, 49(1), pp. 14-23

Diener, E. and Seligman, M. E. P. (2004) 'Beyond money: Toward an economy of wellbeing'. Psychological Science in the Public Interest, 5(1), pp. 1-31

Driver, M. J. (1982) 'Career concepts - A new approach to career research' pp. 23-32 in Katz, R. (Ed.) Career Issues in Human Resource Management. New York, NY: Prentice-Hall

Duda, J. L. and Nicholls, J. G. (1992) 'Dimensions of achievement motivation in schoolwork and sport'. Journal of Educational Psychology, 84(3), pp. 290-299

Fishbach, A. and Labroo, A. A. (2007) 'Be better or be merry: how mood affects selfcontrol'. Journal of Personality and Social Psychology, 93(2), pp. 158-173

Fisher, C. S. (1982) 'What do we mean by "friend”? An inductive study'. Social Networks, 3, pp. 287-306

Gardner, H., Csikszentmihalyi, M. and Damon, W. (2001) Good Work. When Excellence and Ethics Meet. New York, NY: Basic Books

Germain, M.-L. and Ruiz, C. E. (2009) 'Expertise: myth or reality of a cross-national definition?' Journal of European Industrial Training, 33(7), pp. 614-634

Gilligan, C. (1982) In a Different Voice. Psychological Theory and Women's Development. Cambridge, MA: Harvard University Press

Gilpin, J. M. (2008) 'Teaching happiness. The role of positive psychology in the classroom'. Pell Scholars and Senior Theses, 12, pp. 1-23

Haavio, M. (1948) Opettajapersoonallisuus [Teacher Personality]. Jyväskylä: Gummerus

Hakanen, J., Perhoniemi, R. and Toppinen-Tanner, S. (2008) 'Positive gain spirals at work: from job resources to work engagement, personal initiative and work-unit innovativeness'. Journal of Vocational Behavior, 73, pp. 78-91

Hall, D. T. and Lawler, E. E. (1970) 'Job characteristics and pressures and the organizational integration of professionals'. Administrative Science Quarterly, 15(3), pp. 271-281

Haller, M. and Hadler, M. (2006) 'How social relations and structures can produce happiness and unhappiness: an international comparative analysis'. Social Indicators Research, 75, pp. 169-216

Hallinan, M.T. (1979) 'The process of friendship formation'. Social Networks, 1, pp. $193-210$

Hansen, K. (2009) 'Strategies for developing effective teaching skills in the affective domain'. Journal for Physical and Sport Education, 23(1), pp. 14-19

Harper, S. and Ruicheva, I. (2010) 'Grandmothers as replacement parents and partners: the role of grandmotherhood in single parent families'. Journal of Intergenerational Relationships, 8(3), pp. 219-233 
Hatt, B. E. (2005) 'Pedagogical love in the transactional curriculum'. Journal of Curriculum Studies, 37(6), pp. 671-688

Inkson, K. and Amundson, N. E. (2002) 'Career metaphors and their application in theory and counseling practice'. Journal of Employment Counseling, 39, pp. 98-108

Irwin, T. (1979) Plato's Moral Theory: The Early and Middle Dialogues. New York, NY: Clarendon Press

Isen, A. M. (2001) 'Some perspectives on positive affect and self-regulation'. Psychological Inquiry, 11(3), pp. 184-187

Isen, A. M. (2003) 'Positive affect as a source of human strength' pp. 179-196 in Aspinwall, L. G. and Staudinger, U. M. (Eds.) A Psychology of Human Strengths. Fundamental Questions and Future Directions for a Positive Psychology. Washington, DC: American Psychological Association

Jakku-Sihvonen, R. (2005) 'Kasvatustieteiden opetus ja asiantuntijan arkipätevyys [Education of the educational sciences and expert's everyday competence]' pp. 125-150 in Jakku-Sihvonen, R. (Ed.) Uudenlaisia maistereita. Kasvatusalan koulutuksen kehittämislinjoja [New Kinds of Masters: Developmental Guidelines of Education of the Educational Sciences]. Jyväskylä: PS-kustannus

Johnson, C. L. (1998) 'Effects of adult children's divorce of grandparenthood' pp. 184-192 in Szinovácz, M. (Ed.) Handbook on Grandparenthood. Westport, CT: Greenwood Press

Kalimo, R., Pahkin, K., Mutanen, P. and Toppinen-Tanner, S. (2003) 'Staying well or burning out at work: work characteristics and personal resources as long-term predictors'. Work and Stress, 17(2), pp. 109-122

Kinjerski, V. and Skrypnek, B. J. (2006) 'Creating organizational conditions that foster employee spirit at work'. Leadership and Organization Development Journal, 27(4), pp. 280-295

Leone, C. and Hawkins, L. B. (2006) 'Self-monitoring and close relationships'. Journal of Personality, 74(3), pp. 739-778

Lindgren, A. (2012) 'Sociology as a science'. International Journal of Asian Social Science, 2(1), pp. 22-24

Luthans, F., Luthans, K. W. and Luthans, B. C. (2004) 'Positive psychological capital: Beyond human and social capital'. Business Horizons, 47(1), pp. 45-50

Lyubomirsky, S. (2001) 'Why are some people happier than others? The role of cognitive and motivational processes in wellbeing'. American Psychologist, 56(3), pp. 239-249

Lyubomirsky, S., Sheldin, K. M. and Schkade, D. (2005) 'Pursuing happiness: the architecture of sustainable change'. Review of General Psychology, 9(2), pp. 111-131

Määttä, K. and Uusiautti, S. (2012) 'Parental love -Irreplaceable for children's wellbeing'. Global Journal of Human Social Sciences, 12(10), pp. 1-8

Maddux, J. E. (2002) 'Self-efficacy. The power of believing you can' pp. 277-287 in Snyder, C. R. and Lopez, S. J. (Eds.) Handbook of Positive Psychology. Oxford: Oxford University Press

Magnusson, D. and Mahoney, J. L. (2006) 'Holistinen lähestymistapa myönteisen kehityksen tutkimuksessa [Holistic approach in research on positive development]' pp. 232 250 in Aspinwall, L. G. and Staudinger, U. M. (Eds.) Ihmisen vahvuuksien psykologia [A Psychology of Human Strengths]. Helsinki: Edita

Mahoney, M. J. (2002) 'Constructivism and positive psychology' pp. 745-750 in Snyder, C. R. and Lopez, S. J. (Eds.) Handbook of Positive Psychology. Oxford: University Press 
Maijala, E.-L., Uusiautti, S. and Määttä, K. (2012) 'Grandparental love: a challenge or richness?' Early Child Development and Care, 183(5), pp. 627-642

Mikucka, M. (2013) 'The wellbeing lessons on employment' pp. 251-262 in Sarracino, F. (Ed.), The Happiness Compass: Theories, Actions and Perspectives for Wellbeing. New York, NY: Nova Science Publishers

Myers, D. G. and Diener, E. (1995) 'Who is happy?' Psychological Science, 6(1), pp. 10-19

Noddings, N. (1988) 'An ethic of caring and its implications for instructional arrangements'. American Journal of Education, 96(2), pp. 215-231

Ojanen, M. (2001) Ilo, onni, hyvinvointi [Joy, Happiness, Wellbeing]. Helsinki: Kirjapaja

Otake, K., Shimai, S., Tanaka-Matsumi, J., Otsui, K. and Fredricsson, B. L. (2006) 'Happy people become happier through kindness: a counting kindnesses intervention'. Journal of Happiness Studies, 7(3), pp. 361-375

Pahl, R. (2000) On Friendship. Cambridge: Polity Press

Patterson, B. R. (2007) 'Relationship development revised: a preliminary look at communication in friendship over the lifespan'. Communication Research Reports, 24, pp. 29-37

Polak, E. L. and McCullough, M. E. (2006) 'Is gratitude an alternative to materialism?' Journal of Happiness Studies, 7, pp. 343-360

Powdthavee, N. (2011) Life Satisfaction and Grandparenthood: Evidence from a Nationwide Survey. Bonn: IZA. Available online at: http://ftp.iza.org/dp5869.pdf (last accessed 26 March 2014)

Prewitt, V. (2003) 'Leadership development for learning organizations'. Leadership and Organization Development Journal, 24(2), pp. 58-61

Rego, A., Ribeiro, N., Pina, M. and Jesuino, J. C. (2011) 'How happiness mediates the organizational virtuousness and affective commitment relationship'. Journal of Business Research, 64(5), pp. 524-532

Rusbult, C. E., Drigotas, S. M. and Verette, J. (2007) 'The investment model: an interdependence analysis of commitment process and relationship maintenance phenomena' pp. 115-139 in Canary, D. J. and Stafford, L. (Eds.) Communication and Relational Maintenance. Thousand Oaks, CA: Academic Press

Schaufeli, W. B., Salanova, M., Gonzalez-Roma, V. and Bakker, A. B. (2002) 'The measurement of engagement and burnout: A two sample confirmatory factor analytic approach'. Journal of Happiness Studies, 3, pp. 71-92

Schmalenbach, H. (1977/1922) 'Communion - a sociological category' pp. 64-125 in L schen, G. and Stone, G. P. (Eds.) On Society and Experience. Chicago, IL: Herman Schmalenbach

Sciplino, C., Smith, P. K., Hurme, H., Rusek, M. and Bäckvik, P. (2010) 'Representations of grandparents in children's books in Britain, Italy, Greece, Finland, and Poland'. Journal of Intergenerational Relationships, 8, pp. 298-316

Seligman, M. E. P. (2002) Authentic Happiness. New York, NY: Free Press

Seligman, M. E. P., Steen, T. A., Park, N. and Peterson, C. (2005) 'Positive psychology progress. Empirical validation of interventions'. American Psychologist, 60(5), pp. $410-421$

Sennett, R. (2004) Kunnioitus eriarvoisuuden maailmassa [Respect in the World of Inequality]. Tampere: Vastapaino

Sim, M. and Kim, J.-U. (2010) 'Differences between experts and novices in kinematics and accuracy of golf putting'. Human Movement Science, 29(6), pp. 932-946 
Snyder, C. R. and Lopez, S. J. (2002) 'The future of positive psychology. A declaration of independence' pp. 751-767 in Snyder, C. R. and Lopez, S. J. (Eds.) Handbook of Positive Psychology. Oxford: Oxford University Press

Spence Laschinger, H. K., Finegan, J. E., Shamian, J. and Wilk, P. (2004) 'A longitudinal analysis of workplace empowerment on work satisfaction'. Journal of Organizational Behavior, 25, pp. 527-545

Thiele, D. M. and Whelan, T. A. (2006) 'The nature and dimensions of the grandparent role'. Marriage and Family Review, 40(1), pp. 93-108

Uusiautti, S. (2008) “Tänään teen elämäni parhaan työn” Työmenestys Vuoden Työntekijöiden kertomana ["Today, I'll work better than ever" Success at work described by the employees of the year]'. PhD Dissertation, University of Lapland, Rovaniemi, Finland

Uusiautti, S. (2013) 'On the positive connection between success and happiness'. International Journal of Research Studies in Psychology, 3(1), pp. 1-11

Uusiautti, S. and Määttä, K. (2010) 'What kind of employees become awarded Employees of the Year in Finland?' Enterprise and Work Innovation Studies, 6, pp. 53-73

Uusiautti, S. and Määttä, K. (2011) 'Love for work as the way towards wellbeing'. Global Journal of Human Social Science, 11(9), pp. 63-68

Uusiautti, S. and Määttä, K. (2013) 'Brisk attitude and optimism - Top workers' childhood experiences forming the basis of success at work'. European Journal of Educational Research, 2(2), pp. 69-82

Van De Bunt, G.G. (1999) Friends by Choice: An Actor-oriented Statistical Network Model for Friendship Networks in Time. Amsterdam: Thela Thesis

Van Manen, M. (1991) The Tact of Teaching: The Meaning of Pedagogical Thoughtfulness. London: Althouse Press

Varila, J. and Lehtosaari, K. (2001) Työnilo - Ahkeruudella ansaittua, sattuman synnyttämää vai oppivan organisaation vaatimaa? [Joy of Work - Earned by Diligence, Occurs by Accident or Required by Learning Organization?]. Joensuu: University of Joensuu

Zombylas, N. (2007) 'Emotional ecology: the intersection of emotional knowledge and pedagogical content knowledge in teaching'. Teaching and Teacher Education, 23, pp. $355-367$ 


\section{Notes on the authors}

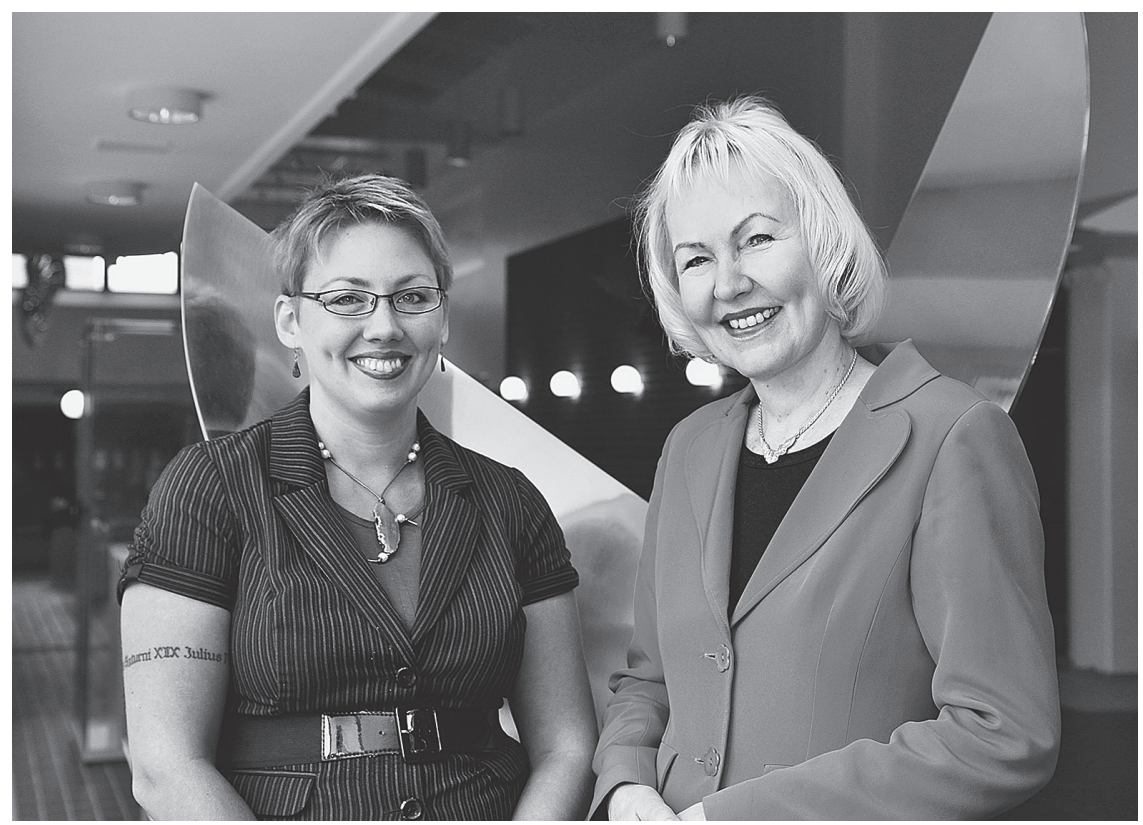

Satu Uusiautti (left) and Kaarina Määttä (right)

Satu Uusiautti, Ph.D. has worked as a researcher at the University of Lapland. She is an Adjunct Professor in Educational Psychology at the University of Helsinki, Finland. Her personal research interests are in positive psychology and human strengths, happiness, success and wellbeing in life in general but especially in diverse work and education contexts. Her latest publications include How to Study Children? Methodological Solutions of Childhood Research (edited by S. Uusiautti and K. Määttä, Lapland University Press, Finland, 2013) and Many Faces of Love (K. Määttä and S. Uusiautti, Sense Publishers, 2013). 
Kaarina Määttä, Ph.D. is the Professor of Educational Psychology at the Faculty of Education, University of Lapland, Finland. During her career she has supervised over 50 doctoral theses, written hundreds of articles and dozens of textbooks, especially about love, human strengths, early childhood education and student guidance, and teacher training and teacherhood. Her latest publications include Obsessed with the Doctoral Theses: the Supervision and Support in the Phases of Dissertation Process (edited by K. Määttä, Sense Publishers, 2012), Early Child Care and Education in Finland (edited by K. Määttä and S. Uusiautti, Routledge, 2013), and Sámi Education (authored by P. Keskitalo, K. Määttä and S. Uusiautti, Peter Lang, 2013). 


\section{Index}

abilities 13

absenteeism 34

absorption 10, 13, 14, 31

accomplishments 45, 46, 99

achievement(s) 6, 7, 17, 42, 58, 127

Achor, S. 8, 127

Ackerman, P.L. 13

action-related attributes 18

action(s): of good supervisors 79; intrinsic

attribution 11 ; love as 127 ; merging

awareness and 103; pedagogical 68; and

success 123; wellbeing-promoting 69

active jobs 10,16

adaptation 35,44

adaptive creativity $37-8$

adherence 9

adjustability 58

Adler, P.T. 9

adolescence see childhood and adolescent experiences

advice 63,99

affect 6,7

affection 67

altruistic acts 124

Amundson, N.E. 116, 117

analysis of narratives 21

analyzing tools: metaphors as $115-17$

Anderson, N. 38

anxiety 60

appreciation 49; of beauty and excellence

37,42 ; of challenging work 29-32;

child's need for 124; of families 2 ;

of marriage and marital happiness/

satisfaction 94; of work 13, 119

Appreciative Inquiry (AI) 69

archetypal metaphors 116

Argyle, M. 30

Aristotle 125
Arnold, J. 30, 44, 65

Arnold, K.A. 51

Aspinwall, L.G. 88

atmosphere 12, 48, 51, 73, 79

attachment 58, 68

attitudes: about future and future occupations 63; change in 2 ; home influence 59 ; imbibing brisk $65-7$; and persistence 39 ; proactive 32,44 ; respectful marital 94; and success at work 114-15; towards opportunities 33 , see also positive attitudes

attributes: of top workers 18-19

authentic leadership 106

authenticity $36,39,43,44,101,106$, 107,128

authority (pedagogical) 67, 68, 70

autonomous motivation 9

autonomy $6,11,15,30,33,34,58,96$, 101,127

autotelic experience 102

awareness: merging action and 103; of one's strengths and weaknesses 9, 44, 65 ; of the real consequences of work 15 ; of reality 8

Baltes, P.B. 14, 35, 121

Barnett, R.C. 88, 93

Bass, B.M. 98

Baum, N. 2

beauty 37,42

behaviour 12, 16; conscious control of 121; context and 15; positive 58; positive organisational (POB) 22; understanding 88

belief(s) $8,11,72$

belittlement 49

benefit value 11-12 
Berscheid, E. 58, 88

big optimism 8

biological aspects 16

blending 89

border crossers (family-work) 89

Boreham, N. 48

boundaries 124

Bradbury, T.N. 22

bravery $36,39,40,45,50$

'broaden-and-build' model 6-7

Brown, K.W. 51

Caldwell, C. 71

capability 47,105

career(s): -related hardships 64; change 119; choices 59-64, 65, 96, 117, 118; counselling 61-4, 65, 66, 118, 119, 120; enhancement 65,114 ; metaphors 116 ; orientation 2; skills 121; types 114

caring 66,123 , see also ethics of caring caring leadership 98-108

caring teacherhood $67-76,126$

Carver, C.S. 14, 44

causal thinking 10

challenge(s) 47, 49; expectations and reaction to 14 ; and performance 11,15 ; willingness to accept new 114; workrelated $10,15,29-32,102-3$

change: in attitudes 2; developmental 14; societal 16, 63; willingness to tolerate 38 character 66

child-centred upbringing 66

childhood and adolescent experiences $57-67$

civic skills 6

clarity $71,103-4$

Clark, S.C. 89

climate 49

co-workers 30, 33, 48, 104

cognition 12

cognitive skills 10

coherence 122

colleagues 12

collective competence 48

comfort 71

commitment $6,70,71,72,98$

communal experiences $47-8$

communal factors 49,50

communication 9,91

community 123

compassion 67,98

compensation (SOC model) 14 competence 9-10, 11, 12-13, 15, 47, 48, $66,97-8,122,130$

competition 73

competitions: selection of employees of the year 18

compromise(s) 58, 89, 91, 93-5

concentration $10,13,80,104-5,118$

Conchie, B. 103

concrete accomplishments 45, 46

confidence 66,122

conflict situations 13, 31, 38, 115, 120

consistency 65

consummate passion $34,50-1$

contentment(s) 30, 32, 33, 102

contextual factors $12,15-17,35,129,130$

control: of behaviour 121; leadership and

105; parent's belief in child's sense of 65 ,

see also perceived control; work-control

cooperation 30

coping $10,44,58,88,95,97,114,120$

core skills $29-30$

counselling 115

counterbalance: hobbies as a $96-7$

courage $36,38,39-40,65$

Covey, S.R. 14

Covington, M.V. 12

'creative work' metaphor 116

creativity $11,36,37-8,115$

credibility 9

crossroads 117,120

Cruce, T. 71

Csikszentmihalyi, M. 1, 95, 101, 102, 106

cultural norms 14

'cultural phenomenon' metaphor 116

curiosity $36,38,46$

curriculum/work 78-9

customers: perceiving students as $75-6$

data-driven categorisation: of success 49

Deci, E.L. 9

decision-making: ethics of caring 72, 98; family-oriented workers 91 ; issues for spouse in work-related 88; participation 15 ; prudence in 42

dedication 13, 31, 43, 118, 119, 120

demands 16

depression 8

design (AI process) 69

destiny (AI process) 69

development 33, 35; opportunities for $15,33,47,96,124$, see also personal development; positive development; 
professional development;

self-development

developmental change 14

developmental processes 16, 57

developmental stages 10

diachronic perspective 35

dialogic leadership 101

Diener, E. 1, 2, 6, 50, 96, 126

diligence 43, 119

diligent colleagues 12

disappointments 60

discipline 126

discover (AI process) 69

dispositional optimism 8

distractions 105

divergent creative reasoning 38

Dixon, R.D. 71

dream (AI process) 69

Driver, M.J. 114

Eccles, J.S. 11

education 33, 47; goals 59; good practices

71; ideal institutions 79-80; in-service

and voluntary 114, 120; occupational

131; socioeconomic factors and achievement 58 ; solidarity among students and faculties 73-5, see also further education; higher education; teacher education

educators: imbibing optimism from 65-7

effective leadership 72, 98, 99

efficiency $6,11,51,72,99,100$

egalitarian relationships (marital) 92

emotional expressions 98

emotional intelligence 72, 98

emotional intimacy 90

emotional resources 99

emotional rules 42

emotions 72; in leadership process 98 ,

99; regulation of 9-10; and social intelligence 40, see also negative

emotions; positive emotions

empathy 9, 67, 123

employees: needs and motivation 12; spreading flow among 106-7

Employees of the Year 23n; criteria for 17-19, see also 'top workers' study

empowerment 71, 77, 101, 123

encouragement $65,98-108,124$

energy 13,38

engagement 65,131 , see also student engagement; work engagement enthusiasm $13,31,128$

equality 12

esteem 127

ethics of caring $67,72,98,126$

events: negative $8,34,69$; optimism and experience of 8

example setting 74-5, 100, 123

excellence 37,42

excitement 48, 107, 128

execution 103

expectation value 11,12

expectations $7,8,12,14,16,32,50,71,78$

experiences: of the importance of work 15 ; qualitative research 1; of success 44-51, 69 , see also negative experiences; positive experiences

expertise $15,18,47,67,122-4,131$

failures 118

fairness $12,36,40-1,47-8$

faith in oneself 121

family $2,32,58,59$

family-oriented relationships 90

family-work balance 88-9, 90-3, 119

family-work interaction 88-93

favours 48

feedback 15, 119

Feldt, T. 6

financial success 2

Finnish married couples study 21-2

Finnish social policies 87-8

Finnish workers 2, 33, see also 'top workers' study

Fischer, A.H. 99

'fit' metaphor 116

flexibility $11,15,38,58,68,69,89$, 121,123

flow $6,7,10,13-14,31,46,49,96,101-7,123$

forgiveness $36,41,68,71,98$

Fredrickson, B.L. 1, 6, 7, 34, 70

free-time activities $65,78,95$

Freund, A.M. 14, 35, 121

friendship 32, 61, 125

Frone: M.R. 88,89

functional resources 123

further education 119, 120

Gable, S. 5

gap year 63-4

Gardner, H. 13, 121

gender 14

gender roles 95 
Germain, M.-L. 131

Gillham, J. 7

Gilligan, R. 65

goal orientation 38

goal theories 11

goal value 11-12

goal-oriented action 68

goals $7,12,14,35,44,51,59,70,103-4$

Goleman, D. 80

good deeds 48

good human beings 68

grandparents 125

gratification 128

gratitude 37,42

group level success 6

group work 38

'growth' metaphor 114, 116

guidance $76,79,99$

guilt 60,94

Hackman, J.R. 15

Haidt, J. 5

Hakanen, J. 101

Hall, D.T. 127

hands-on experiences 45

happiness: at work 30; caring teacherhood 70,71 ; curiosity and 38 ; and efficiency $6,72,99$; hedonic treadmill theory 14 ; interaction and 113, 123; levels of 128; love for work 127; marital 90, 94, 126; mindfulness and 51 ; modesty and 41 ; perceived 51, 107; studies/research 2, 5-6; and success 6, 127, 128-31

The Happiness Advantage 8

hardships 64

Hare, W. 67, 70

Harjunen, E. 67

health 8 , see also mental health; physical health

health and fitness programmes 96

healthy work 51

Healthy Work Model (HWM) 6

hedonic treadmill 14

'heritage' metaphor 116

high expectations 71

high performance 51,127

high performance cycle 11

high performance jobs 15-16

high self-efficacy 13, 39, 51

high standards of performance 98

high work engagement 34,51

higher education 70-6 higher-order needs 127

hobbies $11,32,58,78,95-8,118,119,120$

holistic perspective 32

home 2, 58, 59

honesty 98

hope $6,7,8,34,37,43,45,60,70,122$

hopeful leaders 107

housework 95

human resources 122-4, 131

humanistic work values 51

humanity 36,40

humility 70

humour 37, 43

Hyde, J.S. 93

identity: competence and well-developed 9; of work 121

idols 61

imagination 65

immediate feedback 14, 30, 101, 103, 104

in-service education 114, 120

income 2, 92

independence 38, 90

indifference 10

individual factors 49,50

individualism 95

informal organisations 15

information-seeking 38

Inkson, K. 116

inner direction 38

inner drive/motivation 9, 123

inner processes $16,57-8$

innovations 38

innovativeness 7,131

inspiration 13, 31

instrumental resources 99

intelligent thought 49

interaction: and development 16; familywork 88-93; happiness and satisfaction

113, 123; pedagogical 67; skills 9, 123

interdependence 48, 90

interesting content 33,120

interest(s) 65, 123

interviews ('top workers' study) 20

intrinsic motivation 7, 9, 11, 34, 51, 94

investment models 125

invigoration 128

Isen, A.M. 1, 7

Job Demands-Resources (JD-R) Model 30

job resources 30, 101

job satisfaction 107, 120, 126 
‘journey' metaphor 116

‘journey' narratives 117-21

joviality 43

joy $6,49,128$; of work $7,31,46,123,128$

justice $36,40-1,48,67$

Kalimo, R. 122

Kanfer, R. 13

Karasek, R. 10, 16

Karney, B. 22

Kaufman, H.G. 15

Kezar, A.J. 71

kindness 36, 48

Kinjerski, V. 124

Kinnunen, U. 34, 101

Kinzie, J.L. 71

knowledge 13, 14, 36, 37-9, 47, 62, 65, 77, $79,97,114,120$, see also self-knowledge

Krueger, D.W. 8

Kuh, G.D. 78

Latham, G.P. 11

Laubach, M. 15

Lawler, E.E. 127

leadership 6, 36, 40, 41, 123, see also caring leadership; caring teacherhood learned helplessness 8

learned hopefulness/optimism 8

learning: environments 71 ; from mistakes 63 , 98; life-long 35,63 ; love of 36,38 , 46; motivation for 130; relationships 67

leisure 95, 97

Lent, R.W. 39

Lerner, R.M. 66

life crises 10

life management 35

life satisfaction $6,7,8$

life situations $32,51,88$

life-long learning 35, 63

lifespans: positively behaving people 6,16

limitations 14,16

linear careers 114

listening to oneself 64,65

little optimism 8

Locke, E.A. 11, 14

Lopez, S.J. 59

love $36,58,67,71,72,98,124-7$; of learning $36,38,46$; pedagogical 67,68 , 70,126 ; for work $123-4,126-7$

Love is a Story theory 22

love-based leadership 99-101, 107

Love-based Leadership - An Interdisciplinary Approach 22 low-esteem 49

loyalty 71,98

Lubart, T.I. 37

Lundgren, L. 88

Lutgen-Sandvik, P. 49

Luthans, F. 8, 22, 107, 122, 131

Lyubomirsky, S. 7, 131

Määttä, K. 21, 79

McGillivray, C. 96

Maddux, J.E. 121-2

'magnitude of shared worlds' 89-93

Magnusson, D. 16, 57

Mahoney, J.L. 16, 57

Mäkikangas, A. 66

marital happiness $90,94,126$

marital relationships 89-90, 92

marital satisfaction 90, 94, 95

marriage 87-95

Our Marriage of Two Individuals 90

The Marriage of Two Individuals 91

mastery $8,9,30,69$

materialistic values 2

maximal performance 13,49

meaning 47, 128

meaningful life 128

meaningful retirement 96

meaningful study $71,78,79$

meaningful work $11,31,76$

meaningfulness 107

mental aspects 16

mental health $32,60,95,96$

metaphors 115-17

mindfulness 51

misjudgements 115

mission 121,123

mistakes 63, 98

Mitchell, T.R. 12

modesty $36,41-2$

Moller, A.C. 9

moods 6

moral courage 39

moral nature: of pedagogical love 126

moral valuations 1

motivation 13, 14, 129; autonomous 9; inner 123; intrinsic 7, 9, 11, 34, 51, 94;

and persistence 39 ; students 78 ;

and success $10-12$; to learn 130 ;

variety in 17 , see also work

motivation

multiple roles 92

mutual respect 67,71

Myers, D.G. 2, 50, 96, 126 
narrative analysis 21

narrative research 20-1

narratives 115

National Research and Development Centre for Welfare and Health of Finland 33

negative emotions $6,97,101$

negative events $8,34,69$

negative experiences 62,106

negative factors 49,50

'network' metaphor 116

networks 48, 58, 97, 98, 125

norm-dependent: human strengths as 35

obligations 16

obstacles 50, 60, 64, 115, 118, 120

occupational education 131

Ojanen, M. 43

Oldham, G.R. 15

open-mindedness 36, 37, 38, 44, 46, 118

openness 119

opportunities 14, 16, 29, 32, 49; for

development 15, 33, 47, 96, 124; for

further education 119

optimism $6,7-8,14,31,34,38,43,44,66$, $114-15,121,122$

optimization (SOC model) 14

order 126

organisational commitment 6

organisational culture 71

organisational integrity 123

organisational virtuousness $98,127-8$

Our Marriage 90

outcomes: and expectations $8,11,12$; work-related 15

outer processes 16,58

ownership 128

Pajares, F. 101

parental love $124-5$

parental relationships 58

parental support 59-60, 65

parents: and the acquisition of positive values/attitudes/behaviours 58; advice

from 63; belief in child's sense of control 65 ; imbibing optimism from $65-7$

participation: decision-making 15

passive jobs 10

passivity 8

'patchwork quilt' metaphor 116

paternal involvement 89

patience $68,123,126$

patriotism 61

pedagogical authority $67,68,70$ pedagogical interaction 67

pedagogical love $67,68,70,126$

pedagogical professionalism 78

pedagogical tact 68,70

perceived autonomy 58

perceived control 6,10

perceived happiness 51, 107

perceived meaningfulness 107

perceived success/failure 34,51

perceptions of occupations $65-6$

performance(s): ability to recognise good

42; challenge and 11, 15; happiness and

130; high standards 98; mastery and

9; motivation and 9; rewards and 12;

self-efficacy and 101; success and good

$12-14$, see also high performance

permeability 89

perseverance $8,37,38$

persistence $9,11,14,36,39-40,44,45$, 46,121

person-environment system 16, 57

personal development 15, 96, 127, 129

personal experiences: of success 45-7

personal history 16

personality $1,11,13,32,38,43,51$

perspective $36,38-9$

pessimism 8

Peterson, C. 8, 35

Peterson, S.J. 8, 107

phenomenon: in metaphors 115-16

physical courage 39

physical health 32, 95, 96

physical working conditions 124

planning 10

Plato 125

platonic friendship 125

pleasure 6,128

poetry metaphors 116

political nature of leadership 103

Polkinghorne, D.E. 22

positive atmosphere 48,79

positive attitudes $31,32,42,51,58,115$,

129 , see also hope; optimism

positive development $2,16,32,57-8,65$, $66,100,124,129$

positive emotions/feelings $1,6-7,51,66$, $69,95,100,101,107,121,123,129$

positive expectations 8

positive experiences $6-7,11,13,32-4,51$, $61,62,64,92,99,104$

positive factors 49,50

positive feedback $78,104,119,123$

positive learning environments 71 
positive organisational behaviour (POB) 22 positive parental relationships 58 positive paternal involvement 89 positive people-management 98 positive psychological capital 122 positive psychology $1,5-8,22,34,65,66$, 95, 98, 102, 107

positive strategies 14

positive values 58

positive working environments 101

positivity $22,43,101$

possibilities 16

power 11

practical experiences 66

praise 65

prejudices 66

pride $7,42,70,72$

proactive attitudes 32,44

problem-solving 7, 10, 107, 123, 131

processual nature of success $6,113,114-22$

production 2

productivity $15,71,73,74,80,101,107,131$

profession-specific attributes 18,19

professional development 18, 123

professional expertise 15,18

professional knowledge 114

professional proficiency 32,51

professional skills 120,121

professional standards 18

proficiency $32,51,79,105,119$

prudence $36,41,42$

psychological capital 122

psychological courage 39

psychological states 15 , see also mental health

Putnam, D. 39

qualitative research 1

quality education $71,72-3$

quality performance 14

questionnaires ('top workers' study) 19-20

Quick, J.C. 51

Rath, T. 103

reactive people 32

realism 94

realistic optimism $8,43,50$

reciprocal feedback 101

recognition 123

Reeve, J. 7

reflection 30

reflective approach 122

reflective practice 69 regard: positive 7

Rego, A. 98

regulation: of emotions 9-10; of goal direction 35 , see also self-regulation

reinforcement theory 125

Reivich, K. 7

relationship building 103

relationships 49; and development 58; family-oriented 90; marital 89-90, 92; positive learning environments 71 ; positive parental 58; social 33, 40, 97 , $98,119,120$; social resources supporting 123 ; strengths based on 88 ; students' success 78 ; teacher-student 67,75 ; work and family life 87-95; in the workplace $30,33,40,115$

relatives 61

reliability 9

reliability issues ('top workers' study) 21

religiousness $37,42,61$

research: work-related 1

resilience $8,14,44,69,122$

'resource' metaphor 116

resources 49; acquisition of necessary 10; of good supervisors 79; leadership provision of 72-3, 99; multiple roles, and the individual's 92, see also human resources; job resources

respect $67,71,94,98$

responsibility $11,15,71$

responsiveness 65,99

results $2,38,126$

retirement 96, 97, 121

reward(s) $12,30,32,34,101$

risk-taking 65

'road' metaphor 116-17

'road' narratives 117-21

role metaphors 116

romantic love 126

Ruiz, C.E. 131

rules 16,42

Ryan, F.J. 69

Ryan, R.M. 9, 51

safe boundaries 124

Salmi, M. 88

Salovey, P. 40

satisfaction $6,11,15,71,131$; of higherorder needs 127; interaction and 113 , 123, see also job satisfaction; life satisfaction; marital satisfaction

Schaufeli, W.B. 13 
Scheier, M.F. 14, 44

Schneider, S.L. 8, 50

schools: careers counselling 61-4; tools for employing strengths-based approaches 68-70

Schunk, D.H. 101

science metaphors 115

'seasons' metaphor 116

selection-optimisation-compensation

(SOC) model 14, 121

self-appreciation 123

self-assessments 68-9, 122

self-awareness 8, 98, 106, 107

self-conception 9, 106

self-confidence 122

self-consciousness 106

self-determination 11

self-determination theory 15

self-development 15,58

self-directedness 65

self-direction 122

self-efficacy $8,12,13,32,34,39,47,51$, $65,71,77,101$

self-enhancement 122

self-esteem 12, 30, 49, 58, 60, 122, 124

self-fulfillment 123, 127

self-image 13

self-knowledge 8, 67, 98, 101

self-regard 49

self-regulation $36,41,42,123$

self-worth theory 12

Seligman, M.E.P. 1, 8, 35, 37, 45, 46, 47, $69,101,126,128$

sensitive leaders 99

sensitive upbringing 66

sensitivity 9,68

servant leadership 101

shared worlds 89-93

Shimai, S. 41

sidetracks $64,115,117$

signature strengths 41, 69, 70, 128

Simonton, D.K. 37

situational flexibility 69

skills $13,14,15,97$; balance between work-related expectations and 32 ,

50 ; challenging activity that requires

102-3; professional 18, 119, 121, see

also career, skills; civic skills; cognitive skills; core skills; interaction, skills

Skrypnek, B.J. 124

Snyder, C.R. 59

social connection 66 social inclusion 49

social influences 12

social intelligence $36,37,40,41,44,47$

social policies (Finnish) 87-8

social problem-solving 10

social reality 10

social relationships 33, 40, 97, 98, 119, 120

social roles 9,88

social skills $1,40,65$

social support $30,49,98$

socially intelligent leaders 80

societal changes 16,63

socioeconomic factors 58

solidarity $73-5,78$

spiritual life 61

standards 18, 98, 121

Staudinger, U.M. 88

stereotypes 66

Sternberg, R. 22, 37

stimulating tasks 12

'story' metaphor 116

strategic thinking 103

strength(s): awareness of one's 9, 44, 65;

based on relationships with others 88 ;

caring teacherhood and discovery of

pupil's 67; dynamic contexts 35; and

happiness 107,128 ; leadership as a 103 ;

positive feeling as a source of 1 ; of top

workers $34-44$, see also signature strengths

strengths-based approaches: in schools 68-70

stress/stressful experiences $1,10,88,95$,

$119,120,121$

student engagement 71,78

students' study success: caring

teacherhood 70-6; factors behind 77-80

study atmosphere 73,79

subjective experiences 6

success: associations 2; concept analysis

1-2; definitions 2; as fullest expression

of mastery 8; and happiness 127 ,

128-31, see also students' study success

success at work: career orientation 2 ;

definition 9; encouragement from caring

leaders 98-108; factors contributing

to 9-17, 21-2; hobbies 95-8; human

resources and expertise 122-4; love

124-7; positive psychology 1, 5-8;

processual nature of $6,113,114-22$,

see also 'top workers' study

successful behaviour 88

successful marriage 94

Sundvall-Huhtinen, A. 63 
supervisor/mentor 49, 79

support: marital 91; parental 59-60, 65; students' success 75, 76, 79; workrelated 48, see also social support supportive work environments 120 Swedish housework study 95 synchronic perspective 35 systematic working 46, 120

tact $68,69,70$

talents 11

tasks 12,15

teacher education 126

teacher-student relationships 67,75

teacherhood (caring) 67-76, 126

team-based experiences $47-8$

teamwork $6,30,36,41,47,49$

temperance $36,41-2$

theatre metaphors 116

Theilheimer, R. 71

Theorell, T. 16

thriving 66, 100

time: transformation of 105-6

time metaphors 116

togetherness 73, 74, 90, 94

tolerance 38

'top workers' study 17-21; challenging work 29-32; childhood and adolescent experiences 57-67; data and analyses 19-21; experiences of success 44-51; family-work balance 90, 91-3; hobbies 96-7; human strengths 34-44; marital happiness 94; participants 17-19, 20; positive experiences 32-4; processual nature of success 114-22

transactional leaders 98

transcendence 36-7, 42-3

transformational leaders 98

treadmill 14

Triangular Theory of Love 22

triumphs 49

trust $6,43,68,71,98,126$

trust-building 67

try-harders 34

Tugade, M.M. 34

Tuomi, K. 96

Turner, N. 6

turning points 64

typical performance 13

upbringing 58, 59-60, 66, 124

ups and downs 117,119 values $2,51,58,59,65$

van Kleef, G.A. 99

van Manen, M. 67, 68

variation 33

versatile roles 93

vigor $8,13,31$

virtues $35-44,128$

voluntary acts 124

voluntary education 114

voluntary work 97

Von Wright, M. 70

Vulnerability-Stress-Adaptation Model of Marriage 22

warmth 65

weaknesses 9, 44, 65

Weiner, B. 11

wellbeing 6, 7, 11, 13, 34, 44, 47, 50, 51, $69,95,98,100,101,122,128$

White, R.W. 9

Wigfield, A. 11

will 14, 79

willingness: for teamwork 48; to accept new challenges 114; to compromise, in marriage 89; to educate oneself 47; to stay in the same job 34; to tolerate change 38 ; to understand employee's perspective 105; to work well 13

willpower 123

wisdom 36, 37-9

work: ability to develop 31 ; core dimensions of 15 ; joy of $7,31,46,123$, 128; love for 123-4, 126-7; marriage and 87-95; meaningful 11, 31, 76; success at see success at work

work context 12, 15, 16

work engagement $7,11,12,13,14,15,30$, $31,34,51,101,107,123$

work environments 12, 34, 101, 120

work life 1, 62, 63, 95

work motivation 1, 7, 10, 12, 15, 30, 32, $51,101,102,114$

work-control 2, 10, 11, 15-16, 46

work-oriented employees 93

work-related research 1

working conditions 33, 100, 124

workplace culture 12, 123

workplace wellness programmes 96 wrong choices 64

zest $36,39,40,46,128$

Zorro circle 97 